\title{
Die europäische Integration und die Kirchen
}

Akteure und Rezipienten

Herausgegeben von

Heinz Duchhardt und Małgorzata Morawiec

Vandenhoeck \& Ruprecht

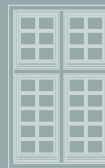

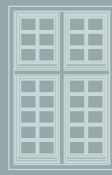

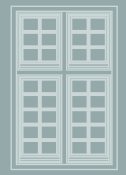

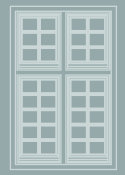
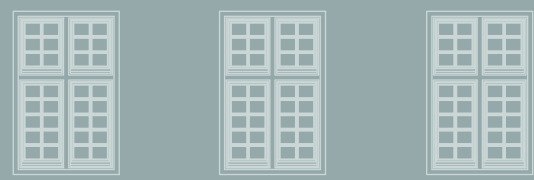

偖
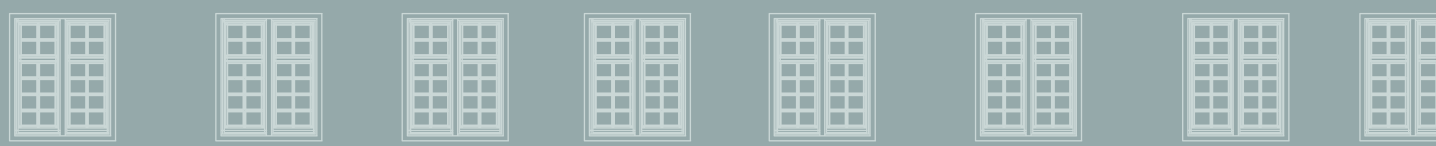

\section{㽬}
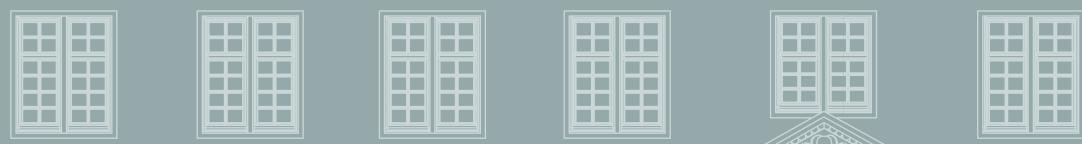

重
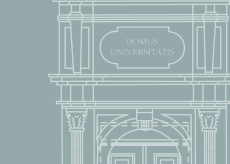
V\&R 


\title{
Veröffentlichungen des Instituts für Europäische Geschichte Mainz
}

\author{
Abteilung für Abendländische Religionsgeschichte \\ Abteilung für Universalgeschichte \\ Herausgegeben von Irene Dingel und Heinz Duchhardt
}

Beiheft 85

Vandenhoeck \& Ruprecht 


\section{Die europäische Integration und die Kirchen}

Akteure und Rezipienten

Herausgegeben von

Heinz Duchhardt und Małgorzata Morawiec

Vandenhoeck \& Ruprecht 
Eine Publikation aus dem Graduiertenkolleg 1575.

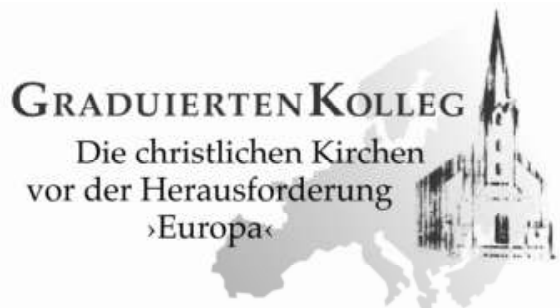

Bibliografische Information der Deutschen Nationalbibliothek

Die Deutsche Nationalbibliothek verzeichnet diese Publikation in der Deutschen Nationalbibliografie; detaillierte bibliografische Daten sind im Internet über http://dnb.d-nb.de abrufbar.

ISBN (Print) 978-3-525-10099-8

ISBN (OA) 978-3-666-10099-4

https://doi.org/10.13109/9783666100994

(C) 2010, Vandenhoeck \& Ruprecht GmbH \& Co. KG, Göttingen/ Vandenhoeck \& Ruprecht LLC, Oakville, CT, U.S.A.

www.v-r.de

Dieses Material steht unter der Creative-Commons-Lizenz Namensnennung - Nicht kommerziell - Keine Bearbeitungen 4.0 International. Um eine Kopie dieser Lizenz zu sehen, besuchen Sie http://creativecommons.org/licenses/by-nc-nd/4.0/.

Satz: Barbara Kunkel

Gesamtherstellung: $\circledast$ Hubert \& Co, Göttingen 


\section{Inhalt}

Vorwort

Keith Robbins

Avoiding the Challenge?

British Churches, British Society and European Integration,

1947-1949

Heinz Hürten

Papst Pius XII. und die Einigung Europas

Anita Prettenthaler-Ziegerhofer

Brückenbauer Europas:

Die österreichischen Bischöfe und

der europäische Integrationsprozess

Michael Kißener

Boten eines versöhnten Europa?

Deutsche Bischöfe, Versöhnung der Völker

und Europaidee nach dem Zweiten Weltkrieg

Mark D. Chapman

Public Religion in post-Christian Europe:

Some English Examples

Risto Saarinen

Die neuesten Soziallehren der Kirchen

und ihr europäisches Umfeld

Josef Homeyer

Kirchliche Arbeit auf europäischer Ebene:

Strukturen und Erfahrungen

Personenregister

Autorenverzeichnis 



\section{Vorwort}

Das am 1. April 2009 eröffnete, gemeinsam von der Johannes GutenbergUniversität Mainz und dem Institut für Europäische Geschichte getragene und von der Deutschen Forschungsgemeinschaft geförderte Graduiertenkolleg 1575 »Die christlichen Kirchen vor der Herausforderung >Europa«« startete im Rahmen seines Ausbildungsprogramms im Sommersemester 2009 mit einer Ringvorlesung, die sich im Wintersemester 2009/10 fortsetzte. Sie stand unter dem Thema $»$ Die europäische Integration und die Kirchen - Akteure und Rezipienten «

Aus den insgesamt zwölf Vorträgen, die im Rahmen dieser Ringvorlesung gehalten wurden, haben die Herausgeber eine repräsentative Auswahl getroffen, die das Thema von verschiedenen Seiten und aus unterschiedlichen Perspektiven beleuchtet. Die Reduktion auf eine Auswahl an Beiträgen fiel einerseits schwer, wurde andererseits aber dadurch erleichtert, als sich nicht alle Vorträge zur Druckwiedergabe eigneten. Erfahrungsberichte von Repräsentanten der Kirchen oder von Wissenschaftlern, die im Auftrag der Kirche(n) europapolitisch zu wirken versuchten, drängten sich zum Beispiel weniger zur Veröffentlichung auf, und es gab Referenten, die aus ihrem Vortrag ein größeres Manuskript zu machen gedenken und deswegen ihrerseits davon Abstand nahmen, ihren Beitrag jetzt zum Druck freizugeben. So ist eine eher repräsentative Auswahl von überarbeiteten Vorträgen hier zusammengefügt worden, die gleichwohl etwas von der Internationalität der Vorlesungsreihe erkennen lässt und die unterschiedlichen Heransgehensweisen von Theologen und Historikern spiegelt.

Am Beginn dieser Auswahl steht der Beitrag des britischen Zeithistorikers Keith Robbins, der die Distanz der (sehr heterogenen) britischen Kirchen zu »Europa« in den ausgehenden 1940er und beginnenden 1950er Jahren herausarbeitet - für die britischen Kirchenführer gab es andere, durch den Commonwealth und die traditionellen Bande nach Amerika geprägten Prioritäten; dementsprechend zurückhaltend waren auch die Äußerungen britischer Bischöfe gegenüber dem beginnenden europäischen Integrationsprozess, der für sie letztlich eine andere Welt war. Das korrespondierte im Übrigen auch mit der Regierung, die selbst nach Churchills Rückkehr in die Downing Street alles Andere als ein Vorreiter der europäischen Integration wurde, wie es nach seiner Zürcher Rede zeitweise ja hatte scheinen können. Der Eichstätter Zeithistoriker Heinz Hürten untersucht sodann auf der Grundlage der Ansprachen Pius' XII. vor Kongressen 
und seiner Weihnachtsansprachen die seine ausgeprägte Affinität zum Zusammenwachsen Europas spiegelnde Haltung des Papstes, der sich bezeichnenderweise auf dem Haager Europakongress 1948 persönlich vertreten ließ. Für Pius war ein befriedetes Europa die Grundvoraussetzung einer weltumgreifenden Entspannung, und er war von seinem theologischen Verständnis her überzeugt davon, dass das Christentum seine belebende Kraft in Hinsicht auf die Grundfreiheit der Menschen eher in einer übernationalen Gemeinschaft entfalten könne. Die Grazer Rechtshistorikerin Anita Prettenthaler-Ziegerhofer analysiert die Stellungnahmen der Österreichischen Bischofskonferenz zum Prozess der Europäisierung, die selbstredend erst in dem Augenblick einsetzten, als die Beitrittsverhandlungen begannen (1993). Die Europa-Affinität - oder auch -distanz - der mit ihren Sprengeln an Nachbarstaaten angrenzenden deutschen Oberhirten untersucht mit einem generationellen Zugriff, auch auf der Grundlage ungedruckten Materials, der Mainzer Zeithistoriker Michael Kißener. Außenkontakte über die Grenzen hinweg in den Jahren unmittelbar nach Kriegsende herzustellen, erwies sich in etlichen Fällen als ein mühsames Unterfangen, was die vielen Beispiele von Zusammenarbeit wie etwa das deutsch-französische Bischofstreffen in Bühl (1949), die grenzüberschreitenden Wahlfahrten, Kreuzfahrten und Priestertreffen in ihrer Wertigkeit um so deutlicher hervortreten lassen.

Der Oxforder Theologe Mark Chapman macht auf ein aktuelles Tätigkeitsfeld der britischen Kirchen (und der britischen Administration) aufmerksam, das auf den ersten Blick nur wenig mit »Europa« zu tun hat, gleichwohl aber für alle christlichen Kirchen in Europa zu einer zentralen Herausforderung geworden ist: einen modus vivendi mit den anderen Religionsgruppierungen auf lokaler Ebene zu finden. In England ist das vor dem Hintergrund rapide zurückgehender Zahlen von Menschen mit einem kirchlichen Hintergrund und einer Gesellschaft, die unbeschadet dessen ihre 》Christlichkeit« zu unterstreichen neigt, ein besonders schwieriger Prozess. Schließlich untersucht der finnische Theologe Risto Saarinen ein Sample von drei in den Jahren um 2000 entstandenen Soziallehren der lutherischen finnischen Kirche, der orthodoxen Kirche Moskauer Obedienz und der COMECE, also der katholischen Vertretung der europäischen Bischofskonferenzen bei der EU. Er fragt nach ihren Gemeinsamkeiten und unterschiedlichen Akzentuierungen und sieht in den Auseinandersetzungen europäischer Kirchen mit dem Globalisierungsparadigma ein europäisches Spezifikum, weil nur hier eine Denkweise zum Tragen komme, die, ausgehend von gesellschaftstheoretischen Modellen, wie sie in den europäischen Nationalstaaten praktiziert würden, auf eine weltweite, gerechte und demokratische Ordnung ziele. 
Am Ende steht der Vortrag des Hildesheimer Altbischofs Homeyer, über Jahrzehnte hinweg in der COMECE und anderen Organisationen einer der maßgeblichen Repräsentanten der katholischen Kirche gegenüber »Europa« und einer der einflussreichsten Protagonisten kirchlich-politischer Zusammenarbeit. Sein Beitrag, der aus jahrzehntelangen Erfahrungen schöpft, führt in die Praxis der kirchlichen »Überzeugungsarbeit« in Brüssel und im Europäischen Parlament ein.

Homeyer verstarb im März 2010, hatte aber vor seinem Tod das Manuskript noch für den Druck überarbeiten können. Mit Zustimmung des Nachlassverwalters veröffentlichen wir den bis auf die Schlussformulierungen abgeschlossenen Text gerne als eine besondere Reverenz für einen der Architekten der Zusammenarbeit zwischen der katholischen Kirche und den europäischen Gremien.

Die erste Publikation des gerade ein Jahr alten Graduiertenkollegs soll auf ihre Art widerspiegeln, dass zwar nicht die Absicht besteht, alle kleineren und größeren Ergebnisse, die im Rahmen des Ausbildungsprogramms zustande kommen, publizieren zu wollen. Auf der anderen Seite bewegt sich das Graduiertenkolleg thematisch in einer noch weitgehend unerschlossenen Forschungslandschaft, so dass es sich am Ende doch aufdrängte, mit diesem Sammelband einem breiten Publikum einen ersten Eindruck zu geben, welche Fragen die Kollegiaten und die Träger des Graduiertenkollegs beschäftigen.

Einen vollständigen Überblick über die im ersten Bewilligungszeitraum geförderten Themen stellt die Homepage des Graduiertenkollegs bereit: (http://www.ieg-mainz.de)

Die Druckvorlage erstellte Frau Barbara Kunkel, das Personenregister erarbeitete Frau Anna Matzkowitz. Beiden Damen sei auch an dieser Stelle herzlich gedankt.

Mainz, im Juni 2010

Heinz Duchhardt Małgorzata Morawiec 



\section{Avoiding the Challenge? British Churches, British Society and European Integration, 1947-1949}

»European Integration «, however we understand the term, raised (and raises) profound and unsettling issues of political and cultural identity within the United Kingdom - perhaps more than anywhere else within the contemporary European Union. In the wake of two world wars which had begun in Europe, it is hardly surprising that many »solutions « to »the problem of Europe « were being canvassed in Britain from all points of the political spectrum, though with no unanimity. C. R. Attlee, new Labour Prime Minister in 1945 had written in 1939 that »Europe must federate or perish $\ll^{1}$. That was the title of a book published under the auspices of a new organization, Federal Union, which also published many other expositions on the same theme ${ }^{2}$. It looked, for a time, as though a new climate of opinion was developing. Even so, there remained a substantial body of opinion which agreed with E. H. Carr, the writer on international relations, that Britain could »never become a predominantly European Power «. Further, while other writers agreed that the pre-war state system in Europe could never be put back, it was far from clear that »Europe« as a whole could in fact federate. It might be better, some thought, to envisage two or three »Europes « integrating. A prominent constitutional lawyer thought in terms of a »Western Europe« which would include France, Germany and the United Kingdom ${ }^{3}$. These schemes cannot be described in more detail here. They have an intrinsic interest, but their exponents were not in government. »Events « were to make their implementation implausible and the Foreign Office, of course, had its own appraisals of possible European futures and how far and in what way Britain would be directly involved in any of them. The actual course of British foreign policy as regards »Europe« at this time

Keith RoBBINS, Britain and Europe, 1789-2005, London 2005, pp. 236-8.

John S. Hoyland, Federate or Perish, London 1944. Amongst the series of Federal Tracts were contributions from such public figures as William Beveridge and Lionel Robbins.

W. Ivor Jennings, A Federation for Western Europe, Cambridge 1940. 
is not the subject of this paper. Needless to say, it has been scrutinized and evaluated from many different points of view ${ }^{4}$.

British churches did not stand aloof from this wartime reflection and unsettlement. However, it is important to note that there was not (and is not) one ecclesiastical figure or institution generally acknowledged to speak on behalf of, or be deemed to be »representative« of, »the British Churches« . There has not been and is not a »British church « let alone »a United Kingdom Church«. Roman Catholics had three hierarchical structures - England and Wales, Ireland and Scotland ${ }^{5}$. Anglicans had four structures, the Church of England, the Church in Wales, the Scottish Episcopal Church and the Church of Ireland. Presbyterians (Reformed) were to be found most strongly in Scotland, Northern Ireland and Wales. »The Free Churches «Baptists, Congregationalists and Methodists - were most strongly present in England and Wales and had a »Federal Council« which to some extent contributed a »Free Church voice« in national affairs. Besides these "mainline " denominations are to be found other Protestant bodies. This ecclesiastical diversity, of course, has deep historical roots, though they cannot be probed here in any detail. Given the territoriality of this diversity, a territoriality which showed no sign of weakening, no ecclesiastical figure in any part of the United Kingdom, be he archbishop, bishop, moderator, president or possessor of some other designation of leadership, could "speak for the British churches « on the future of Europe (or, indeed, on any other matter). In addition, just what »authority « a »leader « possessed was differently understood within different ecclesiastical traditions. The »leaders « of the non-episcopal churches were almost invariably in office as "moderator " (or whatever title) for a period of a year. Such constant change of personnel makes it very difficult, if not impossible, to crystallize a particular »Methodist« view since the emphasis could change very significantly from person to person. Archbishops and bishops, Anglican or Roman Catholic, held office for very much longer and were therefore, if so minded, able to be identified with a particular stance. Moreover, Free Churches and, increasingly, Anglicans, had representative structures which gave voice to »lay« opinion, not that lay opinion was all of one mind. Some opinion in

4 For example: David DiLKs, Britain and Europe, 1948-1950: The Prime Minister, the Foreign Secretary and the Cabinet, in: Raymond PoIDEvin (Ed.), Histoire des Débuts de la Construction Européenne/Origins of the European Integration, Brussels 1986, pp. 391-418; John W. Young, Britain and European Unity, 1945-1992, London 1993; Roy DenMan, Missed Chances: Britain and Europe in the Twentieth Century, London 1996.; Roger BROAD / Virginia PRESTON (Ed.), Moored to the Continent? Britain and European Integration, London 2001.

5 These and many other pertinent matters are discussed in: Keith RoBBINs, England, Ireland, Scotland, Wales: The Christian Church, 1900-2000, Oxford 2008. 
some churches might deprecate "political« statements on Europe or other international issues but some church participation in public discussion of these matters was general. That did indeed take place. »England « wrote the Professor of Theology in the University of Birmingham in 1942 »must remain embodied with Europe. What our responsibilities will be, we cannot foresee, but we must not shirk them $\ll^{6}$. Temple, as Archbishop of York, while reaffirming that nations existed »by God's providential guidance« saw the prospect of a Europe in which there would be »profitable union «. »Great Britain, France with, perhaps, Belgium, Luxembourg and Holland « might be one such, though the detail of what was feasible he would leave to $»$ the political specialist $\ll$ ?

There was, however, one other additional complication in trying to assess what »the British churches « felt, said and did, and what weight, politically, attached to their actions and observations. The United Kingdom state embodied, in its four territories, three distinct relationships between $»$ church $«$ and $»$ state $\ll^{8}$. In Northern Ireland and Wales, as a result of nineteenth and twentieth-century political pressures respectively, no church was »established«. In Scotland, the Church of Scotland as a Reformed church was one of the institutions which remained »different « under the terms of the 1707 Act of Union with England. It was a »national church« and »established«. The Crown, however, was not its »head«. The monarch, when in Scotland, worshipped in the Church of Scotland. He sent annually a »Lord High Commissioner« to the church's General Assembly but this person was an observer of the proceedings rather than a participant. The monarch, however, was »Supreme Governor « of the Church of England. That church remained the »established church « in England. The archbishop of Canterbury had his place firmly within the state's »order of precedence«. He and certain other bishops had seats in the House of Lords and could therefore participate in public affairs in whatever manner they saw fit. A »British Council of Churches « had been formed in 1942, the year in which William Temple became archbishop of Canterbury. He was the first chairman of what was the first ever such pan-British body - though without any Roman Catholic participation. It was, however, not a »super-church« and its mem-

\footnotetext{
Herbert Georg Wood, Christianity and Civilisation, Cambridge 1942, p. 99.

William TEMPLE, The Hope of a New World, London 1940, p. 96.

The role of the churches as »carriers « of national identity, in the absence, until the late twentieth century, of political institutions, is explored in: Robert POPE (Ed.), Religion and National Identity: Wales and Scotland, c.1700-2000, Cardiff 2001. What »British churches« thought about »European integration« cannot be altogether divorced from what the churches in different parts of the United Kingdom thought about »British Integration«. See Keith RoBBINS, Religion and Identity in Modern British History, reprinted in his History, Religion and Identity in Modern British History, London 1993, pp. 85-104.
} 
ber churches were anxious that it should not attempt to be one or speak as though it were one. Temple, it was well-known was a member of the Labour Party. There was, however, no »Christian« party, nor was there likely to be. What Christianity had to say and what »religious establishment« meant, in these circumstances, was complex and, to a degree, contentious9. There was, however, a considerable national consensus that Britain had been fighting for $\gg$ Christian Civilization $\aleph^{10}$.

So much by way of background. This paper focuses on certain developments in 1947/49 but looks tangentially forward to the 1970s, and indeed beyond into the present. There are, however, many matters pertinent to how the British churches did or did not position themselves in relation to »Europe« to which only the briefest allusion can be made. It must be obvious, too, that attitudes towards »Europe« on the part of the churches of the United Kingdom have a very much longer history which can only be alluded to rather than developed. It can be summarized, however inadequately, by stating that the contours of insular religious alignment did not easily map onto the pattern of »continental« confessionalization (not that that was uniform). It was, of course, in 1975 that the UK electorate endorsed by substantial majority the accession to the European Economic Community which the government had concluded two years earlier. It hardly needs to be said, however, that this turning point has not brought to an end the emotions generated by the word »Europe« in British public discourse.

Philip Coupland has recently published a detailed investigation of post1945 attitudes in the churches on the question of Europe. He has concluded that

Christian supporters of the European Movement were numerically a tiny minority, drawn from among the political and intellectual leadership of the Churches. As such, they contributed to what was itself a narrow political elite, whose worldview and preoccupations were not shared among wider society.

However, he does consider that the concept of Europe as »Christendom« was not an insignificant myth, particularly as developed in the 1940s and 1950s, and it had wider political resonance - a view broadly shared in this paper. Even so, he suggests, one can only guess at what claims the discourse of Europe as Christendom had on the minds and hearts of Britons « ${ }^{11}$. It is not the purpose of this paper to join in the guessing game. The inten-

9 John Kent, William Temple, Cambridge 1992, offers a particular interpretation of Temple as a $»$ priest in politics«.

10 See Keith RoBbins, Britain, 1940 and »Christian Civilization«, reprinted in his History, Religion and Identity in Modern Britain, London 1993, pp. 195-214.

11 Philip Coupland, Britannia, Europe and Christendom, Basingstoke 2006, p. 204. 
tion, rather, is to seek to explain the cultural, political and ecclesiastical context in which, in the event, this minority was »tiny«. Why, in other words, did it prove so difficult to translate general expressions of being »embodied « in Europe, some of which have been cited, into a vision which captured and captivated both the churches as a whole and the wider society in which they existed?

»We must get back to the idea of Europe«, George Bell, Bishop of Chichester had proclaimed as the Second World War drew to a close, and his federal enthusiasm had not been hidden. There was no British churchman, perhaps no other British public figure, professional diplomats apart, whose work over the previous two decades had brought him more into personal contact, through the emerging ecumenical movement, with the continent of Europe in all its conflicting diversities. If the country, or perhaps simply the Church of England, was to "get back « to that idea there was no better man than Bell to help it do so. William Temple had a significant national role during the war ${ }^{12}$. He unexpectedly died in 1944. Bell did not succeed him as Archbishop of Canterbury, so, while he remained a significant national figure, he was not »in charge«. Temple's successor was Geoffrey Fisher, who had been a public-school headmaster for eighteen years before becoming a bishop, first of Chester and then, in 1939, of London. Bell, through travel and correspondence, had developed a formidable European network. Temple had spent happy and carefree time in Jena in 1905-6, mixing lectures by Hans Heinrich Wendt with visiting a Zither Glee Club. Oxford-educated in Classics and Theology, Fisher, in contrast, had had no such experiences. His world had been a very English one and, even though, in wartime London, there were various European governments-in-exile to be found he did not have contact with them. »Foreign" Europe was scarcely »at home« in the bishop's diocese.

It was, even so, as Archbishop of Canterbury, it was Geoffrey Fisher, who chaired the inaugural meeting of the United Europe Movement held in the Royal Albert Hall in London on 14 May 1947 - five Anglican bishops were present. In the centre of the hall hung a large banner with the words »EUROPE ARISE«. For several years, Fisher had been lobbied on »Europe«. He had been cautious. He had replied to various correspondents to the effect that he supported »the general idea« and the »broad conception « but he did not want to find himself committed to any particular constitutional scheme. He was also no doubt aware of the fact that no major Labour figure had been signed up and he liked, if possible, to be non-partisan,

12 Suzan BRAY, William Temple's BBC Radio Sermons during World War II: Between Politics and religion, in: Gillies Teulié / Laurence LuX-SterRitT, War Sermons, Newcastle 2009, pp. $222-42$. 
in party terms, when appearing on a public platform. It is not surprising, therefore, that his name did not appear on the published list of supporters of United Europe, though the names of some Anglican bishops and leading deans did. The principal speeches on this occasion were broadcast by the B.B.C. on the Home and European services. »We all believe in the unity of Europe«, Fisher declared, »and assert that belief as the remedy for the present chaos and despair«. There could be no nostalgic return to a past order. A catastrophe could only be avoided if Europe found a new expression of its old heritage. The archbishop introduced various speakers, but the star of the occasion was Winston Churchill, introduced as the man who had »led Europe out of the jaws of death « who now was »leading a crusade for its continuing life«.

The Roman Catholic Archbishop of Westminster sent a message of support to the meeting, indicating that had he not been in Rome he would certainly have attended and spoken. He wrote privately to Churchill that he thought many nations in Europe were looking to Britain for guidance. Like Fisher, however, he was cautious, though he welcomed the picture, emanating from various Catholic circles, of a Europe undergirded by a common faith in which, as in the past, there might, for example, be an Irish bishop in Italy, a Greek archbishop in Canterbury and perhaps, even, another Englishman as pope. Perhaps the most eloquent plea for »The Renewal of Civilisation « came from the historian Christopher Dawson (a convert from Anglicanism) $)^{13}$.

The Moderator of the Free Church Federal Council, therefore, was the only other church leader to speak at this event. He declared that only when the peoples of Europe rediscovered and revitalised the unity of the continent would they have anything distinctive to contribute to the world. He had no doubt that rediscovered unity would involve many changes, economic, spiritual and political and people must be prepared for them. He argued, however, that to anticipate them would be disastrous and might »even break the unity itself«.

Here was a rather frank admission that the »unity« on display was one which might not survive detailed consideration of specifics. Churchill, who was of course not in power, accepted that structures were a matter for responsible statesmen. It was the task of the meeting »to lay the foundation, to create the atmosphere and give the driving impulsion«. Even so, he could not help giving some clues about the future. The aim was to »bring about

13 Christopher Dawson, author of The Making of Europe (1934) and Religion and the Rise of Western Culture (1934), was writing fluently and frequently on these matters. See Stratford CALDECotT / John MorriLl (Eds.), Christopher Dawson and the Catholic Idea of History, Edinburgh 1997. 
the unity of all nations of all Europe«, though some would come into the brotherhood sooner than others. It was not, Churchill stated, a sinister plot against Soviet Russia. One of the reasons why Fisher declined to lend his name to the United Europe Movement, and thus appear to commit the Church of England, was because of his awareness that it was being criticised in some quarters as »anti-Russian«. The United States of America, Churchill continued, would applaud United Europe. The journey would be a long one but it was essential to start.

Rhetorical flourishes were only to be expected on such an occasion. Speakers might be »leaders « but governments could only act, in a democracy, if the people were behind them. Hence the creation of a movement which would put the idea of United Europe forward with such enthusiasm that it would capture »the minds of our fellow-countrymen « to such an extent that it would affect their actions and influence the course of national policy. Churchill wrote to Fisher afterwards, claiming that the archbishop's speech had made a deep impression and would doubtless have moved the millions who listened to it on the »wireless « (that is to say, radio).

In this context, it was necessary to make some reference to what this might mean for the United Kingdom's conception of itself. Churchill accepted »without question« the world supremacy of the United Nations Organisation. Beneath it were »the Four Pillars of Peace«: the United States "with all its dependencies«; the Soviet Union; the British Empire and Commonwealth; and there was Europe«. In promoting the idea of United Europe »our country « was to play »a decisive part« but even so it did not look as though it was going to undermine its own pillar. Churchill spoke here of Great Britain being profoundly blended with this Europe but at the same time $»$ We are the centre and summit of a world-wide commonwealth of nations «. Any policy which this island might adopt towards Europe and in Europe would have to enjoy »the full sympathy and approval of the peoples of the Dominions. He was confident, however, that the cause of United Europe, in which the mother-country had to be a prime mover, would not be contrary to the sentiment which united all in the august circle of the British Crown $\ll^{14}$.

In putting matters thus, Churchill was unlikely to have struck notes which would have upset the churchmen who shared the platform with him. It is noticeable that »the community of culture « which in Fisher's opinion made »the nations of Europe a family« rested on the heritage of Greece,

14 The remarks of all the above-mentioned speakers on this occasion were published in a booklet United Europe, London 1947. For further on Churchill, see Keith RoBBINS, Winston Churchill und Europa in: Heinz DuchHARDT (Ed.), Europäer des 20. Jahrhunderts, Mainz 2002, pp. 145-64. 
Rome and Palestine. He was rather more intimate with the origins of that heritage than he was with the more recent history of Europe. His visit to Germany in November 1948 - I believe his first - was in part a "goodwill visit« but was primarily to meet British personnel in Germany. In an address to British Army rank and file he told them that they were in part responsible for what Europe would be like in thirty, fifty or a hundred years. Germany would once again be a "great nation«. In context, it would have been surprising if he had reached any other conclusion, but the »nuts and bolts « of creating a European future did not engage him fundamentally, and, as a generalization, this is a comment which applies to the Church of England as a whole. His mind-set, and that of many of his episcopal colleagues, reflected the fact that their knowledge was of the ancient rather than the modern history of Europe. In so far as they had studied »modern history « at school or even, in a few cases, at university, they had done so within structures in which »British history« and »European History« were presented as being $» d i f f e r e n t ~ « ~_{15}$. Temple's predecessor as Archbishop of Canterbury, Cosmo Gordon Lang, had received an invitation in 1930 to attend celebration of the Augsburg Confession. He could see why German Lutherans might want to celebrate, but could not imagine why anybody should think that the Church of England might want to join in ${ }^{16}$. Fisher, by the end of his time in office, had accumulated five honorary degrees from American universities (Princeton, Pennsylvania, Columbia, North Western and Yale) and one from a Canadian. No European university had stepped up to the mark!

In October 1948, at Lambeth Palace - part of which had been in ruins and rather hastily repaired for the occasion - 329 Anglican archbishops and bishops »assembled from all parts of the earth « under the Presidency of the Archbishop of Canterbury. They were received by the King at Buckingham Palace and entertained to lunch by the Lord Mayor of London at the Mansion House. This was a kind of world assembly - with the bishops of the British Isles heading the list of those attending. The conference had last met

15 Keith RobBins, Ethnicity, Religion, Class and Gender and the >Island Story/ies $<$ : Great Britain and Ireland in: Stefan Berger / Chris LoRENZ (Eds.), The Contested Nation: Ethnicity, Class, Religion and Gender in National Histories, Basingstoke 2008, pp. 231-55.

16 Amongst the Free Churches, it was British Baptists which had the strongest »continental connections « in various countries but, as a recent study has shown, British and German Baptists during the Third Reich differed immensely in their views on Church and State. These, and the difficulties that had ensued took time and charity to overcome and certainly provide no basis for Baptist »Europhoria«. Bernard GREEN, European Baptists and the Third Reich, Didcot 2008, p. 2.; Gerhard BESIER, Religion, State and Society in the Transformations of the Twentieth Century, Berlin 2008. 
in 1930. The surnames of bishops from across the world still testified to the extent to which this "Anglican Communion" was still a kind of extension of »the English Church« worldwide. Fisher's successor as Bishop of London, William Wand, had returned to England only in 1943, having spent nine years as Archbishop of Brisbane in Australia. This was a »family« which in large measure knew each other »at first hand «. There were bishops from Cape Town and Kansas, Sydney and Saskatchewan - but no bishop from »Europe«. The bishops had before them information on schemes, contentious schemes, for church union in the Indian sub-continent. There was talk, but not much more than talk, of creating a similar conference, which would meet at regular intervals, which would include the bishops of all other Episcopal churches. The report on »unity « matters concluded with a short section on $»$ Relations with Foreign Churches«. It noted that the Church of England had had a "Council of Foreign Relations « since 1930 and recommended that »from the point of view of our relations with foreign Churches « all Anglican Provinces should do likewise ${ }^{17}$. It seems to be assumed that all Anglicans were supposed to have a »unity" in their approaches to the »foreign«, a unity, very largely, of »English-speaking peoples«.

In retrospect, in terms of composition and participation, this Lambeth conference was the last of such old-style gatherings. The indigenization of episcopal leadership almost everywhere gathered pace and, with it, the establishment of new Anglican provinces, particularly in Africa. In the 1950s Fisher threw himself into this task with vigour, travelling tirelessly. What is notable, for present purposes, however, is the extent to which the focus of activity was extra-European. Anglicanism had a presence in Japan and elsewhere, but it was substantially coextensive with what Churchill in 1948 was still calling »the British Empire and Commonwealth«. Independence for India and Pakistan had occurred in the previous year and the last years of Fisher's archiepiscopate - he retired in 1961 - saw independence for Ghana and Nigeria. The process would continue. The "pillar of peace« identified by Churchill in 1948 crumbled. There were still intractable issues in Africa arising from decolonization, but »empire « was disappearing. The »Commonwealth of Nations«, which replaced it - with the Queen as »Head « - lost the adjective »British « which it had initially possessed. It was still presented as a »family « but its diversity, which accelerated, rendered it less and less of a »pillar«. But, while scepticism about »the Commonwealth« might be growing amongst »realist« policymakers in the Foreign

17 The Lambeth Conference 1948. The Encyclical Letter from the Bishops, together with Resolutions and Reports, London 1948. 
Office and government, the affairs of Africa retained high prominence in Anglican circles, not least, of course, in respect of South Africa. There, English priests working under the Apartheid regime, such as Trevor Huddleston, continued to receive much public attention and support from Britain.

The evolving Anglican Communion, therefore, seemed to sit alongside an evolving Commonwealth of Nations. Both bodies made use of the language of »family « although, at different speeds and with differing consequences, relationships within the family were undoubtedly changing. The UK government was to find that it certainly could not »lead« the Commonwealth and indeed, on certain African issues, was to find itself uncomfortably »in the dock « in the eyes of »the new Commonwealth«. The ancestral call of »the mother country « weakened in the »old Dominions«. The Archbishop of Canterbury was not the Pope. He could not »dictate« within the Communion but the ecclesiastical »club« over which he presided would find itself beset by increasingly complex issues of theological and cultural identity, issues not without their political dimension. They cannot be pursued here. The important point is that for English Anglican leaders »imperial disintegration « and its consequences seemed more pressing. It consumed their time and energy. Few personalities attached themselves to $\gg$ European integration «.

There was also, too, some church suspicion that behind the eulogies pronounced on the subject of »European culture « lay a mentality which could be characterized as wanting »Festung Europa «. In the Royal Albert Hall in May 1947 the Archbishop of Canterbury warned against "a selfish preoccupation with Europe alone«. That was a recurring theme from other church leaders. There was something narcissistic about »Eurotalk «. In the interwar period, the British churches had »invested « heavily in the League of Nations as, notionally, an embryonic move towards »world authority «. It was this prospect rather than »the United States of Europe«, as envisaged by Coudenhove-Kalergi - Europe Must Unite had been published in wartime Britain with a preface by Leo Amery - or by any other "visionary «, which had engaged their enthusiasm. George Bell successfully moved what appeared to be a far-reaching resolution at the Convocation of Canterbury in October 1947 calling for $»$ the progressive establishment of a United States of Europe with a common, foreign, military and economic policy«, though perhaps unanimity behind the motion had only been achieved by avoiding the word $»$ federal $\aleph^{18}$. Back in 1926 the then Permanent Under-Secretary at

18 Coupland, Britannia, Europe and Christendom, p. 94. 
the Foreign Office had described Coudenhove as »a thoroughly impractical theorist $\iota^{19}$. That view was not dead.

So it was »world order«, as exemplified in the new United Nations Organization, which now seemed to offer the best hope of avoiding catastrophe in what had become a nuclear world. In the minds of church leaders, it was important to think globally rather than continentally. For some, »European Integration « was a distraction from this central and ambitious task (with the UK as a permanent member of its new Security Council). »Building Europe « was rarely seen as a complementary stage along the path to a new world order. It was arguably because Churchill was aware of the extent of this anxiety on the part of church leaders that he addressed the issue head on in his Albert Hall speech. He accepted that without "some effective world super-government « the prospects of peace and human progress were dark and doubtful. But he was emphatic that »without a United Europe there is no sure prospect of world government«. It was »the urgent and indispensable step towards the realization of that ideal «. It was not an argument which all church leaders found convincing. If there was a conflict between »supporting the United Nations« and »supporting United Europe« then the former had greater »moral « authority as the focus of their efforts. It scarcely needs to be added that all these statements are at a high level of generality. The statement of policy of the United Europe Movement had declared that it was premature to define the precise constitutional relationship between the nations of a unified Europe«. Yet, without something definite to fasten upon, it was difficult to understand what was really supposed to emerge from this bout of sloganizing.

The picture as a whole was also inevitably complicated by the $/$ special relationship « with the United States. Churchill admitted that in the early 1930s, when he had first written on the subject of the United States of Europe, he had suspected that Washington would be hostile and would even conceivably regard such a development as contrary to American safety. He now offered the opinion that Americans were favourable to the revival and recreation of Europe. He was not unaware of some aspects of »European « thinking was hostile to the United States and to capitalism, but for Churchill a new Europe could not be fostered by creating the United States as Europe's »Other«. The American »occupation« of Britain 1942-1945, still fresh in the memory, brought the two countries together in unparalleled intimacy. Mass-Observation, an organisation which sought to establish popular opinion on a host of issues concluded at the time that

19 Cited by Ralph White, The Europeanism of Coudenhove-Kalergi, in: Peter M. R. STIRK (Ed.), European Unity in Context. The Interwar Period, London 1989, p. 39. 
British people have never regarded Americans as on all fours with other foreigners. To start with, they speak the same language and this leads to an exaggerated idea of the proportion of British blood in the population of the United States. Consequently there is at the back of many British minds the idea that Americans are a rather eccentric kind of Englishman... ${ }^{20}$.

At the very least, they were cousins. David Reynolds, the historian of this »occupation «, naturally presents a more nuanced account of perceptions and relationships. At the level of high politics, there were of course many uncomfortable adjustments to be made by the British in the face of American status and power. There was no possibility that the impact of $»$ the American way of life« could be eradicated, although he concludes that Britain was »never crudely Americanized «.

Yet, rather surprisingly, however, Reynolds pays no attention to »American religion « as domiciled at this time in the United Kingdom or how the churches reacted to the American presence. This is perhaps all the more surprising because of the long and well-established Anglo-American Evangelical linkages. Preachers passed back and forth across the Atlantic in both directions. The sense of a »common heritage « was particularly strong amongst the Free Churches. In addition, post-war, there was a crude calculation. Only Americans had money. Cathedrals, churches and chapels destroyed or damaged by bombing needed to be rebuilt. Only by receiving money from wealthy Americans or Americans trusts would it be possible. It is not surprising, therefore, that there were regular trips across the Atlantic trips which met with considerable success. In 1941, addressing a Peace Aims Conference in Oxford under the auspices of the National Peace Council, the prominent Methodist minister, Henry Carter, accepted that. »It was difficult for us as English people to look at ourselves as the European peoples look at us... We ought to try hard to see and feel the position and the problems of Anglo-Saxondom ${ }^{21}$. Evidently, that was easier said than done.

Preaching in the National Cathedral in Washington in September 1946 Fisher expressed the view that unless Britain and the United States stood together "the vision of one world can become a delusion and a snare to entrap civilisation itself«. The Governor of New York placed a car at Fisher's disposal and he was driven through the streets to the accompaniment of police motor cycles. If he had any doubt on the matter, it was a ride which must have made the archbishop feel important. He stayed with the President of Princeton University where he preached a Commemoration

\footnotetext{
20 Cited in: David ReYNOLDS, Rich Relations. The American Occupation of Britain 1942-1945, London 1995, p. 42.

21 Carter in: Edward Hallett CARR / Salvador De MAdARIAGA, The Future of International Government, London 1941, p. 19.
} 
Sermon. All of this suggested warm amity. Yet there were undercurrents. In 1930 American Episcopal bishops had been judged (by the English) to have been somewhat obstreperous. In 1948, with the balance in political power having shifted to the New World, would its bishops continue to endure what some considered to be a subordinate status. In the event, all went reasonably well. The presiding American bishop claimed in a letter to Fisher that it was impossible to overstate what the Conference meant to "all of us Americans «. Here then, was another example, of the Anglican Communion underpinning the Anglo-American world. »Europe« could not offer a comparable scenario.

The Lambeth Conference was only one example of Anglo-American religious contact at this time. It was to take another form, a few years later, in the celebrated mission of Billy Graham, the American evangelist. Acute minds, however, were well aware of the uncomfortable »bridge « between America and Europe which Britain occupied at this juncture. In 1948 the Free Church theologian, Daniel Jenkins, began a year in the United States at Union Theological Seminary in New York. The result was a short book. On both sides of the Atlantic, he concluded, the churches were living with unhelpful stereotypes of each other. Jenkins found himself shocked by the way in which some European churchmen appeared to consider it beneath their dignity to attend to America's particular situation. They seemed to think that America was simply a provincial and rather ignorant extension of their own. It wasn't. He himself considered Karl Barth to be »a theologian without a peer in the world today « - not a conclusion which had invariably been reached by English churchmen over the previous couple of decades but Jenkins had to admit that Barth seemed to write as though »no British or American theologian had written a word «. If he had an intimate knowledge of the situation in Anglo-Saxon countries Barth would surely not have written about many things in the way that he $\mathrm{had}^{22}$. The rest of the book consisted of an exposition of ways in which he thought European and American church life and theology could come together. It was implied throughout that Britain could perform a vital link in this necessary process. An integration of Europe which proceeded, as far as the churches were concerned, by retrenching »continental« introversion and academic hauteur would be a sad business. Being neither entirely comfortable with »America" nor with »Europe«, the British churches could perhaps act as »gobetweens «.

Though few of the writers or resolutions which have so far been referred to explicitly acknowledged the fact that when they spoke of »Europe« they

22 Daniel Jenkins, Europe and America. Their Contributions to the World Church, London 1949, p.16. 
were in reality referring to the particular grouping of countries which came to be referred to as "Western Europe« (though whether Scandinavia or the Iberian peninsula formed »part« of it remained obscure). One of those who did so explicitly was the Dean of St. Paul's in London, W.R. Matthews. A student in Marburg before 1914, he had been a member of the first British party of churchmen to visit Germany after the war. Writing in the NewsLetter of the United Europe Movement in August 1948, he cautioned against any simple identification with a political programme. Jesus had meant what he said when he proclaimed that his Kingdom was not of this world. The tension between East and West in Europe was not a simple conflict between Christianity and Anti-Christ. He expressed the view that the real menace presented by the East was not the professed creed of Communism but the fact of state totalitarianism. The defence of the West against the new bigotry and encroaching dogmatism was »a holy task «. A Christian believer had adequate motives and incentives »to support West European unity «.

In the circumstances of 1948, therefore, particularly after the events in Prague, there was a widespread, if reluctant, acceptance of the fact that $»$ the best of Europe « had come to be embodied in a particular form of »West Europe« into which a Germany was on the brink of admission. It was, of course, to be a division of »Europe « which would run through Germany itself. In reality, too, its survival rested not on its own intrinsic capacity at this juncture but on the military and economic power of the United States. Notwithstanding its economic recovery, it was a structure whose secure existence appeared to depend upon the maintenance of »Euro-America « in the shape, first, of Marshall Aid, and then of the newly-formed North Atlantic Treaty Organization. It was this Europe which commended itself to most church leaders, though there remained a minority who disliked the renewed militarization which they thought it embodied. A figure like the »Red Dean « of Canterbury, Hewlett Johnson who toured the country on behalf of the Anglo-Soviet Friendship League, and was to pick up a Stalin Peace Prize in Moscow, was exceptional ${ }^{23}$. Even so, the absence of the United Kingdom from that further consolidation of this »West Europe« in the form of the Treaty of Rome excited little ecclesiastical expression of regret. There had been little done by Churchill on his return to office in 1951 to play that decisive role in a "United Europe« about which we have noted him speaking with such enthusiasm. We need not argue why that was so here. Perhaps there was always an ambivalent note even in the most apparently firm statements of intent. It was an ambivalence, if so, which pervaded the churches.

23 Robert Hughes, The Red Dean, Worthing 1987, pp. 142-153. 
There was a recognition that the integration of the Federal Republic into this Europe would be a key element in its viability. Given the complicated nature of British-German relations, there was an acceptance of the fact that British churches had a key role to play in "reconciliation « as part of Germany's »long march « to the West. The visit of leading churchmen as a first step in that direction has already been alluded to. It was followed by a keen church participation in the »twinning " arrangements between German and English cities, as, for example, that between Bristol and Hanover, which began in $1947^{24}$. The impact of such city to city, diocese to diocese, contact would take time to blossom and develop. In time, in inter-church terms, it would contribute to making possible the Meissen Agreement. Even so, it still remained a far-off day, so it seemed, when men of every country, as Churchill put it, would think as much of being a European as of belonging to their native land (or, to put it another way, when English Anglicans and German Lutherans felt able to be fully »in communion « with each other).

One other pertinent aspect must be mentioned. It was in a divided Europe that the first meeting of the World Council of Churches was held in Amsterdam in the summer of 1948. When the provisional Committee had been held in Utrecht in May 1938, it had been Temple who had been elected chairman. Although the 1948 inauguration was happening in Europe, and it was in fact very much a Euro-American world which was speaking there, its vision and ambition could not be other than global. Its focus could not be continental. It was Fisher who was in the Chair when the formal resolution was passed which established the Council. It was in Bell's diocese of Chichester that the first meeting of its »Central Committee « was held in the following year. The British (or at least English) »world presence« was very evident. The disjuncture at this point, however, between views expressed concerning the supra- or trans-national character of Christianity and the political ordering of the world was very apparent. The world remained a world of states, often of nation-states, and the impetus, in a world on the brink of major decolonization was towards an ever increasing number of such states. »Federalism《 seemed to the decolonizing British to be a solution - for example in the West Indies - but its general adoption seemed a remote possibility. The British were not altogether surprised, since, the brief wartime flirtation apart, their conventional wisdom was that »federalism « was of dubious benefit to anybody, least of all to themselves. The United Kingdom, it seemed, formed such a happily integrated and centralized pol-

24 Peter Alter, Building Bridges. The Framework of Anglo-German Cultural Relations after 1945, in: Jeremy NOAKES [et. al.] (Eds.), Britain and Germany in Europe 1949-1990, Oxford 2002, pp. 336-7, notes that this was a British initiative. By 1975, there were 164 such »twinning « relationships. Neither in this contribution nor in the volume as a whole, however, is attention given to the role of churches in »building bridges«. 
ity and had no room for »devolution « except in the extraordinary circumstance of Northern Ireland. The prospect that 'the United States of Europe" would be »federal« deterred rather than attracted, though, apart from a few enthusiasts for »Federal Europe«, few bothered to consider what it might actually mean in practice. People who spoke on behalf of federations, it was suggested, could not really represent anybody. The Church leaders who spoke about a »United Europe« knew very well that in the inter-church discussions which resumed, under fresh impetus from Fisher with some vigour after 1946, a »United Church«, whether of England, of Britain, or of the United Kingdom, was not something they could deliver. They could not, or could not yet, »give a lead « in their own sphere in showing how structures could be created which demonstrated how unity and diversity could be harmoniously reconciled, how, indeed, they could be $»$ in communion« with each other.

All these matters are simply, perhaps too simply, put. They are of central importance, however, not only to illustrate further the difficulty of saying anything authoritatively about what »the British churches" felt, said and thought about »European integration«, but also to illustrate the complexities, below a certain level, which invariably confront us when talking about »unity« or »integration « in any context. In 1947-1949, arguably, the United Kingdom was at its most »united«. It had »won the war«. It had not been conquered or occupied. It had no need to create new structures of government or invent new constitutions. Britishness « seemed smug, secure and self-evident. The enthusiasm for »Europe United « encountered from some ecclesiastical lips was sincerely expressed but, in the event, turned out to be a »passing moment «, some of the reasons for which have been elaborated in this paper, rather than a pervasive and profound shift of political, cultural and ecclesiastical focus leading towards »European integration $«$. 


\section{Heinz Hürten}

\section{Papst Pius XII. und die Einigung Europas}

Wenn der Heilige Stuhl heute unbestrittenes Mitglied einer Institution wie der OSZE, beim Europarat und der Europäischen Gemeinschaft diplomatisch vertreten ist, die Päpste und die ihrem Vorbild folgenden Bischöfe Förderer der europäischen Integration waren und geblieben sind, so ist diese Entwicklung nicht ohne Papst Pius XII. zu denken, der an ihrem Beginn stand, aber nicht nur, weil mit ihm das Engagement der katholischen Kirche für die Einigung Europas einsetzte, sondern weil er - vor Hochhuth - als Repräsentant der Kirche in der Welt wie als Lehrer der Kirche in der Weltöffentlichkeit mehr Gehör fand, als dies seinen Vorgängern beschieden gewesen war ${ }^{1}$.

Das internationale Ansehen des Heiligen Stuhls war trotz seiner Niederlage gegen das neu geschaffene Königreich Italien schon unter den Vorgängern des Papstes, wenn auch nicht ohne Rückschlag unter Pius X., erheblich gestiegen. Die bei ihm vertretenen Mächte hatten nach dem Untergang des Kirchenstaates ihre Gesandten nicht abberufen und ihn weiterhin als Völkerrechtssubjekt betrachtet, die Zahl der diplomatischen Vertreter beim Vatikan hat sich sogar bis zum Amtsantritt von Pacellis Vorgänger, Pius XI., mehr als verdoppelt, wenn auch der Heilige Stuhl unter dem Druck Italiens wie schon 1899 und 1907 von den Haager Friedenskonferenzen auch 1919 von der Pariser Friedenskonferenz ausgeschlossen blieb und dem Völkerbund nicht beitrat. Damit war jedoch der weitere Anstieg des Heiligen Stuhls zu internationaler Bedeutung nicht zu verhindern. Seit 1921 ließ sich auch das laizistische Frankreich wieder beim Vatikan vertreten. Der Zweite Weltkrieg hat dessen internationales Ansehen weiter verstärkt. Es war der Staatssekretär im Auswärtigen Amt in Berlin, Ernst von Weizsäcker, der kritisch vermerkte, dass man auf deutscher Seite die diplomatische Bedeu-

1 Der Vortragsform entsprechend werden im Folgenden lediglich Zitate nachgewiesen. Die einschlägigen Texte Pius' XII. sind amtlich veröffentlicht in den Acta Apostolicae Sedis, Rom 1909 ff., dem Osservatore Romano, Rom 1861 ff. sowie den Discorsi e radiomessaggi di Sua Santà Pio XII., Rom 1941-1959. Deutsche Übersetzungen wichtiger Texte bietet Jürgen SCHWARZ (Hg.), Katholische Kirche und Europa. Dokumente 1945-1979, München 1980. Eine Einordnung der päpstlichen Texte in die internationale Entwicklung des Europa-Gedankens ermöglicht Walter LIPGENS (Hg.), Europa-Föderationspläne der Widerstandsbewegungen 1940-1945, München 1968, der auch Äußerungen Pius’ XII. berücksichtigt. 
tung des Heiligen Stuhls nicht zu würdigen wisse, zu dem immer mehr Staaten formelle Beziehungen aufnahmen².

Eine Voraussetzung für diese Entwicklung war die konsequente Friedenspolitik, zu der sich die Kurie im Laufe der letzten Jahrhunderte durchgerungen hatte, mit der sie um den Preis ihrer weltlichen Herrschaft Napoleon I. den Beitritt zur Kontinentalsperre verweigert und sich 1848 zunächst um den Preis einer möglichen Führungsrolle im italienischen Einigungsprozess und am schließlichen Ende des 1815 wiedererlangten Kirchenstaates sogar dem Anschluss an den von Sardinien ausgehenden Nationalkrieg gegen Österreich entzogen hatte. Die Vermittlungs- und Fürsorgepolitik Papst Benedikts XV. im Ersten Weltkrieg hatte diese Linie konsequent fortgesetzt. Demnach sollte es ausgeschlossen sein, dass irgendein Mensch sich als Feind des Papstes betrachten müsse, weil dieser mit seinem Vaterland im Kriege läge. Der Kardinalstaatssekretär Papst Pius' VII., Ercole Consalvi, hat es in der Abwehr der Werbungen Napoleons um den Papst als Alliierten zum Grundsatz der päpstlichen Politik gemacht, dass dem Haupt der Kirche und padre commune eine unbedingte Friedenspflicht gegen alle obliege, »ohne Unterschied der Katholiken und der Ketzer, der Nahen und der Entfernten, derjenigen, von denen wir Gutes erwarten und denjenigen, von denen wir Böses erwarten « ${ }^{3}$. Eugenio Pacelli hat 1917 unter dem erwähnten Pontifex Benedikt XV. und im Rahmen von dessen Friedenspolitik als Nuntius in Bayern seinen Aufstieg begonnen. Dass die ihm übertragene Mission fehlschlug, war nicht auf das Konto der Kurie zu verbuchen. Das Friedensamt der Kirche blieb ihm dauernde Aufgabe, zu der er sich mit dem Wahlspruch Opus justitiae pax öffentlich bekannte.

Rom war zur allen Zeiten Wallfahrtsort der katholischen Christenheit gewesen. Papst Leo XIII. hat, nachdem 1870 der Kirchenstaat verloren gegangen war, im Zustrom der gläubigen Massen zu den Gräbern der Apostelfürsten und zum »Gefangenen im Vatikan«, wie man den seine Residenz am Petersplatz nicht mehr verlassenden Papst im gläubigen Volk nannte, eine neue Basis seiner Wirksamkeit gesehen und die durch die Eisenbahn ermöglichten Pilgerreisen großer Scharen nach Rom gefördert. Die bei den Audienzen üblichen Ansprachen gaben dem obersten Lehrer der Christenheit zusätzliche Möglichkeiten, auf Gläubige und Ungläubige zu wirken. Im Lauf des 20. Jahrhunderts haben seine Nachfolger dieses Instrument klug und energisch genutzt. Dessen Wirkung wuchs, nachdem es mehr und mehr

2 Vgl. Dieter Albrecht (Bearb.), Der Notenwechsel zwischen dem Heiligen Stuhl und der Deutschen Reichsregierung, Bd. III, Mainz 1980, S. 767 sowie Leonidas E. HILL (Hg.), Weizsäcker-Papiere 1933-1950, Frankfurt/M. 1974, S. 338.

3 Der ins Deutsche übertragene Wortlaut der päpstlichen Note an Napoleon vom 21. März 1806 bei Joseph MÜLLER, Das Friedenswerk der Kirche in den letzten drei Jahrhunderten, Bd. I, Berlin 1927, S. 25-262, Zitat S. 257. 
guter Brauch wurde, dass in Rom tagende Kongresse und Vereinigungen im Vatikan um Audienz nachsuchten, und eben nicht allein die katholischen. So wuchs dem Papst ein Auditorium aus der Weltöffentlichkeit zu, das ihm erlaubte, seine Auffassungen zu Themen darzulegen, die Aufgaben und Absichten des jeweiligen Hörerkreises berührten. Die rasche Wahrnehmung der neuen technischen Mittel, vor allem des Rundfunks, sicherte der Stimme des Papstes früher unerreichbare Aufmerksamkeit.

Dieses Instrument hat Pius XII. in reichem Maß verwendet. Die oft bei zufälligen Gelegenheiten entstandenen Ansprachen waren bei aller Berücksichtigung des jeweiligen Anlasses und Zuhörerkreises weit mehr als Bekundungen diplomatischer Höflichkeit oder freundlicher Geneigtheit. Pius XII. hat vielmehr seine Ansprachen zur Formulierung grundsätzlicher Positionen benutzt. Die Summe seiner Äußerungen zu sozialen Fragen bei solchen Anlässen kommt in ihrem Gewicht den großen Sozialenzykliken seiner Vorgänger durchaus gleich. Die beiden Dominikaner Arthur Fridolin Utz und Josef Fulko Groner haben darum recht daran getan, ihre Sammlung päpstlicher Äußerungen im Untertitel ihres Werks Aufbau und Entfaltung des gesellschaftlichen Lebens (Fribourg 1954) die Soziale Summe Pius' XII. zu nennen ${ }^{4}$. Fehlt diesen Gelegenheitsreden anders als den Enzykliken Feierlichkeit und Systematik der Darlegung mit dem Appell an die gesamte Christenheit, so wird dies wettgemacht durch die direkte Ansprache an die Betroffenen und die Einbeziehung der konkret gegebenen Handlungsmöglichkeiten der Zuhörer.

Diese Eigenart erschwert es freilich, die Haltung des Papstes zur Einigung Europas, wie sie vornehmlich in zahlreichen Ansprachen zum Ausdruck kommt, in wenigen Sätzen systematisch zusammenzufassen. Denn seine Äußerungen sind im doppelten Sinne situationsgebunden: Sie wenden sich an einen definiten Hörerkreis und stehen in Bezug zur gegebenen poltischen Situation. Es erscheint daher sinnvoll, seinen Gedankengängen in ihrer historischen, durch die wechselnde politische Lage nicht unbeeinflussten Abfolge nachzugehen. Die Kontinuität seiner Konzeption wird dabei gleichwohl sichtbar bleiben.

Der Papst hat sich, was nicht überall als Selbstverständlichkeit genommen wurde, auf dem ersten, im Mai 1948 im Haag veranstalteten Kongress der Union Européenne des Féderalistes persönlich vertreten lassen. Er rechtfer-

4 Lipgens, S. 339 Anm. 3 hebt die Umsetzung der katholischen Staatslehre Leos XIII. durch Pius XII. »im Bereich der internationalen Beziehungen« (die durch seine Ansprachen erfolgte) als »das geschichtliche Verdienst« Pacellis hervor. 
tigte diesen Schritt am 2. Juni 1948 in einer Ansprache vor den Kardinälen als »besorgte Ermunterung des Apostolischen Stuhls zur Einigung der Völker $\aleph^{5}$. Warum diese »Ermunterung «, wenn Pius XII. sich doch nicht »in die Wirkung rein irdischer Interessen« einmischen wollte, wie er erklärend sagte? Die Antwort ergibt sich leicht aus einer der Grundlinien der päpstlichen Politik und Lehre dieser Jahre. Es ist die Erhaltung und Festigung des Friedens. Seit seiner Wahl im März 1939, fast unmittelbar vor dem deutschen Einmarsch in die Tschechoslowakei, der die appeasement policy ad absurdum führte, hat der Papst mit allen ihm gebotenen Mitteln den Krieg zu verhindern und während seines Verlaufs einzugrenzen oder zu beenden versucht. Der Krieg, wenigstens der Krieg in Europa, war für den Papst in den ersten Jahren zugleich Bedrohung des Christentums, das nach seiner Auffassung Europa zutiefst geprägt hat. Als am 18. Oktober 1939 der Gesandte Litauens, das nicht einmal einen Monat zuvor durch den Vertrag des Deutschen Reiches mit der Sowjetunion vom 23. September aus der deutschen Einflusssphäre herausgelöst und der sowjetischen zugeschlagen worden war, sein Beglaubigungsschreiben überreichte, sprach der Papst davon, dass sich das Unheil von Geist und Werk der Feinde Gottes immer drohender ausbreite ${ }^{6}$. In seinen Weihnachtsansprachen während des Krieges hat Pius XII. öffentlich über Bedingung und Möglichkeiten des Friedens unter den Völkern reflektiert, die sich aus der Anerkennung gerechter Ordnung, wie die Kirche sie vertrete, ergeben. Die Schaffung eines neuen Europa, sagte er dem neuen französischen Botschafter Jacques Maritain, als dieser am 10. Mai 1945 sein Beglaubigungsschreiben überreichte, sei verknüpft mit einer Erneuerung der christlichen Kultur »selon la doctrine sociale catholique $\ll^{7}$, - ein Zusatz, der zunächst überraschen mag, aber in seiner Bedeutung für die Europa-Vorstellung des Papstes noch deutlich werden wird.

Pius beharrte nicht allein auf der ordnungspolitischen Bedeutung der katholischen Soziallehre, die er in seinen Weihnachtsansprachen während des Krieges systematisch ausbreitete, sondern auch auf einem politischen Willen zur Neugestaltung Europas als opinio communis der Kämpfenden ${ }^{8}$, und in diesem Zusammenhang hat er auch die Notwendigkeit betont, den Frieden durch eine internationale Institution zu sichern. Schien hier noch die Möglichkeit gegeben, auf frühere Institutionen wie den Völkerbund zurückzugreifen, so schien ihm diese am fünften Jahrestag des Kriegsausbruchs nicht mehr gegeben. Der Papst sprach jetzt von der Notwendigkeit, interna-

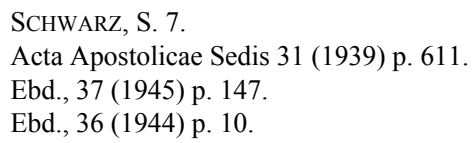


tionale Institutionen zu schaffen, welche die Mängel und Schwächen der Vergangenheit überwindend wirklich (realmente) geeignet seien, den Frieden zu sichern'. War dies auch noch kein Programm, das unmittelbar zur UNO oder einer europäischen Institution führte, so war die Tradition des Nationalstaates doch deutlich in Frage gestellt, als der Friede in Europa endlich Wirklichkeit wurde.

Während des Krieges und in den nächsten Jahren danach von Europa zu sprechen, war für den Papst auch eine Frage seiner Neutralität oder, wie er lieber sagte, seiner Unparteilichkeit im Streit der Nationen: Mit dem Ausdruck Europa waren beide Seiten der kriegerischen Fronten angesprochen. Was für sie alle galt, konnte so allen gesagt werden, ohne Rücksicht in welchem Lager sie standen, und zugleich erinnerte das Wort Europa an die Gemeinsamkeit, die Sieger und Besiegte verband. Es ging darum, ein neues Europa aufzubauen, nicht allein die Siegermacht Frankreich, wie Pius XII. Jacques Maritain als erstem Vertreter des freien Frankreich nach dem Krieg zu verstehen gab. Der Friede konnte nach seiner Ansicht »nur blühen und gedeihen in einer Atmosphäre sicherer Gerechtigkeit und vollkommener Redlichkeit, verbunden mit gegenseitigem Vertrauen, Verständnis und Wohlwollen $\aleph^{10}$. Darum ergab sich für ihn zwei Jahre später die erregte Frage:

Wie können die siegreichen Völker ihrerseits die Methoden des Hasses und der Gewalt anwenden oder dulden, aus denen jenes System [NS-Deutschlands] lebte und handelte [...]? Und wer könnte je vernünftigerweise im Zusammenbruch und in der Verelendung des Nachbarn eine Garantie für die eigene dauerhafte Sicherheit suchen? ${ }^{11}$

Pius XII. hat den heiligen Benedikt von Nursia Vater Europas genannt, weil er Römertum und Evangelium miteinander verbunden und damit jene Verbindung geschaffen habe, aus der die Kräfte erwuchsen, die Europa einmal zu einer christlichen Gesellschaft machten $^{12}$, und wenige Monate vor seinem Tode betete Pius, der heilige Benedikt möge den Staatslenkern beistehen, damit diese zum Erfolg gelangen, »die europäischen Völker in einem Band der Brüderlichkeit« zu verbinden ${ }^{13}$.

Weil somit Europa eine religiöse Dimension besaß, konnte der Papst durch die Entsendung eines Vertreters zum Europakongress im Haag 1948 die europäische Bewegung unterstützen und von seinen Gläubigen erwarten, dass sie an der Seite derer stünden, »die der gegenseitigen Verständi-

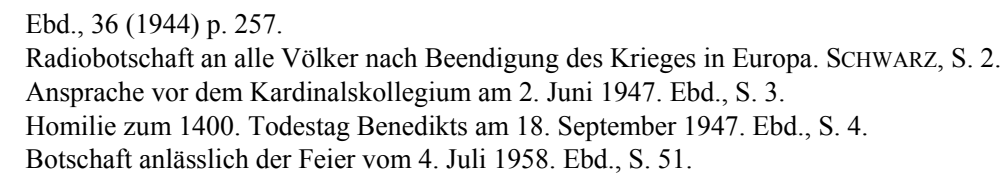


gung und der Wiedererweckung einer ehrlichen Friedensgesinnung unter den Völkern die Wege bereiten « ${ }^{14}$.

Die starke Betonung Europas in den Darlegungen des Papstes darf freilich nicht zu dem Irrtum führen, dass sein Weltbild auf diesen Kontinent beschränkt geblieben sei. Er trat derartigen Missdeutungen gelegentlich selbst entgegen; Europa nahm nicht zuletzt einen so hohen Rang in seinen Überlegungen ein, weil er der Ansicht war, dass ein befriedetes Europa dazu beitragen werde, eine weltumgreifende Entspannung herbeizuführen.

Im November 1948 umriss der Papst vor den Delegationen des Zweiten Internationalen Kongresses der Europäischen Union der Föderalisten erste Konturen einer künftigen europäischen Union. Er warnte davor, mit ihrer Errichtung zu zögern, bis die Erregung der miteinander verfeindet gewesenen Völker abgeklungen sei, es sei vielmehr höchste Zeit, dass sie zustande komme. Denn die jetzt noch schwer erträglichen Leiden, die der Krieg verursacht habe, könnten und müssten den Anstoß geben, endlich nationalistische Voreingenommenheiten zu überwinden und der Wiederkehr der durch sie verursachten Übel zu wehren. Deshalb müssten die großen Staaten von allen Erinnerungen an ihre vergangene Größe absehen und sich mit den anderen auf der »Ebene einer höheren wirtschaftlichen und politischen Einheit« vereinen. Die Achtung vor der kulturellen Identität eines jeden Volkes verlange zugleich, dass gewaltsame Nivellierung vermieden werde. Niemand werde leugnen können, dass ein solches Europa einer sittlichen Grundlage bedürfe. Sie kann nur im Christentum gefunden werden, das Europa einmal geformt hat. Darum begrüßt der Papst die Erwähnung der "gemeinsamen Erbschaft der christlichen Zivilisation" in einem Papier der Föderalisten-Union. Aber dies reicht nach seiner Auffassung nicht aus. Die Rechte Gottes müssen anerkannt werden, mindestens das Naturrecht, in dem auch die Menschenrechte verankert sind. Wie sollen sie ohne Bindung an die Religion bestehen? Der Papst erinnerte weiter an die Rechte der Familie, der Eltern und der Kinder, die er als Menschenrechte verstand. Das künftige Europa kann nicht bestehen aus einer abstrakten Idee, sondern nur aus der Zustimmung der Menschen, nicht der alten Eliten, von denen Pius annahm, dass sie verschwunden seien und keinen Einfluss mehr hätten, sondern Menschen, die Frieden, Ordnung, Ruhe und Familienleben als ihre obersten irdischen Werte betrachten. Nur sie können die Basis für das neue Europa bilden. Ob das gelingen wird, scheint dem Papst damals - 1948 noch offen, aber es ist eine Hoffnung ${ }^{15}$.

Wenn Pius stets die Überzeugung vertrat, dass eine Neuordnung der Gesellschaft und auch die Neuordnung Europas nur »selon la doctrine sociale

14 Wie Anm. 5.

15 Ansprache an den Europa-Kongress am 11. November 1948. SCHWARZ, S. 7-10. 
catholique« mit Erfolg betrieben werden könne, so mussten für ihn auch die grundlegenden Prinzipien der katholischen Soziallehre, vorab das Subsidiaritätsprinzip, unbestritten in Geltung bleiben. Einen ersten Hinweis darauf finde ich in der Ansprache an einen Kongress für Internationales Privatrecht vom 15. Juli 1950. Den von dieser Gesellschaft angestellten Versuch, einem internationalen Privatrecht die Wege zu bereiten, nannte der Papst »ein dringendes Unternehmen «, das durch die »Notwendigkeit, in Politik und Wirtschaft die Starre der alten Rahmen geographischer Grenzen zu sprengen oder wenigstens elastisch zu gestalten «, seinen Sinn erhalte; die von ihm für unausweichlich gehaltene Wanderungsbewegung, die in der zweiten Hälfte des Jahrhunderts die frühere Auswanderung in die USA in den Schatten stellen werde, belege die Nützlichkeit der »Vereinheitlichung des Privatrechts «. Aber diese Anerkennung erscheint im folgenden Abschnitt der Rede schon wieder eingegrenzt. Denn Pius fragte nun, ob »eine grundlegende Bereinigung wirklich überall von Vorteil« sei. Vielleicht seien die Unterschiede in den einzelnen Ländern gelegentlich doch $\mathrm{zu}$ groß, um durch ein überall gleiches Privatrecht geregelt zu werden. Für Pius blieb offen, ob eine »Gleichschaltung « des Privatrechts wirklich den Erfordernissen des Gemeinwohls entspricht. Er enthielt sich des Urteils, aber er mahnte implizit als Komplement der vielbeschworenen europäischen Solidarität die Subsidiarität der Institutionen und Rechte $\mathrm{an}^{16}$.

Die folgenden Jahre haben Fortschritte in der Integration Europas gezeigt: 1949 wurde der Europarat gegründet, 1950 entstand die Europäische Konvention zum Schutz der Menschenrechte, 1951 der Vertrag über die Montanunion, von 1952 an wurde der Vertrag über die Europäische Verteidigungsgemeinschaft heftig diskutiert, der im Fall seines Erfolgs die Integration noch weiter vorangetrieben und Frankreich wahrscheinlich eine dauerhafte Führungsrolle in Europa eingebracht hätte. Aber eben dieser Vertrag scheiterte am Veto Frankreichs und warf damit die Frage auf, ob der Weg der Integration überhaupt noch eine sinnvolle Perspektive eröffne.

Noch ehe dieser auch in Deutschland viel umstrittene Vertrag um seinen möglichen Erfolg gebracht wurde, hatte Pius XII. seine Sorgen hinsichtlich der faktischen Funktion der neuen Institutionen ausgedrückt. In einer Rede vor der Pax-Christi-Gesellschaft am 13. September 1952 anerkannte er zwar die Anstrengungen der Politiker um die Einheit Europas, welche die Kirche durchaus unterstüze; aber ihm schien Entscheidendes zu fehlen:

Wenn Wir die Bemühungen jener Staatsmänner verfolgen, so können Wir Uns eines bedrückenden Gefühls kaum erwehren. Unter dem Zwang der Not, die gebieterisch die Einheit Europas heischt, beginnen sie zwar zielbewusst politische Ziele zu verwirklichen, die ein neues Denken bezüglich der Beziehungen von Volk zu Volk

16 Ebd., S. 12. 
voraussetzen. Diese Voraussetzung ist aber leider nicht oder jedenfalls nicht genügend erfüllt. Die Atmosphäre, ohne die jene politischen Neuschöpfungen auf die Dauer unmöglich Bestand haben können, ist noch nicht da. Und wenn es schon ein Wagnis darstellt, die europäische Neuordnung durch das schwierige Zwischenstadium hindurchretten zu wollen, das zwischen dem alten, zu einseitig nationalen, und dem neuen Denken liegt, so sollte wenigstens einem jeden das Gebot der Stunde klar vor Augen stehen, dass nämlich diese Atmosphäre so schnell wie möglich geschaffen werden muss.

Eine solche Atmosphäre erfordert als erstes »eine ruhige Beurteilung der nationalen Geschichte« auf der Basis zuverlässiger Forschung. Keiner Nation sollte verwehrt sein, sich ihrer Siege zu erfreuen und ihre Niederlagen zu betrauern. »Verlangt nichts Unmögliches voneinander, auch keine unechten und unwahren Gesinnungen«, mahnte der Papst. Unrecht der Vergangenheit darf nicht den heute Lebenden zur Last gelegt werden, und bei der Beurteilung der Vergehen der Gegenwart ist zu bedenken, dass der Einzelne den Gang der Dinge doch nur in begrenztem Maß mitbestimmen kann, wenn auch die Völker ihr Kollektivschicksal zu tragen haben. Eine solchermaßen entstehende Atmosphäre sei geprägt von »der Wahrheit, der Gerechtigkeit und der Liebe in Christus«. Gilt dies vom Umgang mit der Vergangenheit, so muss die Zukunft gestaltet sein von der Gerechtigkeit, die jedem Staat das zubilligt, was für den eigenen verlangt wird, von der »gegenseitigen Achtung « der Leistungen und des Leistungsvermögens eines jeden Volkes; Vertrauen zu den anderen Nationen wie zur eigenen, und schließlich: ein "sich eins fühlen« aller, die zur europäischen Gemeinschaft gehören, ein Bewusstsein, das zu fördern der Kirche in vorzüglichem Maße möglich ist ${ }^{17}$.

Eine Rede vor den Angehörigen des Europa-Kollegs in Brügge im folgenden Jahr bot dem Papst Gelegenheit, diesen Gedankengang wieder aufzugreifen. Größer als die Schwierigkeiten der Mitgliedstaaten, ihre Entwicklung einander anzugleichen, »um das Gleichgewicht des Ganzen aufrechtzuerhalten«, schien ihm »das Bewusstsein der inneren Einheit«, der geistigen Werte, deren gemeinschaftlicher Besitz die Gemeinschaft innerlich konstituiert. Materielle Vorteile und gemeinsame Verteidigung werden wegen der damit verbundenen Opfer nicht ausreichen, um auf Dauer Europa zu einer Gemeinschaft zu machen. Denn »unter den Völkern wie unter den einzelnen Menschen hat nichts Bestand ohne wahrhafte Freundschaft«. Diese ist noch nicht voll entwickelt, aber in Ansätzen zu erkennen wie bei der nationale Grenzen nicht achtenden Hilfe für die Opfer der einige Zeit zurückliegenden Flutkatastrophe in den Niederlanden. Die Voraussetzungen für eine solche Haltung sind zu klären, die »heute noch undeutlichen Ge-

17 Ebd., S. 15-19. 
fühle zu beleben, sie zu verbreiten und ihnen Gelegenheit zu geben, sich auszuwirken«.

Bei aller Betonung der Bedeutung geistiger Werte für Europa war Pius XII. doch nicht blind für den materiellen Gewinn, den die Gemeinschaft ihren Mitgliedern in Aussicht stellte. Aber darüber hinaus »muss sich das einige Europa die Behauptung und Verteidigung der geistigen Werte zur Aufgabe machen«, denen es letztlich seine Existenz verdankt.

In Sorge vor einem technizistisch verstandenen Europa hat der Papst auch einmal davor gewarnt, das Problem der Arbeitslosigkeit, zu deren Bewältigung ein vereintes Europa mit seinem erweiterten Wirtschaftsraum bessere Lösungsmöglichkeiten bot als ein national beschränkter Arbeitsmarkt, lediglich als Problem von Produktion und Konsum zu sehen. Noch wichtiger schien ihm im Rahmen des großen europäischen Marktes die Erneuerung der sozialen Ordnung, die den Familien Entfaltungsmöglichkeiten bieten sollte ${ }^{18}$.

Einen deutlichen Appell zur Einheit Europas enthielt die Weihnachtsansprache des Jahres 1953, die sich gegen die Ansicht verwahrte, der Friede könne durch materiale Mittel gesichert werden, wie einst die Parole vom freien Handel als Mittel zum ewigen Frieden behauptet hatte. Der Friede kann nur gesichert werden durch die Anerkennung der gemeinsamen sittlichen und geistigen Ziele der Menschheit und durch gegenseitige Hilfe. Unvermittelt fuhr Pius dann fort: »Alles das kann in Europa geschehen durch das Zustandekommen jener kontinentalen Union der Völker, die sich zwar voneinander unterscheiden, aber geographisch und historisch miteinander verbunden sind «. Den Mut dazu geben das Versagen aller anderen Mittel und die Sehnsucht der Völker nach einer solchen Gemeinschaft. Ein derartiger Schritt sei zwar ein Wagnis, aber ein notwendiges und vernünftiges. Um dieses Zieles willen werden die christlichen Politiker ermahnt, im Innern ihrer Länder Ordnung zu schaffen, wie sie der christlichen Soziallehre entspricht ${ }^{19}$.

Das Jahr 1954 mit dem Scheitern der Europäischen Verteidigungsgemeinschaft, an deren Stelle dann die Verträge der Bundesrepublik Deutschland über den Beitritt zur WEU und zur NATO traten, war nicht dazu angetan, den Papst in seiner Weihnachtsansprache hoffnungsfroh in die europäische Zukunft blicken zu lassen. Die politischen Entscheidungen der zurückliegenden Zeit hatten, so der Papst, »den Leitgedanken einer umfassenden Einigung Europas nicht mehr zur Grundlage«. Pius fürchtete sogar, dass die Politik sich von diesem Ziel abkehren und stattdessen in die Bahnen des Nationalstaates zurückkehren könne. Über diesen fällt er ein hartes

18 Ansprache an italienische Arbeiter am 1. Mai 1953. Ebd., S. $22 \mathrm{f}$.

19 Ebd., S. 24-27. 
Urteil, seine Hochschätzung ist nur möglich geworden, weil man »die ungeheuren, von diesem Staatstyp erpressten Opfer an Leben und Gut sowie die von ihm auferlegten erdrückenden wirtschaftlichen und seelischen Lasten vergessen« hat: nationalistische Politik ist »Keim unendlichen Übels«, nationales Leben hingegen Grundlage unpolitischer Gemeinschaft und bereichert in seiner Vielfalt die Kultur der Menschheit, aber dieses nationale Leben zur Grundlage der Expansion eines zentral organisierten Machtstaates zu machen, ist von Unheil. Ein nationalistisches Europa wird im Wettkampf der Systeme einen schweren Stand haben, weil ihm der innere Zusammenhalt fehlt. Es wird auch seine alte Position in der Welt verlieren; denn der Nationalismus der Kolonialvölker ist »wenigstens zum Teil« Nachahmung des europäischen Modells. In dieser Situation wird sich Europa auf seine Grundlagen, die im Christentum überlieferten Werte besinnen müssen, wenn es bleiben will ${ }^{20}$.

Die Skepsis gegenüber dem Nationalstaat fand auch eher beiläufigen Ausdruck in der Bedeutung, die Pius den Kommunen für die Einheit Europas beimaß. Sie können nach seiner Meinung besser als die Staaten jenen europäischen Geist schaffen, der Vorurteile abbaut, »Bewunderung und Sympathie« für den anderen wachsen lässt. Es ist »der direkte Austausch zwischen den Gemeinden«, der »für die Idee Europas den idealen Kulturboden « abgibt. An dieser Stelle wird auch deutlich, dass der Blick Pacellis über Europa hinausging. Denn er sieht keinen Grund dafür, dass die freundschaftlichen Beziehungen zwischen den Kommunen, die für Europa so wichtig sind, nicht über die Grenzen des Kontinents hinausreichen sollen. Freundschaft und Liebe kennen keinen solchen Rahmen, und das Christentum erkennt allen Menschen die gleiche Würde zu. Es ist die Menschheit, die sich ihrer gemeinsamen Bestimmung mehr bewusst wird, und die Bestrebungen zu einem gemeinsamen Europa sind nur ein Teil davon ${ }^{21}$.

Die große Krise des Herbstes 1956 war für Pius kein Anlass, vom Ziel der europäischen Integration abzuweichen; aber deutlicher noch als früher verwies er auf die Grundlagen, auf denen Europa erbaut werden müsse: Ablehnung der »menschenzerstörenden Philosophiesysteme«, Bereitschaft, überall das Gute zu suchen und zu tun, »die geistige Freiheit zu verteidigen $\aleph^{22}$.

In dieser Zeit trat auch der Gedanke der Solidarität in den Überlegungen des Papstes zu Europa deutlicher hervor. Die europäischen Nationen dürfen, so kommt es in der Weihnachtsbotschaft von 1956 zum Ausdruck, ihre Politik nicht als Null-Summen-Spiel betrachten, bei dem der Erfolg des

\footnotetext{
20 Ebd., S. 27-30.

21 Ansprache vor dem 12. Kongress für Gemeindeverwaltung am 30. September 1955. Ebd., S. 31f.

22 Ansprache an die Campagne Européenne de la Jeunesse am 19. November 1956. Ebd., S. 33.
} 
einen notwendig den Misserfolg des anderen bedeutet, und in der Stunde der gemeinsamen Gefahr darf auch eine berechtigte Kritik am Partner die Gemeinschaft nicht gefährden ${ }^{23}$.

In einer Ansprache vor italienischen Unternehmern im März 1957 beschrieb der Papst, was Europa noch fehlte, um die wirtschaftlichen Statusunterschiede zwischen den beteiligten Staaten zu verringern: Austausch von Arbeitskräften, Anleihen und Schaffung privilegierter Märkte. Damit ist kein Patentrezept empfohlen sondern nur ein Weg gewiesen. Was Abhilfe schaffen werde, ist noch nicht vollends ausgemacht, darum folgt nur der Appell: »Es müssen daher alle, Einzelpersonen wie Organisationen, geeignete Maßnahmen zugunsten der Gesamtwirtschaft studieren und ergreifen«. Die Solidarität korrespondiert eben mit der Subsidiarität nach der Lehre der Kirche $^{24}$.

Mit den Römischen Verträgen vom 25. März 1957, welche die Europäische Wirtschaftsgemeinschaft und die Europäische Atomgemeinschaft errichteten, war ein neuer Ansatz zur Schaffung Europas gefunden. Pius begrüßte ihn ausdrücklich, obwohl die Verträge nur eine Gemeinschaft im Materiellen schufen, aber er gab der Hoffnung Raum, dass ein Erfolg der neuen Gebilde auch die geistige und moralische Gemeinsamkeit stärken werde. Der Papst verschloss aber seine Augen nicht vor einem Mangel, der den neuen europäischen Institutionen anhaftet. Er kritisierte, dass die EWG noch keine eigentliche Gemeinschaft sei, weil ihr eine eigene Autorität fehle, die »wirkliche Gewalt « besitze und Verantwortung trage. Unter diesem Gesichtspunkt bedeute die Exekutive der EWG »einen Rückschritt« im Vergleich zur Europäischen Gemeinschaft für Kohle und Stahl, deren Hohe Behörde weitergehende Vollmachten besitze und vom Ministerrat weniger abhängig sei. Der Papst gab seinen Zuhörern, den Angehörigen des EuropaKongresses, die Aufgabe auf den Weg, »für eine Stärkung der Exekutive in den bestehenden Gemeinschaften zu sorgen und damit die Konstituierung eines einheitlichen politischen Organismus ins Auge zu fassen«. Eine europäische Außenpolitik schien dem Papst schon damals möglich und angesichts der weltpolitischen Blockbildung sogar nötig. Aber auch hier hatte er zu bedauern, dass für sie noch kein »wirksames Instrument« zur Verfügung stand. Wiederum sprach Pius auch in dieser Rede die Verbindung Europas mit Afrika an, die später durch die Assoziation afrikanischer Staaten an die EWG vorankam: Europa darf sich nicht egoistisch abschließen und nur verteidigen wollen, sondern muss sich selbstlos öffnen. Auf der Grundlage materieller Hilfe kann es erzieherisch und bildend wirken ${ }^{25}$.

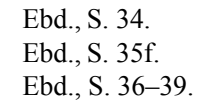


Die letztlich sozialphilosophisch, ethisch begründete Entscheidung des Papstes für Europa nimmt die Grundprinzipien der katholischen Soziallehre, Personalität, Solidarität, Subsidiarität, zu Strukturelementen des neuen Gebildes. Pius hat verschiedentlich vor Gemeindeverbänden über Europa gesprochen. Dies mag Zufall sein, aber in diesen Ansprachen wird deutlich, dass nach seiner Vorstellung den Kommunen im bestehenden Staat wie im künftigen Europa die Rolle zukomme, durch ihre originäre Existenz innerhalb des größeren Ganzen dieses vor monolithischer Geschlossenheit und erdrückender Übermacht des Staates zu bewahren und in ihrem eigenen Freiheitsraum für die Person die Chance zu freiheitlicher Selbstverwirklichung offen zu halten. In einer seiner letzten Reden zum Thema Europa, am 3. Dezember 1957, zehn Monate vor seinem Tod, hat Pius XII. diese seine Auffassung markant zusammengefasst:

Wo die starken Zentralisierungsbestrebungen der modernen Nationen auf eine äußerste Freiheitsbeschränkung der Ortsgemeinden und der Einzelpersonen hinzielen, [mahnen die Kommunen und Individuen an den Vorrang der Persönlichkeitswerte über die Werte wirtschaftlicher und sozialer Natur], [ist] die öffentliche Gewalt [...] zwar im Hinblick auf das Gemeinwohl errichtet worden, aber diese gipfelt im gemeinsamen Leben der Einzelpersonen. Nur eine geistige Interessengemeinschaft vermag die Menschen auf die Dauer zusammenzuhalten. Es gilt also, im werdenden Europa eine breite und zuverlässige Mehrheit von Föderalisten zu schaffen, die als Prinzipien eines gesunden Personalismus einen, möchten Wir sagen, Begriff der bürgerlichen Gesellschaft festhalten, in welchem die Einzelpersonen eine normale Entwicklungsmöglichkeit finden und in Freiheit der Gemeinschaft dienen können ${ }^{26}$.

Dass Pius oft auf die christlichen Wurzeln Europas abhob, war mehr als eine historische Reminiszenz, welche die Mitsprache des Papstes beim Neubau Europas begründen sollte. Vielmehr zeigt sich bei ihm in knappen Umrissen eine theologische Perspektive Europas. Pius sah das Christentum als die belebende Kraft, welche die menschlichen Grundfreiheiten mit den Rechten der Familie und der Völker zu verbinden vermochte und darum einer übernationalen Gemeinschaft die Möglichkeit gab, in gegenseitigem Respekt das je Eigene zu schätzen, zugleich aber, und dies ist das Bemerkenswerte, auch wiederum neue Gestaltungen ermöglichte.

Keine Aufgabe zeitlicher Art gelangt zum Ziel, ohne andere heraufzubeschwören, ohne eben durch ihre Verwirklichung neue Bedürfnisse, neue Ziele zu erzeugen. Die menschlichen Gemeinschaften bleiben immer im Werden, immer auf der Suche nach einer besseren Organisation, und oft kommen sie nur dadurch über sich selbst hinaus, dass sie verschwinden und damit glänzenderen und fruchtbareren Zivilisationen zum Durchbruch zu verhelfen. 
Europa bedeutet also nicht das »Ende der Geschichte«. Das Christentum wird vielmehr immer dazu beitragen, dass neue Gestaltungen gelingen, aber seine Rolle wird sich nicht darin erschöpfen, Helfer bei der Gestaltung von immer wieder Neuem zu sein, sondern auf ein Ziel hinzuweisen. Denn letztes Ziel allen politischen Gestaltwandels ist die »unumstößliche Gewissheit eines Vaterlandes, das nicht von dieser Welt ist und das allein die vollkommene Einheit herstellen wird « ${ }^{27}$. So wenig wie Europa »Endziel der Geschichte« sein kann, so wenig ist es das politeuma, von dem Paulus im Philipperbrief spricht, die endgültige, zeitüberhobene Gemeinschaft der Christen, nichtsdestoweniger aber bleibt Europa Aufgabe für hier und heute.

$*$

Versucht man, aus den vielfältig verstreuten Äußerungen des Papstes zu Europa ein zusammenfassendes Bild zu gewinnen, so sind zunächst Abgrenzungen erforderlich. Europa war für Pius niemals »Dritte Kraft« zum Ausgleich zwischen den Blöcken oder zwischen Kapitalismus und Sozialismus. Auch hat er sich nie zu den Grenzen Europas geäußert. Er verfolgte keinen intellektuellen Entwurf, sondern sprach meist zu den aktuellen Problemen. Gleichwohl war er ein unentwegter Förderer der europäischen Einigung. Sie war, wie er selbst sagte, einer seiner $»$ Lieblingsgedanken $«{ }^{28}$. Mit seiner Haltung meinte er, nicht das Feld der Politik zu betreten, auf dem seine Aufgabe nicht lag, sondern Verständigung und Friede zu fördern, die dem padre commune am Herzen liegen müssen. Europa war für Pius immer eine Chance des Friedens, zunächst der Versöhnung innerhalb seiner Grenzen, dann auch als Element weltweiter Friedenssicherung. Dieses Europa musste wie alle soziale Gestaltung den Grundorientierungen gesellschaftlicher Ordnung entsprechen, wie sie die Kirche mit den Sozialprinzipien Personalität, Solidarität, Subsidiarität vertritt. Schon aus diesem Grunde sollte Europa kein Verband von Nationalstaaten sein, denen Pius aus historischen Gründen mit tiefer Skepsis gegenüberstand. Ihre Konzentration innerer Macht sollte nicht in größere Gebilde übertragen werden. Region und Gemeinde, die dem Leben des Einzelnen näher sind als der Gesamtstaat, sollten hingegen als besser geeignete Gliederungsprinzipien ihr Recht behalten. Denn Europa soll für seine Menschen gemeinsamer Lebensraum werden, der dazu einer gemeinsamen Wertewelt bedarf. Ein technizistisch gedachtes Europa wird keinen Bestand haben können, weil die Gründe, die zu seiner Errichtung führen, irgendwann einmal dahinfallen werden. Als Lebensraum, der freiheitliche Entwicklung ermöglicht, muss Europa subsi-

27 Wie Anm. 26.

28 Ebd. 
diär geordnet sein. Man darf darum der Frage nicht ausweichen, ob eine Internationalisierung oder Europäisierung tatsächlich dem Gemeinwohl dient. Die Solidarität der Europäer darf nicht auf sich selbst beschränkt bleiben, denn die Liebe überschreitet alle Grenzen. Afrika ist eine besondere Aufgabe und Verpflichtung der Europäer. Europa ist kein letzter Zweck in sich selbst. 


\section{Brückenbauer Europas: \\ Die österreichischen Bischöfe und der europäische Integrationsprozess}

Kann man auf Überlegungen zur Statik verzichten, weil der Hochbau schon nahezu fertig gestellt ist? Bauen wir nicht Häuser mitten in die Landschaft, ohne den Flächenwidmungsplan zu bedenken? Und vor allem: Wessen Vorhaben ist die Union? Wer sorgt für die Einsatzfreude und Frustrationstoleranz der Unionsbürger angesichts eines jedermanns Lebenshorizont radikal verändernden Geschehens? Und haben nicht die Ereignisse des 11. September 2001 offenbar gemacht, wie dünn das Eis ist, auf dem wir die Kreise unserer Planung ziehen ${ }^{1}$ ?

Diese Fragen stellte sich der Integrationsbeauftragte im Generalsekretariat der Österreichischen Bischofskonferenz ${ }^{2}$ Franz Eckert im Jahr 2001 und fügte ihnen eine weitere hinzu: »Gibt es innerhalb unseres Alten Kontinents eine spirituelle Leitwährung, die der Europäer nicht außer Kurs setzen darf, wenn er nicht Gefahr laufen will, von seinen identitätsstiftenden Wurzeln getrennt zu werden « ${ }^{3}$ ?

Damit trifft Eckert mitten ins Herz der EU, deren Akteure seit Jahrzehnten darum bemüht sind, den europäischen Staatenverbund nicht mehr bloß auf der Basis der Wirtschaft zu legitimieren. Das komplexe System der Verträge, auf denen die EG/EU aufbaut, gibt jedenfalls auf die aufgeworfenen Fragen keine Antworten. Seitens der Kommission etwa lässt man die Integrationsgeschichte als Erfolgsstory von angesehensten WissenschaftlerInnen jeder Provenienz schreiben ${ }^{4}$, verfasst Dokumente etwa über eine Europäische Identität oder lässt prominente EG/EU-Politiker darüber sin-

1 Franz ECKERT, Ist die Europäische Union ein christliches Vorhaben?, in: Peter-Christian MÜLlER-GRAFF / Heinrich SCHNEIDER (Hg.), Kirchen und Religionsgemeinschaften in der Europäischen Union, Baden-Baden 2003, S. 187-188.

2 Die Österreichische Bischofskonferenz besteht seit 1849; seit dem 2. Vatikanischem Konzil (1962-1965) stellt sie eine Einrichtung allgemeinen Rechts mit jurisdiktioneller Kompetenz dar. Die Österreichische Bischofskonferenz ist eine Körperschaft öffentlichen Rechts, der alle Diözesanbischöfe, die Weihbischöfe und der Abt von Mehrerau angehören. Siehe http:// www.bischofskonferenz.at/content/site/home/index.html

3 ECKERT, Europäische Union?, S. 188.

$4 \quad$ Vgl. etwa jüngst Peter PICHLER, Acht Geschichten über die Integrationsgeschichte. Zur Grund legung der Geschichte der europäischen Integration als ein episodisches historiografisches Erzählen, phil. Diss. Graz 2009. 
nieren, Europa eine Seele geben zu wollen bzw. geben zu müssen (Jacques Delors).

Die Bemühungen, der EU eine andere Legitimität als jene der Wirtschaft oder Politik zu verpassen, sind vielschichtig, doch der Erfolg lässt auf sich warten. Bisher ist es den Entscheidungsträgern in Brüssel noch nicht gelungen, die EU-Bürgerinnen und Bürger für diese zu begeistern, sich mit ihr zu identifizieren, um so etwas wie ein EU-Wir-Bewusstsein zu entwickeln.

Möglicherweise könnte die katholische Kirche der EU in der Beantwortung der einleitend zitierten Fragen eine Hilfestellung bieten. Kritische Stimmen werden sogleich danach fragen, in welcher Art und Weise sich die Kirche an der Integration Europas beteiligen könnte, ist der Integrationsprozess doch ein rein politischer Prozess. Darauf kann man entgegnen, dass die Arbeit für Europa eine politische, aber eben eine gesellschaftspolitische Arbeit ist. Daher kann es der katholischen Kirche und überhaupt den Christen nicht gleich sein, auf welchen Fundamenten oder welchen Berechnungen der Statik dieses Europa und seine Gesellschaft aufgebaut sind ${ }^{5}$.

Die EU ist, um mit Eckert fortzufahren, ein christliches Vorhaben, solange sie nicht von den Christen aufgegeben wird. Diese werden von der katholischen Kirche aufgefordert, am »Bauplatz Europa « mitzuwirken, um die Seele Europas wiederzufinden, die durch eine jahrzehntelange Fixierung auf wirtschaftliche Werte verloren gegangen ist ${ }^{6}$.

Die EU ist ein christliches Unterfangen (Heinrich Schneider); und die »christliche Mitgift« finden wir bereits seit dem Vertrag von Maastricht primärrechtlich gewährleistet, sie erfuhr durch den Vertrag von Lissabon in Art. 1a EUV eine Erweiterung.

\section{Die katholische Kirche in Österreich seit der Ersten Republik - ein kurzer Abriss}

Nach dem Zusammenbruch der Monarchie entwickelte die Kirche in der Ersten Republik als Institution eine sehr starke Bindung an die Christlichsoziale Partei; als rechtliche Grundlage galt das Konkordat aus 1855, das die Beziehung Staat und Kirche regelte ${ }^{7}$. Darin hatte der Staat der katholischen Kirche den Vorrang vor anderen Religionsgesellschaften in Österreich eingeräumt sowie eine erhöhte Einflussnahme etwa auf dem Gebiet

5 Vgl. etwa Michael KunN, Europa - von Brüssel gesehen. Die Europäische Union durch die Brille eines kirchlichen Europa-Lobbyisten, in: Walter KRIEGER / Balthasar SIEBERER, Was ist christlich an Europa, Kevelaer 2004, S. 36-37.

6 ECKERT, Europäische Union?, S. 199.

7 Vgl. etwa Erika WeINZIERL-FISCHER, Die österreichischen Konkordate von 1855 und 1933, Wien 1960. 
des Eherechts oder des Schulwesens. Dieses Konkordat kann als die Basis für den politischen Katholizismus bewertet werden, der in die Erste Republik transformiert wurde ${ }^{8}$. Als »Leitfigur « dieser Form des Katholizismus nennt der Grazer Kirchenhistoriker Maximilian Liebmann Ignaz Seipel'. Der Prälat war Sozialminister in der letzten kaiserlichen Regierung und fünf Mal Bundeskanzler der Ersten Republik. So wie er übten bis 1933 viele Kleriker ein politisches Amt aus, ihre Politik war konservativ und monarchistisch. Eine Entpolitisierung erfolgte mittels kirchlichem Paukenschlag: Die Bischofskonferenz fasste am 30. November 1933 den einstimmigen Beschluss, den Klerus aus der Politik rückzubeordern ${ }^{10}$. Die Träger politischer Mandate wurden aufgefordert, bis spätestens 15. Dezember des Jahres ihre Mandate niederzulegen bzw. aus jeder politisch führenden Stellung auszuscheiden. Jede weitere politische Betätigung bedurfte der Erlaubnis des zuständigen Ordinarius. Die darauf einsetzenden Spekulationen nach dem Grund dieses Beschlusses - die SPÖ etwa deutete ihn als Misstrauensvotum der Bischöfe gegenüber dem autoritären Regierungskurs von Dollfu $\beta^{11}$ - beendete der Weihnachtshirtenbrief vom 21. Dezember $1933^{12}$. Darin dokumentierten die österreichischen Bischöfe einerseits ihre »ergebene Treue« gegenüber dem autoritären Ständestaat, und andererseits begründeten sie ihren Rückzug damit, dass die »katholische Regierung ohnehin die sicherste Garantie für die Wahrnehmung der religiösen Interessen sei « ${ }^{13}$. Dieser »Jahrhundertbeschluss « markierte das Ende des Politischen Katholizismus und den Beginn des Pastoralen Katholizismus ${ }^{14}$. Doch bereits im austrofaschistischen Ständestaat bekleideten Priester wieder eine politische Funktion. Allerdings unterschied sich nun deren politische Tätigkeit gegenüber jener vor 1933 dadurch, dass ihre Entsendung nicht dem Politischen Katholizismus, sondern dem Pastoralen Katholizismus zuzuordnen war $^{15}$. Der Wiener Erzbischof Kardinal Theodor Innitzer ${ }^{16}$ kommentierte das poli-

8 Jüngst erschienen Maximilian LIEBMANN, »Heil Hitler« - Pastoral bedingt. Vom Politischen Katholizismus zum Pastoralkatholizismus, Wien 2009.

9 Ebd., S. 22.

10 Ebd., S. 32. Dieser Beschluss traf fünf Nationalratsabgeordnete, drei Bundesratsabgeordnete und viele Abgeordnete zu den Landtagen und Gemeinderäten.

11 Ebd., S. 33.

12 Rudolf LeEB [u. a.], Geschichte des Christentums in Österreich. Von der Spätantike bis zur Gegenwart, Wien 2003, S. 414.

13 Ebd., S. 414-415.

14 LiEBMANN, »Heil Hitler«, S. 170.

15 Ebd., S. 35-36.

16 Theodor Innitzer war 1929/30 im Kabinett Schober III Bundesminister für Soziale Verwaltung; 1932 erfolgte seine Ernennung zum Erzbischof von Wien, 1933 wurde er Kardinal. Bis zu seinem Tod im Jahr 1955 blieb er Erzbischof von Wien; vgl. Bernd WILDERMUTH, Theodor Innitzer, in: Biographisch-Bibliographisches Kirchenlexikon, Bd. 2, Hamm 1990, Sp. 1277 1279. 
tische Tagesgeschehen. Er stimmte darüber hinaus offiziell dem Juliabkommen von 1936 zwischen Schuschnigg und Hitler zu: eine Vorgehensweise, die seitens des österreichischen Kirchenvolkes heftigst verurteilt wurde. Es sei hier angemerkt, dass die österreichischen Bischöfe bereits 1929 gegen den Nationalsozialismus aufgetreten waren unter dem Motto: Es sei unmöglich gleichzeitig guter Katholik und wirklicher Nationalsozialist zu sein ${ }^{17}$ ! So kam es auch, dass am Tag des deutschen Einmarschs in Österreich, am 13. März 1938, Bischöfe verhört wurden und übrigens der einzige Bischof im deutschsprachigen Raum von den Nationalsozialisten in Haft genommen wurde. Dabei handelte es sich um den steirischen Fürstbischof Ferdinand Stanislaus Pawlikowski; 24 Stunden später entließ man ihn wieder aus der Haft ${ }^{18}$.

Bereits am 14. März, also einen Tag nachdem Kardinal Innitzer die Pummerin anlässlich des Einzugs Hitlers in Wien hatte läuten lassen, stattete er dem neuen österreichischen Staatsoberhaupt Adolf Hitler seinen Besuch $\mathrm{ab}^{19}$. Innitzer betonte ihm gegenüber die Bereitschaft der österreichischen Katholiken zu Loyalität gegenüber dem Staat. Fünf Tage später, am 18. März 1938, unterzeichneten die österreichischen Bischöfe die »Feierliche Erklärung«. Darin forderten sie die österreichische Bevölkerung auf, am Tag der Volksabstimmung, dem 10. April 1938, für den Anschluss Österreichs an das Deutsche Reich zu stimmen.

\section{Feierliche Erklärung}

Aus innerster Überzeugung und mit freiem Willen erklären wir unterzeichneten Bischöfe der österreichischen Kirchenprovinz anlässlich der großen geschichtlichen Geschehnisse in Deutsch-Österreich:

Wir erkennen freudig an, dass die nationalsozialistische Bewegung auf dem Gebiet des völkischen und wirtschaftlichen Aufbaues sowie der Sozial-Politik für das Deutsche Reich und Volk und namentlich für die ärmsten Schichten des Volkes Hervorragendes geleistet hat und leistet. Wir sind auch der Überzeugung, dass durch das Wirken der nationalsozialistischen Bewegung die Gefahr des alles zerstörenden gottlosen Bolschewismus abgewehrt wurde.

Die Bischöfe begleiten dieses Wirken für die Zukunft mit ihren besten Segenswünschen und werden auch die Gläubigen in diesem Sinne ermahnen.

\footnotetext{
17 Auszug aus dem Hirtenbrief des Linzer Bischofs Johannes Maria Gföllner, zitiert in LEEB [u. a.], Geschichte des Christentums, S. 423.

18 Karl Amon / Maximilian Liebmann, Kirchengeschichte der Steiermark, Graz 1993, S. $322 \mathrm{ff}$.

19 LiebMANN, »Heil Hitler«, S. 67-70.
} 
Am Tage der Volksabstimmung ist es für uns Bischöfe selbstverständliche nationale Pflicht, uns als Deutsche zum Deutschen Reich zu bekennen, und wir erwarten auch von allen gläubigen Christen, dass sie wissen, was sie ihrem Volke schuldig sind.

Wien, am 18. März $1938^{20}$.

Kardinal Innitzer wurde darauf hin zum Apostolischen Nuntius in Österreich, Gaetano Cicognani, berufen, der von ihm eine Änderung der »Feierlichen Erklärung« verlangte, denn sonst werde diese »schlimm wirken ${ }^{21}$. Innitzer wurde angehalten, beim Reichskommissar für die Wiedervereinigung Österreichs mit dem Reich, dem späteren Gauleiter, Josef Bürckel, ein dementsprechendes Vorwort zu erbitten. Dieser lehnte jedoch die von der Kirche vorgeschlagene Wortwahl ab und diktierte seine eigene. Innitzer musste diesem als »Vorwort zur Feierlichen Erklärung« betitelten Dokument ein Begleitschreiben hinzufügen. Aus jenem wird die nachträgliche Einfügung des handgeschriebenen »und Heil Hitler « ersichtlich. Innitzer ist dazu wohl überredet worden, zeitlebens litt er aber an diesem Hitlergruß $3^{22}$. Diese drei Erklärungen verwendete das NS-Regime im gesamten »Großdeutschen-Reich« als Propaganda für die bevorstehende Volksabstimmung in Österreich. Proteste kamen vom Papst aber auch von der österreichischen Bevölkerung ${ }^{23}$. Dieser Akt unter Federführung von Kardinal Theodor Innitzer dürfte ein Trauma in der Katholischen Kirche hinterlassen haben, das in die Zweite Republik reichte. Liebmann bewertet das Verhalten der österreichischen Bischöfe als ein Konform-Gehen mit der Pastoraldoktorin, die im Austrofaschismus erarbeitet wurde. Daher waren die Bischöfe weder Opportunisten, noch waren sie umgefallen ${ }^{24}$. Dies ändert jedoch nichts daran, dass Innitzers Haltung eine tiefe Enttäuschung in weiten Kreisen der österreichischen Bevölkerung auslöste!

\section{II. Österreich nach dem Zweiten Weltkrieg, Anfänge der Europäischen Integration}

Nach dem Ende des Zweiten Weltkrieges erhielt Österreich durch Jalta den Status eines »fremdbestimmten« Landes. Die Politik der jungen Zweiten Republik war darauf ausgerichtet, möglichst rasch staatliche Souveränität zu erlangen und einen Staatsvertrag aus zu verhandeln! Dies erfolgte mit

\footnotetext{
20 Ebd., »Heil Hitler«, S. 76 sowie Maximilian LiEBMANN, Theodor Innitzer und der Anschluss. Österreichs Kirche 1938, Graz 1988.

21 LiEBMANN, »Heil Hitler«, S. 81.

22 Ebd., S. 80-83.

23 Ebd., S. 84.

24 Ebd., S. 79.
} 
15. Mai 1955, als dessen Bedingung die Verabschiedung des Neutralitätsgesetzes am 26. Oktober 1955 folgte. Österreichs Westorientierung bestand vorerst darin, Mitglied der UNO (1955) bzw. des Europarates (1956) zu werden. Eine österreichische »Integrationspolitik« begann allmählich »auf sanften Pfoten « (Florian Weiß) gegen Ende der fünfziger Jahre ${ }^{25}$. Bereits zuvor zählte Österreich zu den Empfängerländern der Marshall-Hilfe und war 1948 Gründungsmitglied der OEEC in Paris.

Das Trauma der österreichischen Kirche, das aus der Zwischenkriegszeit herrührte, fand schlussendlich in der Nichteinmischung in die Tagespolitik nach 1945 seinen Ausdruck. In einer Aussendung der Österreichischen Bischofskonferenz aus dem Jahr 2002 weist die einleitende Passage auf diese Situation hin. Sie soll hier wiedergegeben werden, um die Position der katholischen Kirche für die weitere Darstellung abzustecken:

Nach den bitteren Erfahrungen in der Zeit der Ersten Republik haben die Bischöfe den Klerus generell aus der Parteipolitik zurückgezogen. Die Kirchenleitung betreibt keine Parteipolitik und dabei wird es auch in Zukunft bleiben. Wohl aber setzen sich die Bischöfe gemeinsam mit vielen Katholiken des Landes im politischen Leben Österreichs für die Wertepolitik zum Schutz unverzichtbarer Werte ein ${ }^{26}$.

Die Nichteinmischung in die Partei- bzw. Tagespolitik galt jedoch nicht für Laien. Nach dem Zweiten Weltkrieg wurden die Laienorganisationen, die im Zuge der nationalsozialistischen Diktatur zerschlagen worden waren, wieder aufgebaut ${ }^{27}$. Bereits Anfang des Jahres 1948 formulierte der christlich-soziale Publizist Robert Skorpil im katholischen Volksboten, ein SechsPunkte-Programm der europäischen Vereinigung:

1. Europa wird entweder christlich sein oder gar nicht mehr sein.

2. Die europäische Idee, der Wille zur neuen Einigung und die Grundgedanken zu dieser Einigung müssen aus Europa selbst kommen.

3. Berufen ist Frankreich, ihm ist die Lösung und Erlösung seines Nachbarn Deutschland aufgetragen.

4. Das neue Europa kann nur entstehen mit einem innerlich und äußerlich freien Europa.

25 Florian WeIß, »Auf sanften Pfoten gehen«: Österreich und die Anfänge der westeuropäischen Integration 1947-1957, Hausarbeit Univ. München 1989 und Florian WEIß, »Gesamtverhalten: Nicht sich in den Vordergrund stellen«. Die österreichische Bundesregierung und die westeuropäische Integration 1947-1957, in: Michael GEHLER / Rolf STEININGER, Österreich und die europäische Integration 1945-1993, Wien 1993, S. 21-54.

26 Zum Beitritt der österreichischen Nachbarländer zur EU. Wortlaut einer Erklärung der Österreichischen Bischofskonferenz vom 8. November 2002 aus Anlass des bevorstehenden EUBeitritts der österreichischen Nachbarländer, in: Amtsblatt der Österreichischen Bischofskonferenz Nr. 35, 1. März 2003, S. 2.

27 Siehe dazu die kompakte Darstellung bei LieBMANN, »Heil Hitler«. 
5. Russland ist nicht Asien, ist nicht Europa hat aber an beiden Anteil und für beide besondere Aufgaben.

6. Europa kann eine wirkliche Einigung nur auf föderativer Grundlage finden ${ }^{28}$.

Skorpil betonte als gemeinsame Wurzel Europas das Christentum, forderte die Lösung des »europäischen Bruderzwistes zwischen Deutschland und Frankreich« sowie den Föderalismus als Grundlage. Diesen hatten bereits die Widerstandskämpfer als »Allheilmittel« für die Vereinigung des europäischen Kontinents in der Zwischenkriegszeit zum obersten Postulat erhoben. Der Föderalismus wird als die Gegenbewegung, geradezu als das Allheilmittel schlechthin zum Nationalismus bzw. Totalitarismus gesehen ${ }^{29}$. Übrigens: Bereits Papst Pius XII. (1939-1958) bekannte sich zu einer föderalistischen Finalität des europäischen Einigungsprozesses ${ }^{30}$ !

Die österreichische Amtskirche hielt es jedoch mit der Aussage des eben erwähnten Papstes, die er im Zuge einer Audienz mit Innitzer formulierte: »Keine Parteipolitik, wenn aber die Politik an den Altären rühre, müsste die Kirche Politik betreiben « ${ }^{31}$. Den päpstlichen Standpunkt bekräftigte Kardinal Innitzer, indem er die Devise formulierte $»$ Eine freie Kirche in einer freien Gesellschaft «, die ihren programmatischen Niederschlag im sogenannten Mariazeller Manifest von 1952 fand. Darin garantierten die Bischöfe Österreichs, eine freie Kirche bilden zu wollen: Das heißt, dass die Kirche auf sich selbst gestellt und nur auf sich selbst gestellt sei.

Jede geschichtliche Epoche hat ihre eigenen Notwendigkeiten und ihre eigenen Möglichkeiten. Heute hat die Kirche keinen Kaiser und keine Regierung, keine Partei und keine Klasse, keine Kanonen, aber auch kein Kapitel hinter sich. Die Zeit 1938-1945 bildet hier eine unüberschreitbare Zäsur; die Brücken in die Vergangenheit sind abgebrochen, die Fundamente für die Brücken in die Zukunft werden heute gelegt. So geht die Kirche aus einem versinkenden Zeitalter einer Epoche neuer sozialer Entwicklung entgegen. Eine freie Kirche bedeutet daher: Keine Rückkehr zum Staatskirchentum vergangener Jahrhunderte, das die Religion zu einer Art ideologischen Überbaus der staatsbürgerlichen Gesinnung degradierte, das Generationen von Priestern zu inaktiven Staatsbeamten erzog. Keine Rückkehr zu

28 Robert SKoRPIL, Anschluss Europa, in: Der Volksbote 42. Jg,, Nr. 4, 22. Jänner 1948, zitiert bei Konrad GraSS, Die katholische Kirche und die Integration Österreichs in die Europäische Gemeinschaft, phil. Dipl. Arb. Innsbruck 2008, S. 59.

29 Vgl. etwa Anita PretTENTHALER-ZIEGERHOFER, »Die Männer des europäischen Widerstandes werden morgen das neue Europa bauen«. Leitbilder für ein Vereintes Europa, in: Jürgen ElverT / Jürgen NiELSEN-SIKORA (Hg.), Leitbild Europa? Europabilder und ihre Wirkungen in der Neuzeit, Stuttgart 2009, S. 126-138.

30 SCHNEIDER, Die Europäische Einigung, S. 86.

31 Zitiert in LeEB [u. a.], Geschichte des Christentums, S. 443. 
einem Bündnis von Thron und Altar, das das Gewissen der Gläubigen einschläferte und sie blind machte für die Gefahren der inneren Aushöhlung. Keine Rückkehr zum Protektorat einer Partei über die Kirche, das vielleicht zeitbedingt notwendig war, aber zehntausende der Kirche entfremdete. Keine Rückkehr zu jenen gewaltsamen Versuchen, auf rein organisatorischer und staatsrechtlicher Basis christliche Grundsätze verwirklichen $\mathrm{zu}$ wollen ${ }^{32}$.

Das Manifest gilt als ein einzigartiges Dokument, das Priester und Laien gemeinsam über grundlegende Fragen der katholischen Kirche am 4. Mai 1952 verfassten.

Zwei Jahre zuvor, beinahe auf den Tag genau, am 9. Mai 1950, hatte Robert Schuman die Zusammenlegung der deutschen und französischen Stahlund Kohleindustrie verkündet. Es sei darauf hingewiesen, dass die meisten der Gründerväter politisch Christdemokraten und konfessionell Katholiken waren $^{33}$. Somit hatten die europäischen Christdemokraten wesentlichen Anteil an der Gründung der EU: Im Jahr 1947 gründeten die europäischen Christdemokraten den »Genfer Kreis«, sie verstanden dieses Forum als ein nicht an die Öffentlichkeit tretendes Kontakt-Komitee maßgeblicher europäischer Parteienvertreter «, »um dergestalt politische Aufgaben zu erörtern und vereinbarte Maßnahmen durchzusetzen ${ }^{34}$. An diesem Treffen nahmen etwa aus Frankreich Politiker wie Georges Bidault oder Pierre Pflimlin teil, auf deutscher Seite Konrad Adenauer oder Heinrich von Brentano ${ }^{35}$. Robert Schuman nahm erst 1955 im Cercle Koutzine teil, in Genf war er selbst nie anwesend $^{36}$. In diesem Forum beriet man u. a den Schuman-Plan. Gehler bewertet den Anteil der »Genfer-Kreis-Geheimdiplomatie« an der Realisierung des Schuman-Planes ambivalent: Man dürfe den Einfluss des Genfer Kreises nicht überschätzen, aber auch nicht minimieren. Wenngleich die Begegnungen der Christdemokraten in diesem Forum für die Realisierung des Planes nicht entscheidend waren, schufen [sie] aber eine grundsätzlich positive Atmosphäre unter den christdemokratischen Emissären, die dem Projekt sehr gewogen waren ${ }^{37}$. Die Mitglieder des Genfer Kreises pflegten enge Kontakte zu den Nouvelles Equipes Internationales (NEI). Im Gegensatz zum Genfer Kreis war dieser christdemokratische Parteienbund mit

32 Im vollständigen Wortlaut abrufbar unter http://www.graz-seckau.at/bjw30/Mariazeller_Ma nifest.htm.

33 SCHNEIDER, Die Europäische Einigung, S. 73.

34 Michael GeHLER, Begegnungsort des Kalten Krieges. Der »Genfer Kreis« und die geheimen Absprachen westeuropäischer Christdemokraten 1947-1955, in: Michael GEHLER [u. a.] (Hg.), Christdemokratie in Europa im 20. Jahrhundert, Wien 2001, S. 642

35 Ebd., S. 651

36 Ebd., S. 659.

37 Ebd., S. 663. 
bewusster Außenwirkung gebildet worden ${ }^{38}$. Hier waren auch Mitglieder der Österreichischen Volkspartei (ÖVP), etwa Felix Hurdes, vertreten ${ }^{39}$.

Nicht nur die Christdemokraten Europas hatten Interesse an der Vereinigung der europäischen Staaten, sondern auch die Römisch-katholische Kirche. Päpste, Synoden und Bischofskonferenzen äußerten sich immer wieder zum Integrationsprozess und wiesen dabei auf die Rolle des Christentums und Katholizismus in der Frage der Konstituierung einer »europäischen Wertegemeinschaft $\ll \operatorname{hin}^{40}$.

Doch zurück zum europäischen Integrationsprozess: Bereits am 18. April 1951 konnte der sogenannte EGKS-Vertrag in Paris gemeinsam von Frankreich und Deutschland, Italien und den Beneluxstaaten unterzeichnet werden; am 27. Juli 1952 folgte die Gründung der Europäischen Gemeinschaft für Kohle und Stahl (EGKS, Montanunion). Nach der Krise um die Schaffung einer Europäischen Verteidigungsgemeinschaft (EVG), in deren Sog eine Europäische Politische Gemeinschaft (EPG) entstehen sollte, wurde die BRD 1955 vollwertiges Mitglied der neugegründeten WEU bzw. NATO. Eine tiefer gehende Integration, weg von der sektorialen Teilintegration im Bereich Kohle und Stahl hin zu einer europäischen Zollunion bedeutete die Gründung der Europäischen Wirtschaftsgemeinschaft (EWG) durch die Römischen Verträge. So bezeichnete die 1945 von Friedrich Funder gegründete Wochenzeitschrift Die Furche etwa die Abgabe von Souveränität als goldenen Schlüssel ohne ihn ist der kostbare Schatz, den die Einigung Europas bedeuten muss, nicht zu heben ${ }^{41}$. Österreich blieb ein Beitritt aufgrund seiner Neutralität, worüber der Kreml penibel wachte, verwehrt. Bestenfalls konnte an die Schaffung einer Freihandelszone gedacht werden. Diese hoben sieben europäische Staaten (Großbritannien, Irland, Dänemark, Schweden, Schweiz, Österreich und Portugal) im Jänner 1960 als Europäische Freihandelszone (EFTA) in Stockholm aus der Taufe. Die EFTA kann gemeinhin als »Brückenschlag zur EWG« bezeichnet werden: ab dem Zeitpunkt ihrer Gründung stellte Großbritannien sein Beitrittsgesuch und gleichzeitig auch Österreich. In Österreich wurde die eigene EFTA-Mitgliedschaft parteipolitisch heftigst diskutiert, seitens der österreichischen Amtskirche fehlen jedoch diesbezügliche Kommentare. Dies gilt

38 Ebd., S. 642 sowie Wolfram KAISER, Deutschland exkulpieren und Europa aufbauen. Parteienkooperation der europäischen Christdemokraten in den Nouvelles Equipes Internationales 1947-1965, in: GEHLER, Christdemokratie in Europa, Wien 2001, S. 695-719.

39 Dieter A. BINDER, Von der »Rettung des christlichen Abendlandes« und »Europa in uns«. Die Österreichische Volkspartei nach 1945, in: GEHLER, Christdemokratie in Europa, S. 399-424. Hurdes war Mitbegründer der ÖVP, deren erster Generalsekretär bis 1951, Bildungsminister (1945-1952) und Nationalratspräsident (1953-1959).

40 Vgl. grundlegend SCHNEIDER, Die Europäische Einigung, S. 73-102.

41 Ernst ZichY, Der goldene Schlüssel des Schuman-Planes, in: Die Furche 28, 8. Juli 1950, S. 4. 
auch für die weiteren Versuche Österreichs, mit der EWG zu assoziieren. Ein bilaterales Handelsabkommen zwischen EWG und Österreich konnte erst 1972 im Zuge des Beitritts Großbritanniens zur EWG geschlossen werden ${ }^{42}$.

Die Zeit bis zur Thematisierung der Mitgliedschaft in der EG durch die österreichische Innenpolitik Mitte der 80er Jahre war von einer gewissen Orientierungslosigkeit innerhalb der EWG geprägt und wird gemeinhin als »Eurosklerose« bezeichnet. Diese Phase wurde durch die Verabschiedung der Einheitlichen Europäischen Akte (EEA), der ersten Revision der Gründungsverträge, 1986 durchbrochen. Damit nahm der Integrationsprozess wieder Dynamik an.

\section{Der EU-Beitritt Österreichs und die österreichischen Bischöfe}

Die österreichische Bundesregierung (Koalition Fred Sinowatz SPÖ/ Norbert Steger FPÖ) begann sich ab 1985 mit der Frage eines möglichen EG-Beitrittes auseinanderzusetzen. Mehrere Faktoren waren ausschlaggebend, etwa die angesprochene Dynamisierung der Integrationspolitik auf EG-Ebene und innenpolitisch die Tatsache, dass Österreich als »Insel der Seligen « einige Blessuren erhielt: Sei es der Weinskandal, der zu internationalem Imageverlust führte, die Waldheim-Affäre, die 1986 ins Rollen gebracht wurde ${ }^{43}$. Schon Ende des Jahres 1985 dachte der damalige SPÖAußenminister Peter Jankowitsch laut über einen EG-Beitritt nach. Doch erst der Ausgang der Nationalratswahlen 1986, in deren Gefolge eine SPÖÖVP Koalitionsregierung gebildet wurde (Franz Vranitzky SPÖ/Erhard Busek ÖVP), führte zu einer Regierungserklärung, worin die Klärung des Verhältnisses Österreichs zur EG zum zentralen Anliegen der österreichischen Außenwirtschaftspolitik erhoben wurde. Die Regierung installierte eine Arbeitsgruppe (hier waren jedoch keine Vertreter der Kirche eingeladen), die 1988 einen Bericht vorlegte. Darin empfahl man den Beitritt Österreichs zur EG. Ab diesem Zeitpunkt begann sich auch die ÖVP als »Europa-Partei« darzustellen.

Aufgrund der erstellten Expertise verabschiedete der österreichische Nationalrat eine Entschließung an die österreichische Bundesregierung, die Mitgliedschaft in die EG zu beantragen. Der offizielle Antrag wurde am 14. Juli 1989 von dem damaligen österreichischen Außenminister Alois Mock

42 Vgl. etwa Michael GeHLER, Der lange Weg nach Europa. Österreich vom Ende der Monarchie bis zur EU, Innsbruck 2002, 2 Bde.

43 Michael GEHLER, 》 ... eine grotesk überzogene Dämonisierung eines Mannes ...«. Die Waldheim-Affäre 1986-1992, in: Michael GeHLER / Hubert Sickinger, (Hg.), Politische Affären und Skandale in Österreich. Von Mayerling bis Waldheim, Wien 1995, S. 614-665. 
an den Ratsvorsitzenden Roland Dumas übermittelt. Obwohl Brüssel zunächst dem Ansinnen eines neutralen Staates skeptisch gegenüberstand, erhielt Österreich dennoch grünes Licht für die Beitrittsverhandlungen. Nachdem auch das Europaparlament seine grundsätzliche Befürwortung zum österreichischen EU-Beitritt gegeben hatte, erfolgte am 12. Juni 1994 die Befragung des österreichischen Volkes: mit über $66 \%$ stimmten die Österreicherinnen und Österreicher für einen EU-Beitritt. Darauf erfolgte die Unterzeichnung des Beitrittsvertrages auf der griechischen Insel Korfu gemeinsam von österreichischen Regierungsmitgliedern und Vertretern der EU. Seit 1. Jänner 1995 ist Österreich Mitglied der EU.

Erst ab dem Zeitpunkt der Aufnahme von Beitrittsverhandlungen begannen die österreichischen Bischöfe Stellung zu beziehen. Die Österreichische Bischofskonferenz setzte, analog zur österreichischen Bundesregierung, im Jahr 1993 eine Arbeitsgruppe zur Prüfung von Fragen hinsichtlich eines EG-Beitritts Österreichs ein. Der damalige Wiener Weihbischof Christoph Schönborn leitete diese Arbeitsgruppe, an der auch die Bischöfe Egon Kapellari, Kurt Krenn und Florian Kuntner teilnahmen. In ihrer Erklärung über die Einsetzung der Arbeitsgruppe zum Thema »Kirche und Europa« formulierten die österreichischen Bischöfe ihre Erwartung an die Europäische Gemeinschaft, nämlich die Anerkennung der rechtlichen Stellung der Kirchen und der anderen gesetzlich anerkannten Religionsgesellschaften. Die Erklärung endete mit der Feststellung, Der Beitrag der Christen für die rechte Ordnung der Werte, für Solidarität und das friedliche Zueinander von Menschen und Völkern wird für die Zukunft entscheidend sein ${ }^{44}$. Ziel der Arbeitsgruppe war es, zunächst die Veränderungen und Auswirkungen für das Leben einer gründlichen Prüfung und im Lichte des Evangeliums zu unterziehen ${ }^{45}$.

Auf ihrer Herbstvollversammlung im November 1993 gaben die österreichischen Bischöfe eine weitere Erklärung hinsichtlich des Beitritts Österreichs zur EU ab:

[...] Wir Bischöfe begrüßen und ermutigen daher jede Bemühung um sachliche Information in allen mit der europäischen Integration verbundenen Fragen. Weder Euphorie noch Angstmacherei sind gute Berater in solchen Entscheidungen. Unser Sozialhirtenbrief bietet wertvolle Hilfe zur Urteilsbildung. Er erinnert an den Vorrang der Personenwürde vor den Marktgesetzen; an das Prinzip der Subsidiarität, das Auswüchse der Zentralisierung verhindern soll; an die Pflicht zur Solidarität mit den Schwächeren, seien es einzelne oder Regionen und Länder. Österreich kann seine

44 Erklärung der Österreichischen Bischofskonferenz anlässlich ihrer Vollversammlung vom 30. März bis 1. April 1993, abgedruckt in: Die Kirche auf dem Bauplatz Europa. Stimmen der österreichischen Bischöfe zur Wiedervereinigung Europas, Wien 2002 (Die österreichischen Bischöfe 2).

45 Amtsblatt der Österreichischen Bischofskonferenz Nr. 9, 3. Mai 1993, S. 1. 
Zukunft nicht alleine gestalten. Als Christen ist es uns aufgetragen, die einende Kraft des Evangeliums, das allen Völkern verkündet werden soll, sichtbar und wirksam zu machen. In diesen Monaten, da unsere Regierung über den Beitritt unseres Landes zur EU verhandelt, rufen wir Bischöfe alle Gläubigen zum Gebet auf, dass alle Beteiligten erkennen und tun, was dem Wohl unserer Heimat und dem Frieden unter den Völkern am besten dient ${ }^{46}$.

Dieser Erklärung kann man eindeutig die positive Einstellung der österreichischen Bischöfe hinsichtlich eines Beitrittes Österreichs zur EU entnehmen. Bereits im März 1994 empfahlen sie sogar den Bürgerinnen und Bürgern Österreichs, an der Volksabstimmung über die Änderung der Verfassung, wodurch erst ein Beitritt möglich wurde, am 12. Juni 1994 teilzunehmen.

Mit der Abstimmung über einen Beitritt unseres Landes zur Europäischen Union ist dem österreichischen Volk eine Entscheidung von besonderer Tragweite aufgegeben. Wir halten es für eine demokratische Selbstverständlichkeit, dass alle Bürgerinnen und Bürger, denen das Wohl Österreichs am Herzen liegt, sich an einer solchen Volksabstimmung beteiligen und sich vorher sorgsam über die Gründe für oder gegen einen Beitritt informieren. Es steht uns Bischöfen nicht zu, den Katholiken ein Ja oder Nein zur EU zu empfehlen. Wir verweisen aber darauf, dass nach den zwei mörderischen Weltkriegen Staatsmänner aus christlicher Verantwortung das Konzept einer europäischen Integration entworfen und gefördert haben, weil ihnen ein dauerhafter Friede in Europa nur durch wachsende wirtschaftliche, kulturelle und politische Integration als möglich erschien. Diese Sicht ist in der heutigen Situation Europas unvermindert aktuell. Bei aller gebotenen sorgsamen Abwägung des Für und Wider zur weiteren Integration wird ein bewusster Christ den Auftrag und die Chance ernst nehmen, auf dem Bauplatz Europa mit den Maßstäben des Evangeliums mittägig zu $\operatorname{sein}^{47}$.

Der »Bauplatz Europa« wird nun geradezu zum Topos weiterer EuropaErklärungen seitens der Bischofskonferenz. Die österreichischen Bischöfe wurden nicht müde darauf hinzuweisen, dass in einer von der Wirtschaft und Technologie dominierten Welt nicht auf das Individuum, die Menschenwürde vergessen werden dürfe: Europa braucht nicht nur einen politisch-wirtschaftlich funktionierenden Körper, sondern Europa braucht auch eine Seele, wie es Kardinal Franz König treffend formulierte ${ }^{48}$.

Nach dem erfolgten Beitritt meldeten sich die österreichischen Bischöfe immer wieder zu aktuellen EU-Themen zu Wort: So etwa im Zusammenhang mit den Maßnahmen der 14 EU-Staaten gegen Österreich. Hier hatte man, als am 4. Februar 2000 die ÖVP-FPÖ-Regierung (Wolfgang Schüssel

\footnotetext{
46 Ebd., Nr. 10, 3. Dezember 1993, S. 2.

47 Ebd., Nr. 11, 28. April 1994, S. 2.

48 Franz Kardinal KöNIG, Johannes Paul II. auf dem Weg nach Europa, in: Diplomatie im Dienst der Seelsorge, 2002, S. 220.
} 
ÖVP / Susanne Riess-Passer, FPÖ) angelobt wurde, die bereits Ende Jänner angedrohten Maßnahmen der 14 EU-Staaten umgesetzt. Der portugiesische Ratspräsident António Guterres beauftragte daraufhin den Präsidenten des EuGH, Luzius Wildhaber, drei Personen auszuwählen, die einen Bericht über die »Haltung der österreichischen Regierung bezüglich der gemeinsamen europäischen Werte und insbesondere bezüglich der Rechte von Minderheiten, Flüchtlingen und Einwanderern sowie die Entwicklung der politischen Natur der FPÖ« erstellen sollten. Im April bezogen die österreichischen Bischöfe in einer Presseerklärung zu den 14 EU-Maßnahmen Stellung. Darin setzten sie sich für die österreichischen Bürgerinnen und Bürger ein, als Menschen, die die Werte der Solidarität, Menschenrechte, Demokratie und Rechtsstaatlichkeit respektieren. Die Maßnahmen der 14 EU-Staaten werden als pauschale und ungerechte Urteile bewertet.

Österreichische Bischöfe haben in der europäischen Öffentlichkeit klargestellt, daß die Bürger dieses Landes mit Ausnahme kleinster Randgruppen keine Rassisten und Fremdenfeinde sind. Der Respekt vor den Menschenrechten und die Hilfsbereitschaft gegenüber Menschen in Not sind in Österreich tief verwurzelt, ebenso die Werte der Solidarität, der Menschenrechte, der Demokratie und der Rechtsstaatlichkeit [...].

Die Bischofskonferenz weist pauschale oder auch ungerechte Urteile gegenüber Österreich und seinen Menschen - wie dies zuletzt durch die Maßnahmen der 14 EURegierungen geschehen ist - zurück $[\ldots]$.

Zugleich betonen die Bischöfe, dass Österreich im Blick auf seine europäische Aufgabe die besondere Verpflichtung hat, allen Symptomen von Fremdenfeindlichkeit, Ausgrenzung und politischem Extremismus - von welcher Seite immer - mit Entschlossenheit entgegenzutreten. Die katholische Kirche tritt gemeinsam mit den anderen christlichen Kirchen nachdrücklich für ein solidarisches und soziales Österreich ein. Es gilt, sich nicht entmutigen zu lassen, nicht »zurückzuschlagen«, Ruhe und Klarheit zu bewahren. Was wir jetzt weniger denn je brauchen können, sind leichtfertige Worte. Österreich braucht sich nicht aggressiv zu verteidigen. Was allseits not tut, ist die »Abrüstung der Worte $\ll^{49}$ !

Die »Überprüfung « durch die sogenannten »drei Weisen« konnte über Sommer abgeschlossen werden, sodass der Bericht bereits Anfang September dem damaligen französischen Ratsvorsitzenden Jacques Chirac vorgelegt werden konnte. Dieser hob, dem Bericht der »drei Weisen« folgend die Maßnahmen gegen Österreich auf ${ }^{50}$.

49 Amtsblatt der Österreichischen Bischofskonferenz Nr. 28, 1. August 2000, S. 1-2.

50 Waldemar Hummer / Anton PelinKA, Österreich unter »EU-Quarantäne«. Die »Maßnahmen der 14 « gegen die österreichische Bundesregierung aus politikwissenschaftlicher und juristischer Sicht. Chronologie, Kommentar, Dokumentation, Wien 2002. 
Die österreichischen Bischöfe verstanden sich als ordnende Hand einzugreifen und zu helfen, im Sinn des Schutzes der »europäischen« Werte. So auch angesichts der bevorstehenden Erweiterung um die ehemaligen »Ostblock-Staaten «: Im Frühjahr 2001 wiesen sie darauf hin, dass die europäische Einigung nicht nur als bloßer wirtschaftlicher Vorgang missverstanden werden dürfe. Unter Integration verstehen sie einen »geistigkultureller Vorgang, um die Wiederentdeckung der gemeinsamen religiösen Wurzeln des Kontinents«:

Europa muß seine christlichen Wurzeln wiederentdecken - wobei ebenso die Beiträge der jüdischen und der islamischen Tradition, aber auch das humanistische Erbe zu beachten sind. Es geht nicht darum, Europa eine Seele zu geben, sondern die vorhandene, aber mitunter in Vergessenheit geratene Seele Europas wiederzuentdecken ${ }^{51}$.

Dabei komme Österreich als Land an der Nahtstelle zwischen den beiden europäischen Lungenflügeln, dem westlichen und östlichen (Papst Johannes Paul II.), eine besondere Rolle $\mathrm{zu}^{52}$. Die Bischofskonferenz kündigte an, alle Initiativen unterstützen zu wollen, die dem Miteinander in Europa, über alle nationalen, konfessionellen und religiösen Grenzen hinweg dienen. In diesem Sinn etwa installierten sie die Teilorganisation »Pro Europa« innerhalb der Organisation »Missio«, die im Jahr 2002 in Kraft trat. Dadurch unterstützte die Österreichische Bischofskonferenz finanziell den kirchlichen Aufbau in den Ländern Mittel-, Ost- und Südosteuropas. Bereits anlässlich der Ersten Ratspräsidentschaft Österreichs im Jahr 1998 veröffentlichte die Österreichische Bischofskonferenz die »Europa-Erklärung«. Hauptthema war die bevorstehende Osterweiterung. Die Bemühungen um die Erweiterung der EU lasse den Bauplatz Europa noch größer und vielschichtiger werden! Die Bischöfe hofften darauf, dass der österreichische Vorsitz einen zentralen Beitrag zur Integration der beitrittswilligen Nachbarvölker der EU leisten werde ${ }^{53}$. Eine weitere Initiative der Österreichischen Bischofskonferenz stellte die Organisation des Mitteleuropäischen Katholikentages im Jahr 2004 dar $^{54}$. Der Höhepunkt des Katholikentages war die »Wallfahrt der Völker«, die von 21. bis 23. Mai 2004 nach Mariazell unter dem Motto 》Christus - Hoffnung Europa« veranstaltet wurde ${ }^{55}$. Die Pilger kamen aus Bosnien-Herzegowina, Kroatien, Österreich, Polen, der Slowakei, Slowenien, Tschechien und Ungarn und machten damit das ehemals von Mariazell aus unsichtbar geknüpfte Netz der Solidarität öffentlich sichtbar. An

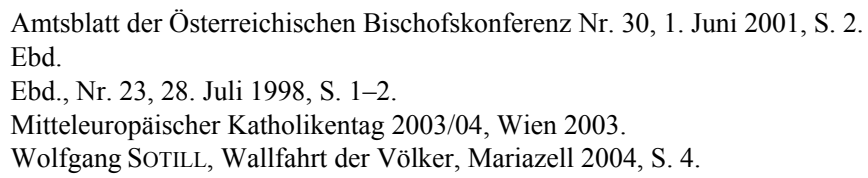


diesem Mitteleuropäischen Katholikentag nahmen acht Bischofskonferenzen, 107 Diözesen und schlussendlich 100.000 Gläubige teil ${ }^{56}$.

Aktiv traten Österreichs Bischöfe in den Dialog mit der EU im Zusammenhang mit den Arbeiten des Verfassungskonventes über die Ausarbeitung einer europäischen Verfassung ein. Untenstehender Aussendung kann man eine gewisse Kritik entnehmen, dahingehend, zu wenig in die Arbeiten der Europäischen Verfassung eingebunden zu sein:

Wenn Europa Heimat sein soll, dann braucht das gemeinsame europäische Haus nicht nur eine gemeinsame Währung, sondern auch eine Seele. In diesem Zusammenhang stellen wir mit Bedauern fest, dass die Glaubensgemeinschaften in die Arbeiten des neuen EU-Konvents - dessen Ziel ja die Erarbeitung einer europäischen Verfassung ist - nicht in ausreichendem Maß einbezogen sind. Papst Johannes Paul II. hat in diesem Zusammenhang von einer »Ungerechtigkeit« und einer »Fehleinschätzung « gesprochen. Denn die Religionen haben ihren Beitrag zu jener Kultur und jenem Humanismus geleistet, auf die Europa stolz ist - und sie leisten ihn immer noch ${ }^{57}$.

Um ihren Einfluss auf die Arbeiten des Konvents geltend zu machen, formulierte die Österreichische Bischofskonferenz einen Vier-Punkte-Katalog.

1. Die Europäische Union möge das Recht der Kirchen und Religionsgemeinschaften anerkennen, sich auf Grund ihrer inneren Ordnung zu organisieren und ihre Aufgaben frei und ungehindert zu erfüllen.

2. Die Europäische Union möge die Identität und den besonderen Beitrag der Kirchen und Religionsgemeinschaften respektieren und mit ihnen einen dauerhaften und partnerschaftlichen Dialog aufnehmen [...].

3. Zum partnerschaftlichen Dialog gehört aber auch die Einrichtung eines $»$ Bureau de Liaison«, einer Anlaufstelle in Brüssel, auf der unterhalb der Spitzenebene fruchtbare und vertrauensvolle Kooperation zwischen den Institutionen der Europäischen Union und den Kirchen und Religionsgemeinschaften möglich ist. Ebenso regen wir die Einrichtung eines Begutachtungsverfahrens an, wie es in Österreich seit jeher üblich ist. Ein solches Verfahren würde es ermöglichen, die sachlich relevanten Standpunkte der Kirchen und Religionsgemeinschaften in Gesetzesvorhaben auf europäischer Ebene einzubringen. Dies könnte auch ein Beitrag zur Vertiefung des Vertrauens zwischen EU-Institutionen und Bürgern sein.

4. Die Europäische Union möge den rechtlichen Status der Kirchen und Religionsgemeinschaften in den einzelnen Mitgliedsstaaten respektieren. Dies könnte am ehesten dadurch zum Ausdruck kommen, dass die »Kirchen-Klausel« des Amsterdamer Vertrages an angemessener Stelle in eine künftige europäische Verfassung übernommen wird ${ }^{58}$.

56 Mitteleuropäischer Katholikentag 2003/04, Wien 2003.

57 Amtsblatt der Österreichischen Bischofskonferenz Nr. 33, 1. Juni 2002, S. 2.

58 Ebd., Nr. 34, 1. September 2002, S. 2-3. 
Hinsichtlich der erwähnten »Kirchen-Klausel« muss angemerkt werden, dass die österreichischen Bischöfe im Rahmen der Kommission der Bischofskonferenzen der Europäischen Gemeinschaft (COMECE) versuchten, der Regierungskonferenz zur Revision des Vertrags von Maastricht folgende Gedanken zu übermitteln. Da die EU die christlichen Werte zu ihren Wurzeln zählt und seit ihrer Gründung einen Raum des Friedens geschaffen hat, wünschten die europäischen Bischöfe, dass das Beispiel der Gründerväter eine Quelle der Inspiration für die Regierungskonferenz sei. Aufgrund der Veränderungen in Europa sah sich die COMECE verpflichtet, der Regierungskonferenz Empfehlungen zu geben. Zunächst unter dem Schlagwort »Europa eine neue Dimension geben«: Die Regierungskonferenz sollte bei der Revision des Vertrages von Maastricht,

sich an den wesentlichen ethischen Werten orientieren, die die Menschen bewegen und eine Antwort auf die Sorgen der Völker Europas geben, insbesondere jene der Jugend. $\mathrm{Zu}$ den grundlegenden Elementen gehören an erster Stelle die jedem Menschen zukommende und unantastbare Würde [...] und die unbedingte Anerkennung der Menschenrechte ${ }^{59}$.

Daher forderte die COMECE eine eigene Menschenrechtscharta oder den Beitritt der EU zur EMRK.

Unter dem Titel »Ein Geist der Offenheit und der Solidarität« subsumierte die COMECE das Postulat einer aktiven Sozialpolitik, die vor allem den Schwächsten zur Hilfe komme. Die schwierige Situation auf dem Arbeitsmarkt müsse in dem neuen Vertragswerk ihren Niederschlag finden. Die EU dürfe nicht zu einer wirtschaftlichen und politischen Macht werden, die sich nach außen abschließe. An der Beantwortung der Fragen im Bereich Asyl, Einwanderung, Grenzkontrollen, Bekämpfung des Rassismus und Respektierung der Minderheiten werde man den Beitrag der EU hinsichtlich der ethischen Werte messen können. Als weitere Bedingung an die EU forderte die COMECE, der Unionsbürgerschaft unter Einhaltung der Prinzipien der Demokratie, Subsidiarität und kulturellen Vielfalt diesen mehr Gehalt zu verleihen, diejenigen Staaten, die der EU beitreten wollen, aufzunehmen und den ärmsten Ländern der Welt ihre Solidarität zu erweisen ${ }^{60}$.

Allerdings teilte man der COMECE seitens der EU unmissverständlich mit, dass für die Aufnahme der »Schutzklausel für Kirchen und Religionsgemeinschaften« niemand zuständig sei. Erst nach zähen Verhandlungen wurde die rechtsunverbindliche Erklärung Nummer 11 zum Vertrag von

59 Ebd., Nr. 17, 12. Mai 1996, S. 5.

60 Ebd. 
Amsterdam verfasst. Erstmals in der Geschichte der Europäischen Union fand die Erwähnung der Kirchen in ein Vertragswerk Aufnahme ${ }^{61}$.

Dieser Artikel wurde letztendlich dem Lissaboner Vertrag implementiert. Hinsichtlich der Diskussion, ob in der künftigen Europäischen Verfassung ein Gottesbezug vorhanden sein sollte oder nicht, brach eine heftige Diskussion aus, die auch die österreichische Innenpolitik beeinflusste: Beinahe zeitgleich zum Europäischen Verfassungskonvent hatte man in Österreich einen Konvent installiert, der die österreichische Bundesverfassung novellieren sollte. Weder dies ist bisher geschehen, noch hat man den Gottesbezug in die präsumptive Europäische Verfassung aufgenommen. Man konnte sich lediglich auf folgenden Text einigen:

Schöpfend aus den kulturellen, religiösen und humanistischen Überlieferungen Europas, deren Werte in seinem Erbe weiter lebendig sind und die zentrale Stellung des Menschen und die Unverletzlichkeit und Unveräußerlichkeit seiner Rechte [...]!

Anlässlich des 50. Jahrestages der Gründungsverträge im Jahr 2007 stellte man in der österreichischen Kathpress resignierend fest, dass trotz christlich geprägter Gründungsväter und kirchlicher Lobbyarbeit in Brüssel ein Gottesbezug in der EU-Verfassung und ein Bekenntnis zu den jüdisch-christlichen Wurzeln manchen ein Dorn im Auge ist ${ }^{62}$.

Die Europäische Verfassung wurde 2005 abgelehnt, der »Kompromiss«Vertrag von Lissabon, den am 13. Dezember 2009 alle Mitgliedstaaten unterschrieben haben, verfügt über eine revidierte Fassung der obengenannten Formel. Der Kirchenartikel ist mit Vertrag über die Arbeitsweise der EU (AEUV) verankert.

Art 17 (1) Die Union achtet den Status, den Kirchen und religiöse Vereinigungen oder Gemeinschaften in den Mitgliedstaaten nach deren Rechtsvorschriften genießen, und beeinträchtigt ihn nicht.

(2) Die Union achtet in gleicher Weise den Status, den weltanschauliche Gemeinschaften nach den einzelstaatlichen Rechtsvorschriften genießen.

(3) Die Union pflegt mit diesen Kirchen und Gemeinschaften in Anerkennung ihrer Identität und ihres besonderen Beitrags einen offenen, transparenten und regelmäßigen Dialog.

Absatz 1 von Artikel 17 stellt die wortwörtliche Übernahme der Erklärung 11 zum Vertrag von Amsterdam dar. Durch ihn erhalten die nationalen Staatskirchenrechtsordnungen einen primärrechtlichen Schutz. Wesentlich ist auch die Bestimmung über die Dialogbereitschaft zwischen Union und

61 Vgl. dazu Franz ECKERT, Eine (geplante) EU-Verfassung aus christlicher Sicht, in: Walter KRIEGER / Balthasar SIEBERER, Was ist christlich an Europa, Kevelaer 2004, S. 23-30.

62 Zitiert bei Konrad GRASS, Die katholische Kirche und die Integration Österreichs, S. 106. 
Kirche in Absatz 3, wo auch die Identität und der besondere Beitrag der Kirchen und Religionsgemeinschaften gewürdigt werden. Gerade der Hinweis »besonderer Beitrag « stellt in dieser »Dialogklausel« einen wichtigen Filter dar gegen Ansprüche von Kleinstreligionen oder Splittergemeinschaften für den Fall, dass die unter Hinweis auf das allgemeine Diskriminierungsverbot den Versuch unternehmen sollten, für sie das gleiche Dialogrecht in Anspruch nehmen zu wollen ${ }^{63}$.

Der steirische Bischof und Europa-Bischof Egon Kapellari zeigte sich ob des Inkrafttretens des Vertrages von Lissabon erfreut und hob die nun erfolgte Rechtsverbindlichkeit der EU-Grundrechtecharta als besonders lobenswert hervor. Bedauerlich stimmte ihn lediglich die Tatsache, dass der Vertrag weder auf Gott noch auf die christlichen Wurzeln Europas Bezug nehme. Dennoch schaffe die Union neue Möglichkeiten, um gemeinsam mit den Kirchen das Zusammenleben der Menschen in Friede, Freiheit und Gerechtigkeit zu fördern, sagte Bischof Kapellari wörtlich ${ }^{64}$.

Es wurde versucht, anhand der Handlungen der Bischöfe Österreichs darzustellen, in welcher Weise sich die Kirche für das vereinte Europa engagiert. Man kann davon ausgehen, dass heute wohl Konsens darüber besteht, dass die Kirche bei der Beantwortung der Frage nach der Identitätsbestimmung Europas einen wesentlichen Beitrag leisten kann, und dies nicht nur, indem sie den Dialog nicht allein mit den christlichen Kirchen, sondern auch mit der Orthodoxie und darüber hinaus mit dem Islam pflegt. Die Kirche tritt als Mahnerin auf: Europa bedeute mehr als Ökonomie und Politik, weshalb man darum bemüht ist, neben der kulturgeschichtlichen Basis eben auch das christliche Fundament Europas zu betonen.

Wie die österreichischen Bischöfe ihr Europa sehen, kann aus der »Europa-Erklärung «, anlässlich der ersten Ratspräsidentschaft Österreichs verfasst, entnommen werden. Sie ist nach wie vor aktuell:

Die Kirche wünscht ein Europa der sozialen Gerechtigkeit und des Friedens, ein Europa gemeinsamer Grundwerte, ein Europa, das der Bürger begreift und akzeptiert. Es soll ein Europa der sozialen Marktwirtschaft sein, ein weltoffenes Europa, schließlich ein Europa, das sich seiner christlichen Fundamente stets bewusst bleibt. Als Kirche in Österreich sollen wir mithelfen, die notwendigen Brücken der Einigung zwischen den Völkern zu bauen, und sehen darin einen eigenständigen Beitrag zur Vereinigung Europas ${ }^{65}$.

63 ECKERT, Eine (geplante) EU-Verfassung, S. 30.

64 Egon KAPELlaRI, Der Vertrag von Lissabon ist ein großer Fortschritt, http://www.bischofskon ferenz.at/content/site/home/article/336.html (Zugriff 9. April 2010).

65 Amtsblatt der Österreichischen Bischofskonferenz Nr. 23, 28. Juli 1998, S. 1-2. 


\title{
Michael Kißener
}

\section{Boten eines versöhnten Europa?}

\author{
Deutsche Bischöfe, Versöhnung der Völker \\ und Europaidee nach dem Zweiten Weltkrieg
}

\begin{abstract}
Am 16. Januar 1948 richtete der Oberbefehlshaber in der französischen Besatzungszone in Deutschland, General Pierre Marie Koenig', ein Schreiben an den Erzbischof von Köln, Kardinal Frings, mit dem er auf ein Dankschreiben der deutschen katholischen Bischöfe reagierte, denen Koenig geholfen hatte, den für die Hl. Messe dringend benötigten Messwein zu beschaffen. Koenig gab seiner Freude über das dabei hergestellte gute Einvernehmen Ausdruck und nutzte dann die Gelegenheit, um den deutschen Bischöfen in wenigen Worten ein politisches Angebot zu machen:
\end{abstract}

Unsere Handlungsweise entsprach der französischen Tradition der Ehrfurcht gegenüber der Katholischen Kirche. Außerdem vergisst Frankreich weder den Kampf der katholischen Priester gegenüber den nazistischen Totalitätsansprüchen, noch die schweren Opfer, die sie bewusst auf sich genommen hatten. Mein Land weiß außerdem, da $\beta$ die Katholische Kirche sich bewusst ist des Friedensamtes, zu dem sie durch die gegenwärtigen Zeitumstände berufen ist, und der aktiven Mitarbeit, die sie am Werk der Annäherung der europäischen Völker, insbesondere des französischen und deutschen Volkes leisten kann².

Die katholische Kirche als Partner der europäischen Einigung? Vor dem Hintergrund der realen politischen Lage im Nachkriegsdeutschland sprach in der Tat vieles für eine solche Koalition. Die katholische Kirche stellte nach 1945 in Deutschland für viele Menschen eine der wenigen politisch nicht kompromittierten gesellschaftlichen Größen dar, die nach den Verbrechen des Nationalsozialismus für die alliierten Besatzer als Ansprechpartner dienen konnten. Als Träger eines christlichen Wertegefüges, an das Frank-

1 Pierre Marie Joseph François Koenig (1898-1970), Berufssoldat, schloss sich 1940 als einer der ersten Offiziere de Gaulles Bewegung »France Libre« an, 1944 Delegierter des französischen Nationalen Befreiungskomitees beim Oberkommando der alliierten Streitkräfte, 1945-1949 Militärgouverneur in Deutschland und Oberbefehlshaber der Besatzungstruppen, 1954 und 1955 Verteidigungsminister. Zur Person siehe u. a. Who's Who in France, 1957/58, Paris 1958, S. 1306; Alain LATTARD, Zielkonflikte französischer Besatzungspolitik in Deutschland. Der Streit Laffon-Koenig 1945-1947, in: Vierteljahrshefte für Zeitgeschichte 39 (1991), S. 1-35.

2 Dom- und Diözesanarchiv Mainz (weiter DDAMZ), 45,1 Nr. 211 Koenig an Frings, 16. Januar 1948. 
reich und die europäischen Staaten anknüpfen wollten, schien sie geeignet für die Gestaltung einer gemeinsamen Zukunft ${ }^{3}$. Darum hatte Papst Pius XII. ja auch hinlänglich oft schon während des Krieges geworben und zur Einigung der christlichen Nationen in Europa aufgerufen ${ }^{4}$.

Nicht nur die Franzosen, auch die amerikanische Besatzungsmacht sah recht bald, dass eine Koalition mit der katholischen Kirche für die intendierte politische Neuordnung vorteilhaft sein könnte. In einem Halbjahresreport der Abteilung für kirchliche Angelegenheiten der amerikanischen Besatzungsverwaltung hieß es z. B. Ende 1946:

The re-establishment of effective liaison relationships between the churches of Germany and those of the democratic countries of the world was essential, if the longterm goal of re-education and re-orientation established by Military Government was to be achieved.

Dort wollte man sogar ein großes Interesse der deutschen Kirchenleitungen an der Wahrnehmung von auswärtigen Beziehungen erkannt haben und rühmte sich, diese kirchlichen Außenkontakte effektiv zu fördern'5

Doch war das realistisch? Verkannte diese politische Idee nicht die tatsächlichen Handlungsmöglichkeiten und Interessen der katholischen Kirche? Lassen sich Koenigs Zeilen an Kardinal Frings nicht vielleicht auch ganz anders interpretieren? Sind sie womöglich nichts weiter als eine von jenen vielen Schmeicheleien, mit denen die Franzosen um die Gunst speziell der katholischen Kirche warben, um ihre eigenen politischen Ziele zu befördern? ${ }^{6}$ Schon der französische General Billotte hatte am 27. Juli 1945, kurz nach der Bildung der französischen Besatzungszone und einem Besuch beim Trierer Erzbischof Bornewasser, seiner Regierung empfohlen, »jouer la carte religieuse $\ll$. Und das hieß nichts anderes als das Einspannen der Kirche für die französischen Sicherheitsinteressen, etwa durch Hilfe bei der Föderalisierung Deutschlands oder gar der Abtrennung des Saargebiets vom deutschen Staatsverband. Muss nicht auch gefragt werden, ob die katholische Kirche, die ja gerade im Dritten Reich darauf bedacht gewesen war, sich politischer Stellungnahmen zu enthalten und ihre alleinige Berufung

3 Michael MÜLLER Zum Verhältnis von Kirche und Besatzung. Erzbischof Bornewasser von Trier und die Franzosen nach dem Zweiten Weltkrieg, in: Peter HÜtTEnBERGER / Hansgeorg Molitor (Hg.), Franzosen und Deutsche am Rhein. 1789-1918-1945, Essen 1989, S. 297308, hier S. 297.

4 Siehe hierzu den Beitrag von Heinz HÜRTEN in diesem Band.

5 Michael LingK, Amerikanische Besatzer und deutsche Kirchen. Kirchenbild und Kirchenpolitik, Tübingen 1996, S. 90, Anm. 250.

6 So auch der Bericht des päpstlichen Sondergesandten Pater Ivo Zeiger SJ vom September 1945, in: Ludwig VolK (Bearb.), Akten deutscher Bischöfe über die Lage der Kirche 19331945, Bd. VI, Mainz 1986 S. 763-767.

7 MÜLLER, Zum Verhältnis, S. 298. 
für das Seelenheil der Menschen zu betonen, überhaupt ein Partner für ein solches politisches Vorhaben sein konnte? ${ }^{8}$ Auf dem ersten Katholikentag der Nachkriegszeit in Mainz 1948 stellte denn auch Pater Franziskus Stratmann ${ }^{9}$ unumwunden fest: »Bisher hat die direkte Erziehung zur Völkerverständigung in der Kirche so gut wie ganz gefehlt $\aleph^{10}$. Und auch Heinz Hürten hat in der historischen Rückschau festgestellt: »In die Zeit gesteigerter gesellschaftlicher Verantwortung trat die Kirche mit minimalem gesellschaftspolitischem Instrumentarium und ohne Willen zu politischer Gestaltung $\aleph^{11}$. Vielmehr noch: Konnte die Kirche und ihre bischöfliche Führung überhaupt im Sinn einer solchen Versöhnung und Vermittlung wirken, angesichts der Tatsache, dass die deutschen Bischöfe ebenso wie ihre Amtsbrüder im europäischen Ausland traditionell auf ihre Diözese konzentriert waren, in der Regel überdiözesane Zusammenschlüsse auch nach 1945 ungerne sahen und faktisch meist nur wenige Außenkontakte unterhielten? Vor dem Zweiten Vatikanischen Konzil war es eher die Regel als die Ausnahme, dass Beziehungen untereinander sich nur über die zentrale Schaltstelle, das Papsttum in Rom, ergaben, nicht aber von Diözese zu Diözese. Und nicht zu vergessen ist auch, dass kaum 30 Jahre zuvor, im Ersten Weltkrieg, die Katholiken beidseits des Rheins den Krieg aus der nationalen Perspektive begrüßt, die Bischöfe Waffen gesegnet und zum Kampf gegen den angeblichen »Erbfeind « aufgerufen hatten ${ }^{12}$. Wie sollte da nun ausgerechnet die Kirche als Botin der Versöhnung dienen?

Eine hinlängliche Antwort auf diese Fragen ließe sich wohl nur finden, wenn man das Verhalten der Kirchenleitungen grenzüberschreitend und

8 Siehe dazu zusammenfassend Karl-Joseph Hummel, Die deutschen Bischöfe. Seelsorge und Politik, in: Karl-Joseph Hummel / Michael Kissener (Hg.), Die Katholiken und das Dritte Reich, Paderborn 2009, hier S. 107f.

9 Franziskus Maria Stratmann (1883-1971) trat 1905 in den Dominikanerorden ein, 1914 Studenten-Pfarrer in Berlin und stellvertretender Divisionspfarrer in Berlin, trat dem $»$ Friedensbund Deutscher Katholiken« (F.D.K.) bei, formulierte mit »Weltkirche und Weltfriede« (1924) eine breite Grundlegung katholischen Friedenshandelns, 1932/33 Vorsitzender des F.D.K., gründete 1930 die »Arbeitsgemeinschaft der Konfessionen für den Frieden«, im Juli 1933 in »Schutzhaft« genommen, emigrierte, kehrte 1947 nach Deutschland zurück, versuchte erfolglos, den F.D.K. wiederzubeleben. Siehe Dieter RIESENBERGER, Stratmann, Franziskus Maria, in: Biographisch-Bibliographisches Kirchenlexikon, Bd. XI, Herzberg 1996, Sp. 20-23.

10 Franziskus StratmanN, Die Verantwortung der Kirche für den Frieden unter den Völkern, in: Der Christ in der Not der Zeit. Der 72. Deutsche Katholikentag vom 1. bis 5. September 1948 in Mainz, hg. vom Generalsekretariat des Zentralkomitees der Katholiken Deutschlands, Paderborn 1949, S. 229-231, hier S. 230.

11 Heinz HÜRTEN, Michael Keller (1947-1961), in: Alois SCHRÖER (Hg.), Das Bistum Münster Bd. 1, Münster 1993, S. 311-319, hier S. 311.

12 Ludwig P. VolK, Die Kirche in den deutschsprachigen Ländern, in: Hubert JEDIN / Konrad REPGEN (Hg.), Handbuch der Kirchengeschichte Bd. VII, Freiburg [u. a.] 1999, S. 537-561, hier S. 538, 540, 552. 
systematisch untersuchen würde. Dies kann im Folgenden nicht geleistet werden, wohl aber soll der Versuch unternommen werden, am Beispiel der westdeutschen Grenzdiözesen die amtierenden Bischöfe daraufhin zu untersuchen, inwieweit sie sich für die Versöhnung mit den Nachbarvölkern eingesetzt und dabei mittelbar oder direkt dem Gedanken der europäischen Integration gedient haben.

Dazu sind die untersuchten Bistümer zunächst zu charakterisieren, sodann nach dem Kriterium der nachweisbaren Versöhnungsanstrengungen zu differenzieren, und schließlich sind verschiedene auffindbare Formen und Intensitäten diözesaner grenzüberschreitender Aktivitäten zu analysieren.

I.

Es sind insgesamt sieben Diözesen gewesen, die nach dem Zweiten Weltkrieg das deutsche Grenzgebiet im Westen abgedeckt haben. Ganz im Norden hatten die Bistümer Osnabrück und, wenn man so will, auch Hildesheim »Außengrenzen« zu den nord- und westeuropäischen Staaten, weiter südlich waren es Münster und Aachen, sodann Trier, Speyer und Freiburg, die an das benachbarte BeNeLux-Ausland und an Frankreich sowie die Schweiz grenzten. Weil Mainz und Rheinland-Pfalz eine traditionell enge Bindung an Frankreich hatten und haben, wurde auch dieses Bistum in die Untersuchung einbezogen. Und schließlich ist auch Luxemburg und sein Bistum für diese »Sondierung" berücksichtigt worden, weil dessen Zweisprachigkeit und Rolle im europäischen Einigungsprozess Aufschlüsse für unsere Frage erwarten lassen. Schließlich wurde Luxemburg neben Brüssel bereits in den 1950er Jahren zum Sitz der ersten gemeinsamen europäischen Institution, der Hohen Behörde der Europäischen Gemeinschaft für Kohle und Stahl (»Montanunion«).

Die genannten Bistümer erstreckten sich am Ende des Krieges über alle drei westlichen Besatzungszonen hinweg. Im Fall von Osnabrück und Hildesheim handelt es sich zwar um die flächenmäßig größten deutschen Diözesen, zugleich aber auch um Gebiete, in denen die Katholiken eine Minderheit darstellten. Anders weiter im Süden: Die Diözesen Münster, Aachen, Trier, Luxemburg deckten Gebiete mit einer überwiegend katholischen Bevölkerung ab, während Speyer, Mainz und Freiburg eine starke konfessionelle Durchmischung kennzeichnete. Für die kirchenpolitische Lage nach 1945 besonders bedeutsam: In Osnabrück und Hildesheim, z. T. auch in Münster und Freiburg veränderte eine große Zahl von Flüchtlingen und Heimatvertriebenen die soziale und auch die konfessionelle Situation schlagartig, während in der französische Besatzungszone dieses Problem 
durch die abwehrende Haltung der Besatzungsmacht weit weniger deutlich zu Tage trat ${ }^{13}$.

Diese Diözesen wurden um 1945 von Bischöfen geleitet, die mindestens zwei deutlich unterscheidbaren Alterskohorten angehörten. Auf der einen Seite standen Bischöfe, die um oder weit über 60 Jahre alt waren und ihr Amt z. T. schon seit vielen Jahren ausgeübt hatten. Die längste Erfahrung konnte Bischof Wilhelm Berning, 68 Jahre, aufweisen, der bereits 1914 das Bistum Osnabrück übernommen hatte. Knapp 60 Jahre alt auch Bischof Joseph Godehard Machens in Hildesheim, Clemens August Graf von Galen in Münster, der mit 67 Jahren 1946 Kardinal wurde und bald darauf starb, sodann Franz Rudolf Bornewasser, 194579 Jahre, davon 23 im Amt, sowie Conrad Gröber in Freiburg, der 73 Jahre zählte sowie schließlich Bischof Joseph Philippe in Luxemburg mit 68 Jahren. Deutlich jünger dagegen die Bischöfe von Aachen, Johannes Joseph van der Velden mit 54 Jahren, Bischof Joseph Wendel von Speyer mit 44 Jahren oder Bischof Stohr von Mainz mit 55 Jahren. Einige der älteren Bischöfe haben bald nach 1945, bedingt durch Krankheit oder Tod, Nachfolger gefunden, die den Kreis der jüngeren Bischöfe dann vergrößert haben, wie etwa Bischof Michael Keller, der 1947 mit 51 Jahren Bischof von Münster wurde oder Bischof Léon Lommel in Luxemburg, der schon 1949 Koadjutor des kranken Bischofs Philippe wurde, bevor er dessen Amt 1956 offiziell übernahm: Er war 56 Jahre alt bei der Übernahme bischöflicher Funktionen. In Speyer übernahm Isidor Markus Emanuel 1953 das Bischofsamt von Joseph Wendel im Alter von 48 Jahren, nur in Freiburg folgte Erzbischof Gröber Wendelin Rauch, der 1948 auch bereits 63 Jahre alt war, bevor 1954 dann mit Eugen Seiterich ein Bischof die Führung übernahm, der gerade 51 Jahre alt geworden war $^{14}$.

II.

Im Alter der Bischöfe scheint ein erster signifikanter Zusammenhang mit grenzüberschreitenden, versöhnenden und auf europäische Integration zielenden Aktivitäten feststellbar zu sein. Nahezu durchgängig ist zu konstatieren, dass die älteren Bischöfe, die im nationalstaatlich orientierten Denken ihre Sozialisation erfahren hatten, sich offensichtlich sehr schwer taten mit

13 Zur Charakterisierung der Bistümer: Erwin GATZ (Hg.), Die Bistümer und ihre Pfarreien, Freiburg [u. a.] 1991. Zur Flüchtlingspolitik der französischen Besatzungsmacht siehe Michael SOMMER, Flüchtlinge und Vertriebene in Rheinland-Pfalz. Aufnahme, Unterbringung und Eingliederung, Mainz 1990.

14 Siehe dazu Erwin GatZ (Hg.), Die Bischöfe der deutschsprachigen Länder 1945-2001. Ein biografisches Lexikon, Berlin 2002. 
dem Aufbau versöhnlicher Beziehungen ins katholische Ausland und der Mitarbeit an einer europäischen Friedensidee. Vielmehr verstand sich gerade diese Generation von Bischöfen angesichts der totalen Kriegsniederlage als Wahrer deutscher Interessen gegenüber den Besatzungsmächten, sie identifizierten sich gleichsam »mit ihrer geschlagenen Nation $\aleph^{15}$ und hatten schon von daher nicht selten heftige Konflikte mit den Besatzungsmächten. Vor allem die Abwehr des Kollektivschuldvorwurfs ${ }^{16}$ gegenüber den Deutschen, die Kritik an der Entnazifizierungspraxis ${ }^{17}$, die Sorge um die deutschen Kriegsgefangenen ${ }^{18}$ und das Problem der Flüchtlinge und Vertriebenen machten sie zu ihrer Sache. Grenzüberschreitende, die Europaidee unterstützende Initiativen lassen sich bei diesen Bischöfen daher so gut wie gar nicht feststellen, nicht einmal Briefkontakte zu Amtsbrüdern im Ausland sind in den bisweilen erhaltenen Briefjournalen der Bischöfe dokumentiert. So sind von Bischof Berning in Osnabrück ${ }^{19}$ wie von Bischof Machens in Hildesheim und ebenso von Bischof Galen in Münster zahlreiche und heftige Auseinandersetzungen mit den Besatzungsmächten überliefert, aber praktisch keine auf Versöhnung zielenden Außenkontakte mit europäischer Perspektive. Obwohl Galen auf seiner Reise nach Rom 1945 von den Kardinälen von Paris und Rouen sowie dem päpstlichen Nuntius in Paris außerordentlich freundlich empfangen wurde, entwickelten sich keine engeren und weiterführenden Kontakte ${ }^{20}$. Bischof Bornewasser in Trier geriet bald schon in Auseinandersetzungen mit der französischen Militärregierung, weil diese die Loslösung des Saargebiets aus seinem Diözesanverband betrieb, um dem politischen Ziel einer Anbindung dieses wirtschaftlich interessanten Gebietes an Frankreich näher zu kommen. Dies war kein Boden, auf dem der Bischof Versöhnungsgesten austauschen wollte oder gar an ein friedliches, geeintes Europa auch nur dachte ${ }^{21}$. Wenig versöhnlich klangen wegen der Kriegsgefangenenproblematik zunächst auch die

15 Heinz HÜRTEN, Beobachtungen zur Situation der katholischen Kirche in den drei westlichen Besatzungszonen Deutschlands, in: Kirchliche Zeitgeschichte 2 (1989), S. 203-210, hier S. 205.

Zur Diskussion um die Kollektivschuldthese siehe Karl-Joseph Hummel, Umgang mit der Vergangenheit: Die Schulddiskussion, in: Hummel / KIsSENER, Die Katholiken, S. 217-235, hier S. 220f.

17 HÜRTEN, Beobachtungen, S. 205.

18 Vgl. Michael KisSENER, Kleine Geschichte des Landes Rheinland-Pfalz, Leinfelden-Echterdingen 2006, S. 13-15 sowie für die französische Besatzungszone Kurt W. BöHME, Die deutschen Kriegsgefangenen in französischer Hand, München 1971, S. 209-214. Die Sorge um die Kriegsgefangenen sollte im Übrigen nicht vorschnell als Solidarität mit den NS-Tätern missverstanden werden: vgl. dazu Hans-Josef WoLLASCH, »Gefangene besuchen« keine Solidarität mit NS-Verbrechern, in: Caritas 94 (1993), S. 239-245.

19 Frdl. Auskunft des Bistumsarchivs Osnabrück, 11. März 2009.

20 Kirche und Leben. Bistumsblatt Münster 15. Jg. 19. Juni 1960, S. 5.

21 Martin Persch / Bernhard SchneIDER, Geschichte des Bistums Trier Bd. 5, Trier 2004, S. $154-157$. 
ersten Stellungnahmen der Bischöfe Stohr in Mainz und Wendel in Speyer, die insofern eine gewisse Ausnahme in dieser Reihe darstellen, weil sie eher der jüngeren Bischofsgruppe zuzurechnen $\operatorname{sind}^{22}$.

Gesondert ist der Fall des Erzbischofs von Freiburg, Conrad Gröber, zu betrachten, der traditionell gute Kontakte zum nahe gelegenen Bistum Basel und zum Bistum Straßburg fortführte, allerdings ohne dabei eine echte europäische Initiative zu entfalten. Nur einmal, als er von den Bestrebungen der evangelischen Kirchen zu supranationaler Zusammenarbeit in Genf hörte, regte sich gleichsam aus dem Empfinden, gegenüber dem Protestantismus irgendwie ins Hintertreffen zu geraten, ein gewisser europäischer Geist. An seinen Amtsbruder in Basel, Bischof Franziskus Streng, schrieb er am 20. April 1946 mit der bemerkenswerten, sonst eher selten zu findenden Anrede »Hochwürdigster, lieber Herr Nachbar!«:

Beim Zusammenschluß der katholischen Kräfte würde der katholischen Schweiz eine besondere Rolle zufallen. Unsere Kirche ist einig, heilig und apostolisch, aber die letzte Eigenschaft sollte sich wirklich nicht bloss auf den apostolischen Ursprung und die apostolische Nachfolge beschränken, sondern auch zu einer zeitgemäßen katholischen Aktion innerhalb der katholischen Länder führen. Ich würde es sehr bedauern, wenn der Einfluss der Protestanten durch den Zusammenschluss derselben den der katholischen Kirche übertreffen würde ${ }^{23}$.

Irgendwelche Folgen dieses Vorstoßes sind in den Akten Gröbers nicht überliefert. Allerdings findet sich ein Brief an den Briten Lord Beveridge vom 9. Februar 1947 und an den französischen Außenminister Bidault vom 16. Februar 1947, die ein bezeichnendes Licht auf Gröbers Lagebeurteilung und die Chancen für eine europäische Einigung werfen. Lord Beveridge ${ }^{24}$ gegenüber beklagte sich der Freiburger Erzbischof geradezu verbittert über die schlechte Behandlung der Deutschen durch die Alliierten, zeichnete das Bild eines verarmten, seiner Heimat und seines Wohlstandes beraubten

22 Vgl. dazu DDAMZ, Kirchliches Amtsblatt für die Diözese Mainz 87 (1945), S. 10-13 Hirtenbrief des Hochwürdigsten Herrn Dr. Albert Stohr, 22./29. Juli 1945 verlesen. Reaktionen ebd. 45/1 Nr. 211. Zum Zusammenhang: Christophe BAGINSKI, Frankreichs Kirchenpolitik im besetzten Deutschland 1945-1949, Mainz 2001, S. 36, 38, 132, 135-143.

23 Erzbischöfliches Archiv Freiburg (weiter EAF), NL Gröber Nb 8/71 Gröber an Bischof von Basel, 20. April 1946.

24 William Henry Lord Beveridge (1879-1963), Wirtschaftswissenschaftler und Sozialpolitiker, 1919-1937 Direktor der London School of Economics, 1937-1945 Universität Oxford, 1941 Berater Winston Churchills in kriegswirtschaftlichen Fragen und Leiter einer Regierungskommission zur Vorbereitung eines umfassenden Versicherungs- und Fürsorgesystems, eines nationalen Gesundheitsdienstes sowie eines Konzepts zur Beseitigung der Arbeitslosigkeit (Beveridge-Plan) als Grundlage der Sozialreform in Großbritannien, 1944-1945 Mitglied des Unterhauses (Liberal Party). Siehe José HARRIS, William Beveridge. A Biography, Oxford ${ }^{2} 1997$. 
Volkes, das von den Besatzern zurückgesetzt werde, obwohl doch die meisten Menschen keine Schuld an den Verbrechen des Hitlerregimes trügen:

Man schlage in dem neuen Friedensvertrag Deutschland in Stücke und verurteile es dazu, auf Jahrzehnte hinaus für andere zu dienen. Man mache dann die große menschliche Kultur mit jenen anderen europäischen Völkern, die als kleine Staaten bestanden und nun als Teilhaber des großen Sieges, den England und Amerika und Russland errungen, sich an der Beute mästen, die ihnen durch den Friedensvertrag zugefallen ist.

Den französischen Außenminister Bidault ${ }^{25}$ machte er noch deutlicher auf das Flüchtlings- und Vertriebenenproblem aufmerksam, das er als Hemmnis einer deutsch-französischen, ja internationalen Verständigung ansah: »Aus meinen gewonnenen Erfahrungen weiss ich, dass eine Ansiedelung im deutschen Westen unmöglich ist und nur dazu dienen muss, eine neue Gefahrenquelle für den Frieden Europas zu bilden«. Nur wenn die Ostflüchtlinge in ihre Heimat zurückkehren dürften, sei an eine Versöhnung und Annäherung im Westen zu denken: »Mir kommt es darauf an, gerade in unserem Westen Zustände zu erreichen, die es uns Nachbarn des französischen Volkes ermöglichen, in Eintracht mit diesem zu leben und am Aufbau eines neuen Europas zu arbeiten $\left\langle{ }^{26}\right.$.

Skepsis gegenüber Versöhnung und Einigung Europas gab es aber nicht nur unter den deutschen katholischen Bischöfen. Die Wunden, die der Krieg und die verbrecherische deutsche Besatzungsherrschaft geschlagen hatten, heilten auch im benachbarten Ausland nur langsam. Als sich der Bischof von Münster, Michael Keller, 1947 an seinen Amtsbruder in Roermond, Guilelmus Lemmens, wandte, um ihn um Hilfe in einem Streit um die Abtretung von deutschen Grenzgebietsteilen ${ }^{27}$ an die Niederlande um Hilfe zu bitten,

25 Georges Bidault (1899-1983), Lehrer, 1934-39 Herausgeber der kath. Zeitung »L'Aube«, schloss sich 1941 der Widerstandbewegung an, 1943 Präsident des »Conseil National de la Résistance« (CNR), 1944 einer der Gründer des »Mouvement Républicaine Populaire« (MRP), 1949-1952 MRP-Vorsitzender, 1946 sowie 1949/50 Ministerpräsident, 1944-1946, 1947/48 sowie 1953/54 Außenminister, ging als Verfechter der »Algérie française« 1961 in den Untergrund, 1962-1968 im Exil. Siehe Jean-Claude DemorY, Georges Bidault 18991983. Biographie, Paris 1995.

26 EAF, NL Gröber Nb 8/72 Gröber an Lord Beveridge 9. Februar 1947, Gröber an Bidault, 16. Februar 1947.

27 Nach dem Ende des Zweiten Weltkriegs verlangten die Niederlande die kompensatorische Abtretung deutscher Gebiete. Im November 1946 forderte die Den Haager Regierung Grenzkorrekturen, die sich auf eine Fläche von 1.750 Quadratkilometer erstreckten. Dies hätte die deutsch-niederländische Grenze von $525 \mathrm{~km}$ auf $340 \mathrm{~km}$ verkürzt und bis zu 150.000 Einwohner betroffen. Letztlich wurde zum 23. April 1949 die sog. Selfkant-Region unter niederländische Auftragsverwaltung gestellt, ein Gebiet von 64 Quadratkilometern mit 9.100 Einwohnern. Zum 1. August 1963 wurde das Selfkant in die Bundesrepublik rückgegliedert. Siehe Horst LADEMACHER, Die Niederlande und Deutschland 1945-1949. Wirtschaftsfragen und territoriale Korrekturen, in: Wilfried EhBRECHT / Heinz SchILLING (Hg.): Niederlande und 
antwortete dieser abschlägig: »Unsere Gläubigen würden eine solche Einmischung nicht ertragen. Denn der deutsche Besetzer hat dem Niederländischen Volke viel Unrecht angetan $\ll^{28}$. Ganz ähnlich lautete auch die Antwort des Kardinals de Jong aus Utrecht an den Aachener Bischof van der Velden, der geradezu flehentlich um unterstützende Intervention des Amtsbruders gebeten hatte, weil die niederländischen Gebietsforderungen altes Unrecht mit neuem vergelten würden und so eine Aussöhnung der Nachbarvölker behindern, wenn nicht unmöglich machen würden. Immerhin anerkannte der Utrechter Erzbischof aber den versöhnlichen Geist in van der Veldens Schreiben: »Der Ton aber Ihres Schreibens war Uns sehr sympathisch und dafür danken wir Ihnen recht herzlich. Glauben Sie: Wir versuchen Ihre schwere Lage zu verstehen, aber Wir bitten: versuchen Sie auch Uns zu begreifen « $1^{29}$. Dieser Anfangskontakt sollte Zukunft haben.

Dass die genannten Bischöfe sich nicht oder in kaum nennenswertem Umfang für Versöhnung oder europäische Einigung einsetzten, bedeutet freilich nicht, dass es solche Anstrengungen in ihren Diözesen nicht gegeben hätte. In der diözesanen Überlieferung von Münster, Hildesheim, Trier oder Freiburg findet sich eine ganze Reihe von Spuren eines ebensolchen Engagements, etwa von katholischen Jugendgruppen, die Kontakte mit Gleichaltrigen in Frankreich, den Niederlanden oder Großbritannien herstellten und sehr engagiert ein gegenseitiges Kennen- und Verstehenlernen organisierten. So erhielt z. B. die christliche Arbeiterjugend Hildesheims 1948 Lebensmittel von der CAJ Antwerpen, die Ausgangspunkt für weitere Kontakte waren ${ }^{30}$. In München trafen sich im Oktober 1948 katholische Jugendorganisationen aus mehreren deutschen und ausländischen Diözesen. In den Ansprachen der belgischen, französischen und italienischen Delegierten wurde immer wieder zum Ausdruck gebracht, dass der Katholizismus keine Grenzen kenne und auch die deutschen Jungkatholiken eingeladen seien, am Aufbau Europas mitzuwirken ${ }^{31}$. Und selbst in Trier fand der B.D.K.J. ${ }^{32}$ Kontakte zu französischen und britischen katholischen Jugendgruppen, mit denen man sich einig wurde im Bestreben, ein gemeinsames

Nordwestdeutschland. Studien zur Regional- und Stadtgeschichte Nordwestkontinentaleuropas im Mittelalter und in der Neuzeit. Franz Petri zum 80. Geburtstag, Köln 1983, S. 456-506, hier S. 478f., 492, 504.

28 Bistumsarchiv Münster (weiter BAM), Büro des Generalvikars A 133, Bischof von Roermond an Kapitularvikar Münster, 5. Februar 1947.

29 Bischöfliches Diözesanarchiv Aachen (weiter BDA), Gvs B 14, I Erzbischof de Jong an Bf. van der Velden, 12. März 1947. Zum Zusammenhang siehe August BRECHER, Bischof mitten im Volk. Johannes Joseph van der Velden 1891-1954, Aachen 1992, S. 129f.

30 Katholisches Kirchenblatt für das Bistum Hildesheim 3. Jg. 9. Mai 1948.

31 Ebd., 3. Oktober 1948.

32 Bund der Deutschen Katholischen Jugend. 
christliches Europa nach dem Kriege aufbauen zu wollen ${ }^{33}$. Letztendlich waren all dies nur Konkretisierungen eines immer deutlicheren, schon auf dem Mainzer Katholikentag 1948 sichtbaren Bestrebens der deutschen Katholiken nach Überwindung des extremen Nationalismus der NS-Zeit und Öffnung hin zur christlich orientierten Wertegemeinschaft des Westens. In Mainz hatte man in einer eigenen Sektion unter dem Titel »Übernationale Zusammenarbeit« unter Beteiligung vieler ausländischer Gäste das Thema diskutiert und schließlich eine Resolution verabschiedet, in der es hieß:

In der Erkenntnis, daß die katholische Kirche vermöge ihrer weltumspannenden Organisation und der ihr zu Gebote stehenden übernatürlichen Kräfte wie keine andere Macht der Erde die Fähigkeit besitzt, für den Frieden unter den Völkern zu wirken, ist es ihr in der gegenwärtigen Weltkrise aufgegeben, von dieser Fähigkeit einen möglichst starken Gebrauch zu machen. [...] Die Herstellung guter Beziehungen zwischen den Völkern ist nicht nur Sache der Politik, sondern mehr noch der christlichen Religion ${ }^{34}$.

III.

Ganz anders als die älteren Amtsbrüder antworteten die meisten jüngeren deutschen Bischöfe auf die Herausforderungen der Zeit nach 1945. Den Bischof von Aachen, Johannes Joseph van der Velden und seinen seit 1954 amtierenden Nachfolger Johannes Pohlschneider könnte man z. B. ebenso wie seinen Speyerer Kollegen Isidor Markus Emanuel getrost als wirkliche »Europäer« unter den Bischöfen bezeichnen. Hinzu kamen vor allem Léon Lommel in Luxemburg, Wendelin Rauch und Eugen Seiterich in Freiburg sowie Heinrich Maria Janssen in Hildesheim und Michael Keller in Münster, die sich zu einer versöhnenden, integrativen europäischen Mitarbeit berufen fühlten. Ihr Wirken zeigt ein großes Spektrum von Möglichkeiten, wie die Kirche Versöhnung und friedliche Einigung in Europa befördern konnte.

Am Anfang stand dabei nahezu immer die Aufnahme des Gesprächskontakts zu den Amtsbrüdern im Ausland, der nicht nur beispielgebend für die Gläubigen sein konnte, sondern nicht selten auch der Versöhnung dienende weitere Aktivitäten der Diözesen oder einzelner Gemeinden nach sich zog ${ }^{35}$. Auffällig ist gerade für die Anfangszeit dabei die sehr aktive Rolle, die der

33 Brigitte Deubel, L'Église catholique et la jeunesse au lendemain de la deuxième guerre mondiale à Trèves et ses environs Tome I, Diss. phil. Strasbourg 1988, S. 179f., $208 \mathrm{f}$.

34 Der Christ in der Not der Zeit (wie Anm. 10), S. 329f.

35 Solche frühen, von der Besatzungsmacht geförderten Kontakte sind mehrfach belegt, erbrachten aber nicht immer engere Kontakte. Siehe beispielsweise die Englandreise des Münsteraner Bischofs Keller 1951, BAM, Bischöfliches Sekretariat A-775. 
französische Militärbischof Picard de la Vacquerie ${ }^{36}$ einnahm, der zu allen genannten Bischöfen der hier untersuchten Gruppe enge Gesprächskontakte zu unterhalten bestrebt war und diese auch später noch ausbaute, als er Bischof von Orléans wurde. Die Beziehungen zwischen der französischen Besatzungsmacht und dem Speyerer Bischof Wendel, die wegen der Kriegsgefangenenfrage zeitweilig empfindlich gestört waren, vermochte er z. B. durch einen Besuch 1947 deutlich zu verbessern. Picard logierte bei seinem Amtsbruder, ließ den hervorragenden Straßburger Domchor in Speyerer Dom auftreten und rief in einer Predigt vor zahlreichen deutschen und französischen Ehrengästen dazu auf, dass sich »Frankreich und Deutschland verbinden sollten, um eine Mauer des Widerstandes gegen Materialismus und Atheismus aufzurichten $\ll^{37}$. Das nahm Wendel für Picard ein und machte ihn bereit zu weiteren Kooperationen wie der Organisation eines deutsch-französischen Priestertreffens. Wie gezielt Picard dabei vorging, wird aus einem Bericht deutlich, den er ein Jahr später anfertigte. Darin hieß es: „L'Evêque allemand de notre Zone d'Occupation qui lui sembla le plus qualifié pour comprendre cette idée et la réaliser avec lui, fut S. Exc. Monseigneur Wendel, Evêque de Spire«. Der Kontakt zwischen ihm und Wendel sei dann so eng geworden, dass daraus eine »veritable amitié« entstanden $\operatorname{se}^{38}$. Auf dieser Grundlage aufbauend, warb Picard im Folgejahr weiter. Ganz typisch war, was er im Januar 1948 an den zuerst so reservierten Mainzer Bischof Stohr schrieb: Sein Ziel sei es, dass die »liens d'amitié, créés déjà entre le clergé allemand et le clergé français, deviennent encore plus étroits«. Darauf musste dann auch Stohr antworten: »Si sensus sacerdotum et maxime episcoporum duorum populorum magis ac magis vertuntur in magnam aestinationem [sic!] et quidem amicitiam, non dubito, quin sensus diffidentiae et contrarietatis de die in diem evanescant $\ll^{39}$.

Besondere Bedeutung erlangte der Kontakt zu dem neuen Freiburger Bischof Wendelin Rauch, den Picard anlässlich der Beisetzungsfeierlichkeiten für den verstorbenen Rottenburger Bischof Sproll im März 1949 kennenlernte. Mit ihm vereinbarte er ein Treffen der deutschen Bischöfe der französischen Besatzungszone mit ausgewählten französischen Amtskollegen. »L'Evêque de Mayence et l'Evêque de Spire ont été enthousiasmés par ce projet lorsque je leur en ai parlé«, ließ er Rauch brieflich wissen und fügte

36 Robert Picard de la Vacquerie (1883-1969), 1951-1963 Bischof von Orléans.

37 Christophe BAGINSKI, Aspekte der französischen Kirchenpolitik im Bistum Speyer nach dem Zweiten Weltkrieg, in: Mitteilungen des Historischen Vereins der Pfalz 94 (1996), S. 481508, hier S. 491. Vgl. auch den zeitgenössischen Bericht in Der christliche Pilger, 97. Jg., 3./10. August 1947, S. 7: »Aus dem Bistum Speyer«.

38 EAF, NL Rauch Nb 9/6 Bericht Picards über Treffen auf dem Maria Rosenberg 6.-11. September 1948 .

39 DDAMZ, 45,1, Nr. 211, Picard an Stohr, 3. Januar 1948, Stohr an Picard o. D. 
hinzu: »cette réunion aurait une grande importance al l'heure actuelle pour l'organisation d'une Europé chretienne ${ }^{40}$. Rauch sollte dieses Treffen für den Oktober 1949 in Baden organisieren und war sehr schnell dazu bereit:

Die katholische Kirche müsste ja ohne Zweifel die erste Macht sein, die über die Grenzen und die jeweilige augenblickliche politische Lage hinweg den Gedanken der Zusammengehörigkeit der Völker sichtbar werden lässt und wirksam in die Welt hinein stellt. Und das aus ihrem innersten Wesen heraus. Sie hat für die Verständigung, für die Eintracht und den Frieden aus ihrer eigensten übernatürlichen Aufgabe heraus wichtigste Kräfte einzusetzen und bereitzustellen ${ }^{41}$.

Offensichtlich war man sich aber nicht ganz im Klaren darüber, wie Rom eine solche Inititative beurteilen würde, und bat deshalb den Papst um seinen Segen für ein solches Vorgehen. Aus dem päpstlichen Staatssekretariat antwortete umgehend G. B. Montini, der spätere Papst Paul VI., dass »Sa Sainteté, benit très volontiers ce projet et les sentiments qui l'inspirent«. Der einzige Vorbehalt, den der Papst machte, war, dass diese Zusammenkunft völlig frei sein müsse und keinerlei Zwang auf die Anwesenden ausgeübt werden dürfe ${ }^{42}$. So kam das erste große deutsch-französische Bischofstreffen im badischen Bühl vom 24. bis 27. Oktober 1949 zustande, dessen vornehmster Zweck, den Einladungsschreiben Erzbischof Rauchs zufolge, das gegenseitige Kennenlernen und die »Verständigung der beiden Völker« war. Von der Zusammenkunft der schließlich sieben deutschen und sieben französischen Bischöfe sollte möglichst wenig öffentliches Aufhebens gemacht werden, in aller Stille gedachte man zu tagen und sich gegenseitig über die Lage in den jeweiligen Diözesen auszutauschen und voneinander zu lernen. Die Kosten dafür übernahm der französische Militärbischof. Die Tagung, die der Papst mit einem Telegramm grüßte und lobte, wurde tatsächlich ein voller Erfolg. Nicht etwa weil brennende politische Fragen diskutiert worden wären - diese standen gar nicht auf der Tagesordnung. Auch konkrete Beschlüsse wurden nicht gefasst. Die Zusammenkunft wurde vielmehr deswegen ein Erfolg, weil nach dem Bekunden nahezu aller Teilnehmer ein tieferes Verständnis für die kirchlichen und seelsorgerlichen Probleme der jeweils anderen Seite gewachsen war, weil Vertrauen entstand, das die Bischöfe in ihre weitere Arbeit mitnahmen. Aus den auch in der Folgezeit nicht mehr abreißenden Kontakten wird ersichtlich, dass das Treffen schließlich auch praktische Folgen hatte. So ließ z. B. einer der Teilnehmer, der Bischof von Besançon, Dubourg, 1950 eine Ausstellung über die katholische Kirche in Deutschland vorbereiten, die er in Besançon zeigte und in deren Rahmen er seinen Priesternachwuchs auf die deutsch-

\footnotetext{
EAF, NL Rauch Nb 9/6 Picard an Rauch, 12. März 1949.

Ebd., Rauch an Picard de la Vacquerie, 24. März 1949.

Ebd., Staatssekretariat des Papstes an Picard, 22. Januar 1949, Abschrift.
} 
französische Aussöhnung und die europäische Integration nachdrücklich aufmerksam machte ${ }^{43}$.

Auch in den Folgejahren und selbst nach seiner Berufung auf den Erzbischofsstuhl von Orléans 1951 ließ Picard nicht nach, sich um die deutschfranzösische Aussöhnung zu bemühen. Den Münsteraner Bischof Keller lud er z. B. 1960 ein, an dem alljährlichen Fest zu Ehren von Jeanne d'Arc teilzunehmen. Keller ließ sich von Weihbischof Tenhumberg vertreten, der im Festumzug mitging und damit die Bande der Städtepartnerschaft zwischen Münster und Orléans wesentlich verstärkte ${ }^{44}$. Tenhumberg hatte bereits 1948 den Kontakt nach Frankreich gesucht und gefunden, weil er als Leiter der Landseelsorge am Erfahrungsaustausch mit Frankreich interessiert war ${ }^{45}$.

Eine erste, nicht zu unterschätzende Folge solcher Bischofskontakte war, wie das Freiburger Beispiel zeigt, also das Entstehen von Vertrauen, das sich zunächst in den Bereich der Seelsorge erstreckte und dort zu ausdrucksstarken symbolischen Handlungen und Gesten der Versöhnung über die Grenzen hinweg führen konnte. Dass der französische Bischof Théas 1947 in Kevelaer deutschen Kindern die Erstkommunion reichte und der Mainzer Bischof Stohr 1956 den Kindern französischer Militärangehöriger auf Bitten des Pariser Kardinals Feltin hin die Firmung spendete ${ }^{46}$, bedeutete in diesen Zeiten etwas ganz Außergewöhnliches. Noch mehr Aufsehen erregte wohl, dass der Aachener Bischof van der Velden schon 1945 im belgischen Wallfahrtsort Moresnet predigen durfte und sein Nachfolger Pohlschneider 1956 auf Einladung der belgischen Armee eine Kapelle auf einem Truppenübungsplatz einweihte ${ }^{47}$. Van der Velden hatte schon im Krieg jenes Grundvertrauen der Belgier erworben, indem er den Bischof von Lüttich Kerkhofs in der Apostolischen Administratur Eupen-Malmedy

43 Ebd., Nb 9/7 Dubourg an Rauch, 7. November 1950. Programm, Referatzusammenfassungen und persönliche Notizen zur Tagung des Mainzer Bischofs Stohr auch in DDAMZ, 41, 5, Nr. 10.

44 BAM, Bischöfliches Sekretariat A 509. Ebd. Presseberichterstattung in »Münster Tag für Tag«, 11. und 13. Mai 1961. Tenhumbergs Beteiligung an den Feierlichkeiten in Orléans brachte weitere Kontakte zum Erzbischof von Marseille. Der Aachener Bischof Pohlschneider begann 1954 sein Pontifikat geradezu mit einer Rundreise im benachbarten Ausland, um Kontakte zu knüpfen und die grenzüberschreitende Zusammenarbeit seines Vorgängers van der Velden fortzuführen. S. August BRECHER, Bischof einer Wendezeit der Kirche. Dr. Dr. Johannes Pohlschneider 1899-1981, Aachen 1997, S. 102.

45 Ebd., Generalvikariat Neues Archiv A 201-43, Domvikar Tenhumberg an Secretariat des J.A.C., 8. Oktober 1948.

46 DDAMZ, 45,1 Nr. 252, L'Aumonier en chef X. Louis an Stohr, 18. September 1956 und Antwort Stohrs vom 11. Oktober 1956. Zum Wirken Théas vgl. Michael KISSENER, Der Katholizismus und die deutsch-französische Annäherung in den 1950er Jahren, in: Corine DEFRANCE [u. a.] (Hg.), Wege der Verständigung zwischen Deutschen und Franzosen nach 1945. Zivilgesellschaftliche Annäherungen, Tübingen 2010, S. 89-98, hier S. 90f.

47 BRECHER, Bischof mitten im Volk, Aachen 1992, S. 131. BRECHER, Pohlschneider, S. $102 \mathrm{f}$. 
vertreten und dabei die Belange der belgischen Katholiken auch gegenüber der deutschen Besatzungsmacht zu wahren gewusst hatte. Das hatte man nicht vergessen ${ }^{48}$. Ein besonderes Zeichen einer neuen Seelsorge über Staats- und Sprachengrenzen hinweg konnte darüber hinaus der Luxemburger Bischof Léon Lommel in der spezifischen Situation seiner kleinen Diözese setzen, als er 1959 in Luxemburg eine Europäische Gemeinde gründete, die den Katholiken in den dortigen europäischen Behörden ebenso eine Heimat bieten sollte wie den Kindern und Eltern der Luxemburger Europäischen Schule. Die stark expandierende Gemeinde existiert noch heute und hat durch ihren Zusammenhalt über alle Nationalitäten hinweg viele familiäre Bande gestiftet ${ }^{49}$.

In der europäischen Perspektive besonders effektiv und weit ausstrahlend wurde die bischöfliche Seelsorge, wenn sie viele Menschen aus unterschiedlichen europäischen Ländern etwa bei Wallfahrten zusammenführte oder den Multiplikatoreffekt nutzte, der sich über den Pfarrklerus ergab.

So initiierte Bischof van der Velden bereits 1947 einen Kreuzfahrt der Versöhnung, bei der ein überdimensionales Friedenskreuz von deutschen Katholiken durch mehrere Gemeinden in Deutschland, Belgien und Frankreich getragen wurde, das die Bitte um Vergebung und Versöhnung mit dem Anliegen der Förderung des Weltfriedens verband. Solche Kreuzfahrten fanden viele Nachfolgeveranstaltungen in den 50er Jahren. Wie deutlich auf Völkerfrieden und Versöhnung abgestellt diese Kreuzfahrten waren, belegt eine Predigt des Paters Hörhammer im belgisch-deutschen Grenzgebiet in Eupen, die in der Feststellung gipfelte: »Das Kreuz kommt über die Grenze, weil es nicht vor Grenzen haltmacht. Für das Kreuz gibt es keine Genzen, sein Wirken geht über alle Länder und Erdteile«. In Lüttich angekommen, empfing in einer der Stadtdekanatskirchen ein belgischer Dechant die pilgernden Gläubigen mit den Worten: »Es ist erstaunlich und erfreulich, daß unsere Landsleute vor diesem Kreuz aus Aachen vergessen haben, was vor einigen Jahren ein verbogenes Kreuz aus Deutschland über sie gebracht hat $\ll^{50}$.

Ergänzung fanden diese Kreuzfahrten in Wallfahrten, die katholische Christen aus ganz Europa zusammenführten. Besonders aktiv war auf diesem Gebiet der Bischof von Montauban, später Lourdes, Pierre Marie

48 Ebd., S. 130f. Vgl. auch BDA, GvS B 20 I Bischof Kerkhofs an Bischof van der Velden, 18. Januar 1945.

49 Georges Hellinghausen, Léon Lommel (1893 1978), in: GATZ, Die Bischöfe, S. 339-341; Michel SchmitT / Jean HengEN, Ein Episkopat zwischen Kontinuität und Umbruch. Zum 100. Jahrestag der Geburt von Bischof Leo Lommel, in: Die Warte 46 (1993), S. 1-2. Vgl. auch http://homepage.internet.lu/european_parish/history.html.

50 August Brecher, Im Kreuz ist Heil. Geschichte des Aachener Friedenskreuzes, Aachen, Kevelaer 1992, S. 72f., KISSENER, Katholizismus. 
Théas, der zugleich auch Gründer der Pax Christi-Bewegung war. In dem Aachener Bischof van der Velden fand er einen Gleichgesinnten, der 1951 die Leitung des deutschen Zweiges der Pax-Christi-Bewegung übernahm. Théas Ziel war die Versöhnung von Deutschen und Franzosen durch Stiftung von Gemeinschaft im Glauben. In deutscher Gestapohaft hatte er bereits 1944 diese Nachkriegsaufgabe gegenüber Mitgefangenen formuliert und zu deren Bewältigung die Laienbewegung Pax Christi gegründet, die bis 1948 bereits 400.000 Anhänger beidseits der Grenze fand. Gemeinsame Wallfahrten, vor allem in das französische Lourdes und das deutsche Kevelaer, waren die Kristallisationspunkte der Aktivitäten, bei denen sich Jahr um Jahr tausende von Gläubigen trafen und zueinander fanden. Die 1948 unter Schirmherrschaft des Münsteraner Bischofs Keller stattfindende Begegnung in Kevelaer beispielsweise stand unter dem Motto »Praktische Wege der Begegnung und Verständigung zwischen den Katholiken der verschiedenen Völker « ${ }^{51}$. Begleitet von symbolträchtigen Akten wie der Spendung der Erstkommunion für deutsche Kinder durch den französischen Bischof, der Heimkehr von deutschen Kriegsgefangenen aus französischem Gewahrsam anlässlich solcher Ereignisse oder auch spektakulären Versöhnungspredigten entfalteten diese Wallfahrten beachtliche Wirkung ${ }^{52}$.

Ganz ähnlich wirkte auch das Kölner Domjubiläum 1948 mit der Beteiligung der Bischöfe von Wien, London, Paris, Mecheln und Utrecht $t^{53}$ oder auch die verschiedenen sog. Heiligtumsfahrten, etwa nach Aachen (1951) ${ }^{54}$ mit der Beteiligung von alleine 30 Bischöfen aus dem In- und Ausland sowie geschätzten 375.000 Pilgern. Zu einem Anziehungspunkt für katholische Gläubige aus vielen Ländern wurde auch das 1952 von deutschen und französischen Katholiken in Bühl/Baden errichtete Friedenskreuz, in das Steine des Westwalls und der Maginotlinie eingearbeitet worden waren. Vor allem die Angehörigen der Besatzungs- bzw. NATO-Streitkräfte fanden hier Verbindungen zu deutschen kirchlichen Einrichtungen, die bis heute andauern ${ }^{55}$. Von besonderer Bedeutung waren nicht zuletzt auch Zeichen katholischer Verbundenheit, die sich in der Überführung von Reliquien äußerten. Mainz erlebte ein solches Ereignis im November 1950, als

51 BAM, Büro des Generalvikars, A 420 Programmzettel Kevelaer 1948.

52 Vgl. Kissener, Katholizismus. Zur Bilanz der Versöhnungsbemühungen in der Erzdiözese Freiburg siehe das Referat von Erzbischof Schäufele vom 18. April 1974, in EAF 86.13.10.

53 Nach Köln kamen die Bischöfe Innitzer (Wien), Griffin (London/Westminster), Suhard (Paris), van Roey (Mecheln) und de Jong (Utrecht) und 30 weitere Bischöfe, z. T. aus Übersee. Der Erzbischof von Paris formulierte in seiner Ansprache: »Ich komme nicht als einzelner: Ich bringe Euch den Gruß Eurer katholischen Brüder in Frankreich«. Vgl. Norbert TRIPPEN, Josef Kardinal Frings (1887-1978) Bd. 1, Paderborn [u. a.] 2003, S. 217, 222.

54 Anton Joseph Wäckers, Erlebte und gelebte Kirche von Aachen. Erinnerungen aus den Jahren 1929-1978, Aachen 1995, S. 158f.

55 Vgl. KISSENER, Katholizismus. 
der französische Militärbischof Picard de la Vacquerie anregte, der Mainzer St. Quintinskirche Reliquien aus dem französischen St. Quentin zu schenken und dies zur Demonstration katholischer Verbundenheit über Grenzen hinweg zu nutzen. Das von Politikern wie dem rheinland-pfälzischen Ministerpräsidenten Altmeier und dem französischen Botschafter FrançoisPoncet begleitete Ereignis, das eine "große Menschenmenge« anlockte, erreichte sein Ziel: Die Presse hielt fest, die katholische Kirche wolle mit der Reliquienüberführung die »Brücke zwischen Deutschland und Frankreich festigen«, man wolle »vor Gott zeigen, daß wir Brüder sind « ${ }^{56}$.

Verstärkt wurden diese Bande durch die Organisation eines Priesteraustauschs und regelmäßiger grenzüberschreitender Priesterkonferenzen, wie sie vor allem in Aachen bereits 1950 wieder begonnen wurden. Der direkte, grenzüberschreitende Kontakt zwischen dem Klerus benachbarter Diözesen hatte allerdings Vorläufer: In Freiburg und Trier hatten die Priesterseminare schon während des Krieges die Priesterausbildung des Nachwuchses aus Straßburg und Luxemburg übernommen. Während dies im Fall Triers offenbar keine weitergehenden Folgen nach 1945 zeitigte, förderte der Direktor des Freiburger Priesterseminars Wendelin Rauch in seiner Zeit als Freiburger Erzbischof die alten Kontakte und konnte so zu einer gegenseitigen Annäherung beitragen ${ }^{57}$. Auch sein Nachfolger Erzbischof Seiterich knüpfte daran an und intensivierte noch die Kontakte, so dass er schließlich 1954 in Anerkennung dieses Versöhnungsdienstes Ehrendomherr in Straßburg wurde ${ }^{58}$.

In der Diözese Speyer hatte auf Veranlassung des französischen Militärbischofs Picard de la Vacquerie Bischof Wendel bereits 1948/49 zwei deutsch-französische Priestertreffen organisieren lassen. Dabei wuchs das Vertrauen der Kleriker zueinander so, dass Bischof Wendel in seiner Abschlusspredigt formulieren konnte: »Vom Altare aus soll die Völkerverständigung ihren Ausgang nehmen und die Völker als Brüder den Altären zurückführen; daran mitzuhelfen, ist wahrhaft eine drängende Seelsorgsaufgabe in der Krisis unserer Zeit « ${ }^{59}$. Der Gesprächsfaden riss auch in der

56 Allgemeine Zeitung, 8. November 1950, S. 3, Glaube und Leben 6. Jg. 5. November 1950, S. 472. Zu den Hintergründen: DDAMZ, Chronik Bischof Stohr 1949-1957, 4. und 5. November 1950, 45,1 Nr. 39 Predigt Bischof Stohrs bei der Reliquienübergabe St. Quintins am 5. November 1950.

57 Vgl. Paul WinNinger, Les séminaristes du diocèse de Strasbourg pendant la guerre. 19391945. Clermont-Ferrand, Fribourg-en-Brisgau, Strasbourg 1996.

58 Auch Bischof Pohlschneider von Aachen wurde französischer Ehrendomherr, und zwar in Amiens. Vgl. BRECHER, Pohlschneider, S. 103. Ebenso Bischof Isidor Emanuel von Speyer in Chartres. Zudem erhielt Emanuel das Offizierskreuz des französischen Zivil-Verdienstordens für seine Verdienste um die deutsch-französische Aussöhnung. Vgl. Hans AMMERICH, Emanuel, Isidor Markus (1905-1991), in: GATZ, Die Bischöfe, S. 519-521. Karl-Heinz BRAUN, Seiterich, Eugen Viktor Paul (1903-1958), in: ebd., S. 215-217, hier S. 217.

59 LAUER, Deutsch-französische Seelsorgertagung auf Maria Rosenberg, in: Dokumente 5 (1949), S. $473 \mathrm{f}$. 
Folgezeit nicht ab, betonte Picard in einem Rechenschaftsbericht ${ }^{60}$, und wurde 1965 in dem Priesterhilfswerk »Contact Abbé« auf andere Weise und unter Beteiligung von Laien fortgeführt ${ }^{61}$. In Münster bildete sich in den 50er Jahren eine »Priester-Union für den Völkerfrieden« als Untergruppe der Pax-Christi-Bewegung ${ }^{62}$. Die größte Ausstrahlung aber hatte offenbar die von dem Utrechter Bischof de Jong 1945 ausgehende »Katholische Gemeinschaft für Geistige Erneuerung «, die 1953 eine »Katholische Gemeinschaft für internationale Beziehungen « (KAGIB) mit einem Büro in Straßburg gründete. In diesem Zusammenschluss arbeitete auch der Aachener Bischof van der Velden mit, der ab 1950 regelmäßige Priesterkonferenzen, die dann bald so genannten »Van-der-Velden-Konferenzen«, einberief, in deren Rahmen zunächst deutsche, niederländische, belgische und französische Priester sich austauschten und Kontakte zu anderen europäischen Diözesen herstellten ${ }^{63}$. Um der Ursprungsintention, den direkten persönlichen Kontakt zwischen katholischen Priestern verschiedenster Länder herzustellen und so für den Aufbau eines grenzüberschreitenden Gemeinschaftsgefühls zu sorgen, besser dienen zu können, wurde innerhalb der KAGIB 1960 die Organisation »Europax« gegründet. Deren Ende der 60er Jahre aufgestellte Leistungsbilanz liest sich über die dort verzeichneten vielfältigen Veranstaltungen hinweg wie ein Handbuch für europäische Versöhnungs- und Einungsaktivitäten. Dort ist die Rede von internationalen Kongressen, Priestertreffen, Hochschulwochen, Schulungskursen, Sommerkursen, speziellen Kontaktangeboten für katholische Familien, Ordensleute und Weltpriester usw. ${ }^{64}$ Bedenkt man, wie hoch alleine der Multiplikatoreffekt durch Hunderte von Geistlichen gewesen sein muss, die ihre Erfahrungen nach der Teilnahme an diesen Aktivitäten in ihre Gemeinden getragen haben, so kommt »Europax « gewiss eine erhebliche Bedeutung für den Aufbau eines europäischen Gemeinschaftsgefühls im katholischen Milieu zu.

Gelegentlich gelang es den am Aufbau Europas interessierten katholischen Bischöfen sogar, sichtbare, große Zeichen der Versöhnung und christlicher europäischer Verbundenheit zu setzen. Das gewiss herausragendste Beispiel für ein solches öffentliches Zeichen ist wohl der Bau der Speyerer Friedenskirche 1953/54, der von deutschen und französischen Katholiken gemeinsam

60 EAF NL Rauch Nb 9/6 Bericht Picards über Treffen auf dem Maria Rosenberg 6.-11. September 1948.

61 Kissener, Katholizismus, S. 95.

62 BAM, Büro des Generalvikars A 420. Informationsblatt der Priester-Union für den Völkerfrieden.

63 Ein Programm und eine über 50 Priester umfassende Teilnehmerliste ist erhalten in BAM, Generalvikariat Neues Archiv A 201-145.

64 BDA GvS B 12, III (B-Bistümer - Generalvikar 1961-1964). 
finanziert wurde und ein »ragendes Denkmal des christlichen Abendlandes« werden sollte. Vor allem deutsche und französische politische wie kirchliche Prominenz fand sich zu dem symbolisch gestalteten Festakt der Grundsteinlegung 1953 in Speyer ein und beschwor den europäischen Geist im Zeichen einer sich damals noch abzeichnenden engen politischen Gemeinschaft zwischen Deutschland und Frankreich. Initiator des Ereignisses war der Speyerer Bischof Isidor Emanuel gewesen, der bereits im Exerzitienhaus in Maria Rosenberg unmittelbar nach dem Krieg die oben erwähnten deutschfranzösischen Priestertreffen organisiert hatte ${ }^{65}$.

Ebenso große symbolische Bedeutung erlangte der vom Luxemburger Erzbischof Léon Lommel organisierte Wiederaufbau der Basilika in Echternach, die 1944 von deutschen Truppen zerstört worden war. Lommel, selbst Verfolgter des NS-Regimes, setzte sich nach dem Krieg unermüdlich für die Versöhnung von Luxemburgern und Deutschen ein. Dass das feierliche Pontifikalamt zur Wiedereröffnung der Kirche in Echternach 1953 nun gerade von einem Deutschen, dem Kölner Erzbischof Frings, gehalten werden durfte, stellte insofern einen besonderen Akt der Versöhnung dar. Zugegen war neben Frings aber auch der Trierer Bischof Wehr, die Bischöfe von Oslo, von Kopenhagen, von Beauvais und der Bischofs-Kodadjutor von Utrecht, womit die europäische Dimension dieses Kirchenbaus von Lommel ein weiteres Mal unterstrichen wurde ${ }^{66}$.

\section{IV.}

Nimmt man alles zusammen, so zeigt diese erste Sondierung in den westdeutschen Diözesen, dass bei weitem nicht alle Bischöfe nach 1945 Interesse am Aufbau eines versöhnten und geeinten Europa entwickelt haben. Es scheint zunächst eine Generationsfrage gewesen zu sein, die das europaorientierte kirchliche Engagement bestimmt hat. Die älteren, sehr national sozialisierten und orientierten Bischöfe taten sich augenscheinlich schwerer als ihre jüngeren Amtskollegen, über die Landesgrenzen hinweg eine Verbundenheit von katholischen Christen und damit den europäischen Geist zu fördern. Unter den jüngeren Bischöfen, die entweder schon $1945 \mathrm{im} \mathrm{Amt}$ waren oder den älteren in den 1950er Jahren folgten, dürfte die unmittelbare Erfahrung der Verfolgung im NS-Staat ein nicht zu unterschätzender Motor

65 Michael KISSENER, Ein »ragendes Denkmal« des christlichen Abendlandes. Der Bau der Friedenskirche in Speyer 1953/54, in: Jahrbuch für Europäische Geschichte 9 (2008), S. 93-106.

66 S. René FisCH, Die Luxemburger Kirche im II. Weltkrieg, Luxemburg 1991, S. 276, Georges HeLLINGHAUSEN, Léon Lommel (1893-1978), 1956-1971 Bf. V. Luxemburg, in: GaTZ, Die Bischöfe, S. 340, Michel SchмiтT, Ein Episkopat zwischen Kontinuität und Umbruch, in: Die Warte 46 (1993), S. 1-2. 
für ein europäisches Engagement gewesen sein. Nicht auszuschließen ist, dass auch die Diasporasituation der Katholiken in den norddeutschen Bistümern wie auch die große Anzahl von Vertriebenen, die von einer vorbehaltlosen europäischen Völkerverständigung zunächst wohl nur schwer zu überzeugen gewesen sein dürften, zu dem reservierten Verhalten der Bischöfe von Osnabrück und Hildesheim beigetragen hat - zu belegen ist dies aus den Quellen derzeit jedoch nicht.

Bei europaorientierten Bischöfen wie van der Velden in Aachen zeigte sich ein gegenüber der älteren Generation gewandeltes Amtsverständnis. Er hatte 1944 bereits ein politisches Amtsverständnis in einem Fastenhirtenbrief erkennen lassen, indem er eine $»$ Verantwortung, die ich als deutscher Bischof vor meinem Volk habe«, reklamierte, während er gleichzeitig sich insgeheim der Widerstandsgruppe des 20. Juli 1944 zur Verfügung gestellt haben soll. Auch nach 1945 rief er die Gläubigen auf, nicht tatenlos beiseite zu stehen, sondern mehr Verantwortung in der Welt zu übernehmen ${ }^{67}$. Eine solche Haltung war mit Sicherheit eine wesentliche Voraussetzunge für die Wahrnehmung von Außenkontakten, die gerade bei älteren Bischöfen in der Regel nicht gegeben war. Die Initiative für solche, den europäischen Geist fördernde Kontakte ging nicht nur von deutscher Seite aus, vielmehr haben etwa Bischof Théas aus Frankreich oder Kardinal de Jong in Utrecht Anstöße gegeben, die von deutschen Bischöfen wie dem Aachener van der Velden oder Bischof Isidor Emanuel in Speyer oder auch von Bischof Lommel in Luxemburg dankbar aufgegriffen wurden. Das inhaltliche Spektrum bischöflicher Aktivitäten zur Förderung der Versöhnung und europäischen Integration war weit und es hatte einen nicht zu unterschätzenden Wirkungsgrad, vermutlich weil politisch brisante Themen gerade nicht im Mittelpunkt standen, sondern die Herstellung menschlicher Kontakte auf der Grundlage des gemeinsamen Glaubens. Von den grenzüberschreitenden Wallfahrten, von den Priestertreffen, den Austauschaktivitäten und anderem mehr wurden viele hunderttausend katholische Christen diesseits und jenseits der Grenzen berührt. Das förderte gegenseitiges Verständnis, Freundschaft, Gemeinschaft und den Willen, sich auch in anderen Zusammenhängen für den Aufbau Europas einzusetzen. »Wo die Hände ineinander gelegt werden, um eine Kirche zu bauen, müssen auch die Herzen mehr und mehr zusammenfinden $\kappa^{68}$, hatte Kardinal Wendel 1954 bei der Einweihungsfeier der Speyerer Friedenskirche festgehalten. Das war eine bedeutende Hilfe für den europäischen Einigungsprozess, eine Hilfe, die von unten, gleichsam zivilgesell-

\footnotetext{
67 BRECHER, Bischof mitten im Volk, S. 94, 99, $128 \mathrm{f}$.

68 Isidor Markus Emanuel, Predigt bei der Jubiläumswallfahrt auf Maria Rosenberg am 9. September 1979, in: 25 Jahre Friedenskirche St. Bernhard Speyer. Gedenkschrift zum Jubiläum und zur Altarweihe 1979, hg. vom Katholischen Pfarramt St. Bernhard, Speyer 1980, o. S.
} 
schaftlich angeregt und organisiert wurde und deshalb in die Breite wirken konnte. Und das zu einem Zeitpunkt, als die Politiker noch viel mehr in nationalen Kategorien dachten und ein offizielles Dokument der Freundschaft zwischen Deutschen und Franzosen, wie es dann 1963 der Elysée-Vertrag wurde, noch weit entfernt war ${ }^{69}$.

69 Zum Elysée-Vertrag und seinen Vorbedingungen siehe Corine DEFrANCE / Ulrich PFEIL (Hg.), Le traité de l'Elysée et les relations franco-allemandes 1945-1963-2003, Paris 2005. 


\section{Public Religion in post-Christian Europe: Some English Examples}

\section{Religious practice and public religion}

Given that Britain has two established churches and 26 bishops of one of these - the Church of England - still sit in the upper house of the British parliament, the House of Lords, people might be forgiven for assuming that public religion in Britain is especially prominent. Yet this is far from the case: most British people are not actively religious and appear to take little interest in religious matters. Increasing numbers have little awareness either of Christianity or, for that matter, of any of the other world religions represented in Britain. Although statistics about religious affiliation are never easy to interpret, it is difficult to read the data in any other way than as evidence of a significant detachment from religion among most of the population ${ }^{1}$. In a report commissioned by the Evangelical relief agency Tearfund ${ }^{2}$, which was based on a statistically significant survey of 7,000 adults, the question was asked: »Do you regard yourself as belonging to any particular religion «? In response, about 53 per cent of the population claimed to »belong' in some sense to Christianity (about 26.2 million adults), and about a further six per cent to other religions (about 3.2 million). This number was broadly similar to a range of other reports, including the Government's British Social Attitudes Survey. According to the Tearfund survey, fifteen per cent of adults attended church at least once a month (7.6 million), with a further three per cent (1.6 million) going at least six times per year. Another seven per cent (3.4 million) attended at least once a year. Again, numbers were broadly in line with the 2005 English Religious Census conducted by Christian Research on 8 May 2005 which estimated that

1 A slightly different interpretation of similar statistics is offered by Adam DiNHAM / Vivien Lowndes, Faith and the Public Realm, in: Adam Dinham / Robert Furbey / Vivien Lowndes (Eds.), Faith in the Public Realm: Controversies, policies and practices, Bristol 2009, pp. 1-19; see also David HerBerT, Religion and Civil Society, Aldershot 2003, pp. 9 25. Some material in this section derives from my book Doing God: Religion and Public Policy in Brown's Britain, London 2008.

2 Jacinta ASHWORTH / Ian FARTHING, Churchgoing in the UK: A research report from Tearfund on church attendance in the UK, London 2007, at: http://news.bbc.co.uk/1/shared/bsp/hi/ pdfs/03_04_07_tearfundchurch.pdf 
there were 3,166,200 adults and children in church in England on that day or about $6.3 \%$ of the population ${ }^{3}$.

The Tearfund survey found that twenty-eight per cent of adults (13.7 million) claimed to have attended church at some time in the past but were unlikely to do so again (the »de-churched «). A further thirty-two per cent of adults (15.6 million) had never been to church in their life, except for weddings, baptisms or funerals (the »unchurched «). The conclusions which were drawn from the Tearfund survey were that about two-thirds of UK adults are $»$ secular in that they have no connection with church at present. The vast majority of these -29.3 million - are >closed to attending church in future (equivalent to 60 per cent of all adults) $\ll^{4}$. This is striking evidence for the loss of significant Christianity from the majority of the adult population of Britain.

The numbers attending the mainline churches have continued to drop rapidly. The two largest denominations have fallen to a weekly attendance of well below a million. The 2006 UK Church Survey estimated that there were 861,800 Roman Catholics attending church weekly compared with 852,500 Anglicans $^{5}$. The larger number of Catholics was accounted for by the significant numbers of new immigrants, particularly from Poland. The rate of regular churchgoing is also much higher among adults of black ethnic origin, and stands at over three times that of white adults. The 2005 UK Church Survey ${ }^{6}$ found that about ten per cent of all churchgoers were black, with forty-four per cent in inner London. Britain, it should be noted, is not significantly different from other European countries. The European Social Survey of 2002 found that about 18.6 percent of UK adults attended religious services at least once a month, which was broadly similar to Germany, the Netherlands, Belgium and Hungary, and higher than in France and Denmark?

While it is extremely difficult to estimate attendances in the past, given the lack of reliable statistics, it has been variously suggested that in 1851, at the time of the Census of Religious Worship, church attendance was at least

\footnotetext{
At: http://www.christian-research.org.uk (accessed 20 January 2009).

4 This is roughly in line with the latest figures from September 2007, where 43 per cent of the 1000 adults surveyed never attended church apart from funerals, baptisms and weddings. See http://www.cofe.anglican.org/info/statistics/orb2007churchpowattendance.pdf (accessed 29 April 2009).

5 In 2007, according to the Church of England's own statistics, there was a usual Sunday attendance of 868,000 (736,000 adults), and approximately 1,173,000 adults on Church of England electoral rolls (the closest equivalent to members of churches). See: http://www.cofe. anglican.org/info/statistics/2007provisionalattendance.pdf (accessed 23 December 2009).

6 At: http://www.churchsurvey.co.uk/?home (accessed 29 April 2009).

7 On this see Grace DAVIE, Religion in Modern Europe: A Memory Mutates, Oxford 2000, esp. ch. 1; and Europe: The Exceptional Case, esp. pp. 6-7.
} 
30-35 per cent ${ }^{8}$ and possibly as high as 61.5-65.1 per cent of the entire population'. Even if this lower figure is accepted this still means that there has been an enormous decline in the numbers of active churchgoers. Church membership in 1900 stood at approximately 27 per cent of the population compared to about 10 per cent in $2000^{10}$. Robin Gill, who has worked on churchgoing in the outer London suburb of Bromley, estimated that in 1903 about 31 per cent of the population was in church compared to about 10.5 per cent in $1993^{11}$. While all these figures are open to question, the evidence is incontrovertible. Something like two-thirds of the people of Great Britain have little if any attachment to a faith community. There is no evidence that attachment to new religions or »holistic spirituality « is likely to make up for the decline of Christianity ${ }^{12}$. Some see the future of religious affiliation as increasingly likely to become de-institutionalised, so that »being religious « will be little different from taking part in some sort of alliance for social justice (like Fair Trade or Climate Change) ${ }^{13}$. For the most part, then, religion is either private or non-existent, and Britain is a secular society.

Despite this - and in apparent contradiction - in recent years religion has become so central to many aspects of public policy that it simply cannot be ignored. It looms large in many recent policy discussions ${ }^{14}$. Particularly after the atrocities of 11 September 2001 in New York and Washington, and even more so following the London bombings of 7 July 2005, which killed fifty-two commuters along with the four suicide bombers, religion - especially Islam - has seldom been off the political agenda. Questions of multiculturalism - and especially the way in which religion functions in forging cultural identity - have become far more urgent ${ }^{15}$. Was there an inevitable clash of civilisations as predicted in the popular Manichaean rhetoric of Samuel Huntington, which probably influenced the strange idea of a war on terror (recently disowned by the British Foreign Secretary, David Mili-

8 Callum Brown, The People in the Pews: Religion and Society in Scotland since 1780, Glasgow 1993, p. 7.

9 Steve BRUCE, God is Dead, p. 63.

10 Figures in Peter BRIERLEY, Religious Trends No. 1: 1999/2000, London 1999.

11 Robin GILL, Religion in Twentieth-century Kent, in: Nigel YATES (Ed.), Kent in the Twentieth Century, Woodbridge 2001, pp. 321-33.

12 See Paul Heelas / Linda WoodHead, The Spiritual Revolution: why religion is giving way to spirituality, Oxford 2005, and David VoAS / Steve BrUCE, The Spiritual Revolution: Another False Dawn for the Sacred, in: Kieran Flanagan / Peter C. JuPp (Eds.), The Sociology of Spirituality, Aldershot 2007, pp. 43-61.

13 Helen Cameron, Decline of the Church in England, in: Grace Davie [et.al.] (Eds.), Predicting Religion, Aldershot 2003, pp. 109-19, esp. p. 118.

14 See most recently Dinham, Faith in the Public Realm; Geoffrey Brahm Levey / Tariq Modood (Eds.), Secularism, Religion and Multicultural Citizenship, Cambridge 2009.

15 See Adam Dinham / Vivien Lowndes, Faith and the Public Realm; Robert FurbeY, Controversies of »public faith«, in: DINHAM, Faith in the Public Realm, pp. 21-40. 
band) ${ }^{16}$ ? Or was British society capable of providing a set of simple universal values capable of assimilating even those of other faiths? Or was the whole set of issues far more complex ${ }^{17}$ ?

In a country in which the chattering classes have tended to regard religion as a bit like sex - a private matter which should take place behind closed doors - the sort of militant political religion demonstrated in the terrorist outrages served as a rude awakening. Secular discourse, which had dominated British political life for so long and in which religion functioned as a purely private phenomenon, had little space for categorising public religion, even in its more benign forms. Whereas in the United States religious language has been used openly by politicians of all hues, and where it would be difficult to imagine an open atheist attaining highest office, British politicians have tended to avoid explicit religious language for a very long time ${ }^{18}$. As Alastair Campbell, Tony Blair's press officer once remarked, »We don't do God «19.

Given this dominant framework of secularism, the resurgence of public religion - especially Islam - is difficult to accommodate within the current political structures which are premised on a secularised world-view. As one of the leading commentators on British multiculturalism, Tariq Modood writes: »The emergence of Muslim political agency has thrown multiculturalism into theoretical and practical disarray $\ll^{20}$. Increasingly public (and political) expressions of religious and cultural identity, however, mean that what Modood calls an »active state policy of multiculturalism « which recognises the country as a »legitimate and irreducible plurality« or »community of communities « will become crucial ${ }^{21}$. In this lecture I draw on a couple of English examples to illustrate the problem.

16 Samuel P. Huntington, The Clash of Civilizations and the Remaking of World Order, New York 1996; David MiLIBAND in The Guardian, 15 January 2009 at: http://www.guardian. co.uk/commentisfree/2009/jan/15/david-miliband-war-terror (accessed 20 January 2009).

17 One of the best and most dispassionate accounts of the recent development of Islam in Europe is Philip JEnKINS, God's Continent: Christianity, Islam, and Europe's Religious Crisis, New York 2007.

18 On the differences between Europe and the United States, see Peter BERGER [et. al.], Religious America, Secular Europe? A Theme and Variations, Aldershot 2008; Grace DAVIE, Europe: The Exceptional Case: Parameters of Faith in the Modern World, London 2002.

19 See my Doing God.

20 Tariq ModoOD, Multiculturalism: A Civic Idea, Cambridge 2007, p. 85.

21 Ders., Multicultural Politics: Racism, Ethnicity and Muslims in Britain, Edinburgh 2007, p. 18. 


\section{Is Tower Hamlets in England?}

Let me begin by relating a visit to East London I made early in the New Year of 2009. I was an observer at the Tower Hamlets Inter-Faith Forum. The group comprised about twenty people representing the different religions and denominations of that extraordinarily diverse Borough. At the 2001 national census 38.6 per cent stated that they were Christian (about $75,000)$, and 36.4 per cent responded that they were Muslim (71,000 and over 10 per cent of all the Muslims in London) ${ }^{22}$. Tower Hamlets has the highest percentage of Muslims of any local authority in Britain ${ }^{23}$. Alongside these were roughly equal numbers of Buddhists, Jews and Hindus (between 1 and 0.8 per cent of the population). In addition, about 21 per cent either had no religion or did not answer the question. The Christian community itself is divided into 62 congregations, 22 of them Church of England, although there are a number of independent churches not listed and which have no buildings. The churches are varied ethnically with significant numbers of Christians from Africa and Eastern Europe. There are fifteen mosques and Islamic centres listed in the borough ${ }^{24}$. The largest number of Muslims by far are from a Bangladeshi background, although there is also a significant minority from Somalia, Algeria and Morocco.

The diversity of the Borough brings with it many tensions (as was apparent at the meeting of the Forum, where participants occasionally exhibited a degree of anger provoked by the conflict in Gaza). At the same time, however, the religious make up of the Borough also displays many fascinating examples of co-operation, not least at the level of education. In December 2008, for instance, The Times reported on a Church of England primary school in the Borough:

Three quarters of the children at St Paul's Whitechapel Church of England Primary School in East London are Muslim. They and the other pupils at the 200-strong school learn about Islam and have a weekly assembly taken by the local vicar. Darren Rubin, the deputy head, said the children were all excited about Christmas and about the Muslim festival of Eid ul-Fitr. »We work in a big Muslim community and what we look to do is celebrate that «, he said. »Seventy-five per cent of children will be off for Eid. They learn about all religions and their festivals. We have lots of children from different backgrounds and they all learn from each other«. Most parents at the

22 For statistics see: http://www.neighbourhood.statistics.gov.uk/dissemination/LeadTableView. do $? \mathrm{a}=3 \& \mathrm{~b}=276772 \& \mathrm{c}=$ tower + hamlets $\& \mathrm{~d}=13 \& \mathrm{e}=16 \& \mathrm{~g}=346968 \& \mathrm{i}=1001 \times 1003 \times 1004 \& \mathrm{~m}=0$ $\& \mathrm{r}=1 \& \mathrm{~s}=1261667252973 \&$ enc $=1 \&$ dsFamilyId=95 (accessed 24 December 2009).

23 See the Tower Hamlets Inter-Faith Forum, Draft Religion/Belief Equality Scheme, 2009 at: http://www.towerhamlets.gov.uk/idoc.ashx? (accessed 31 January 2009).

24 See Tower Hamlets Faith Directory at: http://www.faithintowerhamlets.com/default/1350.di rectory/index.htm. 
school are of Bengali origin and the school runs English classes for those whose second language is English. St Paul's selects on the basis of faith and gives priority to children whose parents attend the local church. It also gives preference, however, to pupils whose parents are of another faith and have chosen the school because of its religious tradition ${ }^{25}$.

Given its religious and ethnic make-up it is hardly surprising that Government policies on Community Cohesion and the creation of Local Strategic Partnerships should dominate the agenda of the Council in its dealings with the different faith communities. In early 2009 there was a lengthy discussion of how best »faith« might be represented on the different local area partnerships as they implement Government policies in the different neighbourhoods, particularly in relation to combating inequality of opportunity, as well as tackling religious and race hate crimes. This has led to the creation of the One Tower Hamlets programme. While there is much in the Government policies that is open to criticism (which I discussed in Doing $G o d)^{26}$, there is at the same time a sense of urgency, particularly in more straitened economic conditions, in working out how best to live together in what is also one of the poorest boroughs in the country ${ }^{27}$. Increased racial and religious unrest is always a possibility, and numbers of reported incidents, although not great, are nevertheless rising.

The day after I visited Tower Hamlets I spent ninety minutes or so with a well-known Labour Party politician with decidedly singular opinions from a gritty post-industrial north-western constituency. He asked me directly about how I found my visit to the Interfaith Forum: did I think, he asked, that I was in England when I went to Tower Hamlets? Could the borough really be described as English? These were interesting questions, even if they were also surprising. They resonated with another discussion of Englishness I had heard the day before when I had been to a House of Commons Committee hearing on the expansion of Aylesbury and Milton Keynes where one of the local Bedfordshire MPs, Nadine Dorries, had sung the praises of what she felt was the perfect English village of Aspley Guise:

It is a village made up of Tudor cottages; it was mentioned in the Domesday Book; it is surrounded by green-belt land; it is a chocolate-box village, which are traditional in England - the kind of village that one imagines when talking about the typical British

25 Alexandra FrEAN, Faith schools must give up religion as basis for selecting pupils, in: The Times, 5 December 2008 at: http://www.timesonline.co.uk/tol/comment/faith/article5289211. ece (accessed 20 January 2009).

26 Doing God. See also Alan BILLINGS' rather more anecdotal treatment of the same material, in: God and Community Cohesion: Help or Hindrance?, London 2009. On faith and public policy, see DiNHAM / LOWNDES, Faith and the public realm, pp. 1-20.

27 Tower Hamlets ranks third in the Index of Deprivation (2007). See http://www.commu nities.gov.uk/communities/neighbourhoodrenewal/deprivation/deprivation07/. 
village. It also has a unique, supportive and strong community. People in Aspley Guise very much identify themselves with the area and the village, and it is an honour to be a Member for a constituency with such a strong community.

Aspley Guise, which faced the admittedly frightening prospect of becoming part of Milton Keynes new town, has a population of about 2,400, with a Muslim population of six. Two other MPs at the hearing had expressed the fear that further expansion would not only disturb the tranquillity of the countryside, but also allow more migrants into the area. This, they claimed, would play into the hands of right-wing extremists like the British National Party ${ }^{28}$. At work in these very different contexts was a vision of a »supportive and strong community«, which expressed something of the nature of Englishness. For one MP, then, Englishness amounted to the working-class solidarity of industry and the values of old Labour and it was disturbed by those who did not abide by the English rules. For the other, Englishness was a vision of a picture postcard village, which would be threatened by expansion and migration.

Although neither MP mentioned it directly, the idea of Englishness was at least implicitly connected with a history in which Christianity and the church played a central role. For Mrs Dorries, supportive and strong communities had a homogeneity and a shared identity rooted in a tradition extending back to the Domesday Book, the survey of land across England in 1086. This historical background is obviously shaped profoundly by Christianity. How this sort of vision of Englishness relates to the multi-cultural setting of much of modern Britain, however, is far from clear: according to a number of MPs from the Buckinghamshire area, the influx of members of different faith communities into the new communities would simply fuel extremism as it challenged traditional ways of being English. Many migrants would presumably come from non-Christian backgrounds: after all, central Aylesbury itself has a relatively high density of Muslims (13.64\%), even if the rest of Aylesbury Vale District Council is fairly monocultural.

There is, of course, a whole range of policy issues that emerge from the co-existence of different faiths close by one another and which are especially relevant to the theme of public religion in modern Europe: two strands are particularly important. First is the practical issue of ensuring that the different groups live together in relative harmony, the problem of what has been called »community cohesion«. This has been the subject of much Government thinking at least since the so-called riots of the summer of

28 Hansard, 13 January 2009 at: http://www.publications.parliament.uk/pa/cm200809/cmhansrd/ cm090113/halltext/90113h0005.htm (accessed 20 January 2009). 
2001 in several northern cities, which led to a number of reports ${ }^{29}$. Second is the related issue of how multi-culturalism is connected to the shared identity implied in any concept of Englishness. In both of these strands the question of faith is of paramount importance: for many communities, faith will be the principal focus of identity and will be one of the major factors through which people are identified by others. At the same time, it is important to discern the extent to which Christian virtues are perceived to be central to English identity, and, if so, precisely how they might be constituted. The issues that emerge from these two strands, and which continue to inform the thinking of the Department for Communities, lead to a number of policy questions: to what extent do all residents, from whatever background, need to ascribe to a minimum set of »British « or English values? How far, and in what ways, should such values be determined by the Government? Should such values be maximised around a universally imposed system of citizenship to which all have to subscribe? Or should the values required for people to live together in relative tranquillity be reduced to the absolute minimum? Some have gone even further (including the Archbishop of Canterbury in his Royal Courts Lecture on sharia law in early 2008): how far should modern Britain champion and encourage diversity, even allowing different religious communities to administer a parallel legal system ${ }^{30}$ ?

\section{Communities}

The two strands do not sit easily together. On the one hand, much recent Government rhetoric has tended to equate religion with a sub-culture which sustains something called »community«, and which governments seek to utilise for the ends of social order and harmony, especially among the members of the new religious communities ${ }^{31}$. On the other hand, however, such an understanding may also promote a sense of belonging to a particu-

29 On Bradford, Herman Ouseley, Community Pride, Not Prejudice: Making Diversity Work in Practice, Bradford 2001; on Burnley, Anthony Clarke, Burnley Task Force Report, Burnley 2001; on Oldham, David RitchiE, Oldham Independent Review Panel Report, Manchester 2001; John Denham, Building Cohesive Communities: A Report of the Ministerial Group on Public Order and Community Cohesion, London 2001; and Ted CANTLE, Community Cohesion: A Report of the Independent Review Team Chaired by Ted Cantle, London 2001. at: http://image.guardian.co.uk/sysfiles/Guardian/documents/2001/12/11/communitycohesionrep ort.pdf (accessed 20 January 2009).

30 See Doing God, chs. 5 and 6.

31 I have traced the history of the concept of community in New Labour thought in Mark D. Chapman, But what is a Community? Ten years in the history of a New Labour Concept, in: Peter Manley SCOTT [u. a.] (Eds.), Re-moralising Britain?, London 2008, pp. 120-135. 
lar faith or ethnic group that is difficult to square with a historic sense of universal Englishness (or Britishness). The principal issue is that of community cohesion, of how the different religious and ethnic communities might be seen as belonging to a wider community. The relation of the particular to the universal becomes key to the problems of multiculturalism ${ }^{32}$.

The faith aspect of community cohesion creates extra problems, particularly as it relates to Christianity as the historic religion of England. There is something decidedly ironic in the fact that community cohesion policies, where religion is seen as perhaps the major factor in human identity, have emerged in a country which, as I have suggested, has one of the lowest overall levels of religious practice in the world, and where increasing numbers have little awareness of either Christianity or, for that matter, of any of the other world religions represented in Britain. Yet, at least since 2001 it has been impossible not to »do God«, even if most politicians have preferred to steer clear of answering questions about their own faith commitments. Religion simply could not be ignored, and neither could it be seen merely as a private matter. Militant religion was quite different from the sort of political religion which had been dominant through the twentieth century. This type had tended towards the benign support of the state, albeit with the occasional outburst: in general, and certainly in most of its Anglican guises, political religion was neither militant nor very religious. It was simply one aspect of what it was to be English. This is the sort of minimal religion exemplified by the influential 1970 Church and State report:

The people of England still want to feel that religion has a place in the land to which they can turn on the too rare occasions when they think that they need it; and they are not likely to be pleased by legislation which might suggest that the English people as a whole were going unChristian ${ }^{33}$.

This is probably about as undemanding an understanding of religion as one could imagine. And such state religion had very little space either for militant Christianity (as Valerie Pitt noted in her dissenting opinion) or for that matter for any other sort of militant religion. There was a profound difference between the residual Christianity embodied in the historic constitutional settlement maintained by the Church and State report, and what she regarded as the real religion of what might be called »traditioned belonging «. Indeed it is possible to see the Report as representing a kind of longing for a dying Christendom: Pitt sees such nostalgia as characterised by »folk memories of life in small, close-knit local communities - ways of life

\footnotetext{
32 On this, see also Maqsood AHMED [u. a.], Faith, multiculturalism and community cohesion: a policy conversation, in: DiNHAM, Faith in the Public Realm, pp. 83-104.

33 Church and State: Report of the Archbishops Commission, London 1970, p. 65.
} 
now outside the experience of millions $\aleph^{34}$. For some, then, even in 1970, Aspley Guise was not the universal understanding of Englishness.

Even though it is usually a tacit assumption, this longing for a universal Christian culture connected with a sense of Englishness shapes much recent political and religious rhetoric: it is undoubtedly behind the vague ideas of Englishness exemplified by both the MPs I cited. And it is little different from the ideals of Britishness (by which he means Englishness) which have been one of Gordon Brown's most often repeated themes (and which I have discussed at length in Doing God $)^{35}$. More recently John Sentamu has entered the debate on such shared values in his John Smith Lecture, »Regaining a Vision for Britain«. Although he criticises the centralisation of the Government's solutions to community cohesion, he nevertheless clamours after a »big vision « appropriate for the contemporary situation which is analogous to that which held sway during the years of the welfare consensus. After a lengthy introduction on William Temple and Christianity and Social Order, he moves on to discuss his thesis that in the depressed society of post-imperial Britain »we have lost our vision of what we are about «. Any solution requires a new vision based on a number of characteristics which have to be shared by all people. Without this there will be increased segregation (presumably something like the nightmarish vision of no-go areas popularised by both Trevor Phillips ${ }^{36}$ and Michael Nazir-Ali ${ }^{37}$ in recent years $)^{38}$. Although he does not discuss the contents of the »big vision « in much detail, Sentamu nevertheless suggests that the starting point for the big vision is the sort of inclusiveness implied by the Christian doctrine of seeing all people as created in the image and likeness of God. This should lead to a sense of fraternity and solidarity among all. The most important question of all is this: »how can I learn to live alongside and contribute to our common life in this community«? There is a stark choice between »dog eat dog « and the Scout's motto of duty to God, duty to the Queen and duty to neighbour ${ }^{39}$. While this may be true and it is certainly less nostalgic than most visions of Aspley Guise Englishness or Britishness, it seems to me

\footnotetext{
Church and State, p. 74.

Doing God, ch. 3.

36 Trevor PHILLIPS, After 7/7: Sleepwalking to Segregation (Speech given at Manchester Town Hall, 22 September 2005) at: http://83.137.212.42/sitearchive/cre/Default.aspx.LocID-0hgnew 07r.RefLocID-0hg00900c001001.Lang-EN.htm (accessed 20 January 2009).

37 Michael NAZIR-ALI, Extremism flourished as UK lost Christianity, in: Sunday Telegraph, 11 January 2008.

38 Many of the myths about migration are exploded by Nissa FinNEY / Ludi SIMPSON, Sleepwalking to Segregation? Challenging Myths about Race and Migration, Bristol 2009.

39 Regaining a Big Vision for Britain, 13 January 2009 at: www.archbishopofyork.org/2127 (accessed 20 January 2009).
} 
that a workable solution will probably need rather more than a scarf and a woggle, and it may bring with it a great deal of discussion and difficulty.

\section{The Clash of the Religious with the Secular: varieties of multiculturalism}

The problems of Britain are certainly not unique: other countries in Western Europe have significantly higher percentages of non-Christians, and sometimes similar issues have emerged, even though the solutions have been different. This means, as José Casanova has suggested in his groundbreaking book on public religion, that modern societies are experiencing what he has called a »deprivatisation « of religion ${ }^{40}$. Others have spoken of post-secularism ${ }^{41}$. Across Europe there has been a frequent clash between the »secular « and the religious. In the Netherlands, for instance, the policy towards Islam has until relatively recently been one of liberal toleration which has allowed minority communities to develop separately. This is an expansion of the historic »pillarized « approach which divided Dutch society, welfare and education between Protestants and Catholics ${ }^{42}$. The addition of a significant third force has been subject to much criticism since such an approach to multiculturalism failed to halt the rise of an anti-liberal and politicized form of Islam which culminated in the murder of the iconoclastic right-wing film-maker Theo van Gogh in 2004. The Dutch response has been to question the earlier policy of state-funding for minority schools and broadcasting (the so-called Minderhedennota) ${ }^{43}$. There have even been calls for repatriation of immigrants and asylum seekers. Liberal rational secularism is perhaps not quite so ingrained in Dutch society as its permissive sexual policies might imply. A lack of a common identity in a pillar-

40 This section is a revised version of sections from Doing God, ch. 1. José CaSANOva, Public Religions in the Modern World, Chicago 1994, pp. 211-34. See also Peter L. BERGER (Ed.), The Desecularization of the World: Resurgent Religion and World Politics, Grand Rapids 1999; and HERBERT, Religion and Civil Society, pp. 25-7.

41 See Gregor MCLennAN, Towards Post-secular Sociology, in: Sociology 41 (2007), pp. $857-$ 80 .

42 See Grace DAVIE, Sociology of Religion, London 2007, pp. 175-7. More generally see Geoffrey Brahm LEVEY, Secularism and religion in a multicultural age, in: Geoffrey Brahm LEVEY / Tariq Modood (Eds.), Secularism, Religion and Multicultural Citizenship, pp. 1-24.

43 See Welmoet BoEnder / Meryem KANMAZ, Imams in the Netherlands and Islam Teachers in Flanders, in: Wasf SHADID / Sjoerd VAN KONINGSVELD (Eds.), Intercultural Relations and Religious Authorities: Muslims in the European Union, Leuven 2002, pp. 169-80, esp. p. 171. 
ized society makes the project of building cohesive communities highly problematic ${ }^{44}$.

The example of France points to a completely different approach, which was exemplified in the headscarves controversy (»affaire de foulard «) in French state schools ${ }^{45}$. The anti-clerical and secular tradition of laïcité has made the conflicts especially heated and has led to a significant politicisation of religion ${ }^{46}$. What one commentator has called the "poorly framed « French law against symbols and clothing

through which [minority communities] exhibit conspicuously a religious affiliation stigmatises a small section of the population as un-French in a manner reminiscent of the Dreyfus Affair: it suggests the fundamental inability of large sections of the French media and government to adapt to the varied and complex cultural framework set in the processes of globalisation ${ }^{47}$.

While in itself the veil may have little significance in Islam and may well be relatively modern, it can quickly become a boundary marker, an expression of embodied and public spirituality among those occupying a marginal position. The veil becomes a marker of what has been called the »frontier body $\aleph^{48}$. It deliberately marks out »difference « rather than commonness and thus presents a challenge to the uniformity of the state. In response, the state (or even the public company like British Airways) is forced to eliminate the symbol through enforced secularism against any form of public religious expression. This will obviously mean that religion will be treated as a private matter by the state even when it is regarded as a public matter by its adherents. In some cases such an approach to multi-culturalism can easily lead to further marginalisation, retrenchment, and radicalisation among minorities ${ }^{49}$.

44 Interesting comparisons can be made with Belgium. See Karel DobbelaERE, Two Different Types of Manifest Secularization: Belgium and France Compared, in: Eileen BARKER (Ed.), The Centrality of Religion in Social Life, Aldershot 2008, pp. 69-82.

45 See Paul Chambers, Contentious Headscarves: Spirituality and the State in the Twenty-First Century, in: Flanagan / JuPp (Eds.), The Sociology of Spirituality, pp. 127-43.

46 See Jean-Paul Willaime, The Paradoxes of Laïcité in France, in: Eileen BARKER (Ed.), The Centrality of Religion, pp. 41-54.

47 Sharif GEMIE, Stasi's Republic: the school and the »veil«, December 2003-March 2004, in: Modern and Contemporary France 12 (2006), pp. 387-97, here p. 395.

48 Philip A. MelloR / Chris SHILling, Re-forming the Body: Religion, Community and Modernity, London 1997.

49 Tariq Modood, Multiculturalism: A Civic Idea, Cambridge 2007, pp. 75-8. 


\section{Conclusion}

The alternative to such models is to engage seriously with pluralism with a far less explicit secularist agenda. In general, British multi-cultural policy has moved in this direction, although frequently it has maintained a covert secularism which has continued to regard religion and cultural identity as something essentially private. After reading through whole swathes of Government literature, it seems to me that implicit in much recent Government thinking has been a general acceptance of the need to embrace a degree of pluralism: the idea of a public ethnic and religious identity as the primary focus for belonging, especially among the marginalised, has been accepted as something of a commonplace. This move, which is a radical departure from the liberal model of privatised religion, is even regarded as desirable as it builds up solidarity and the common good. Similarly, the importance of the »community« and »neighbourhood « as a place for making policy and taking decisions has been widely recognised. Yet at the same time there are powerful forces which make pluralism difficult to put into practice. The long tradition of centralised decision-making and economic prudence implemented through target-driven managerialism continue to prevent the development of a pluralist yet cohesive society. As I have suggested elsewhere $^{50}$, this centralism has led to the stifling of participatory democracy at the local level.

At the same time, however, the Aspley Guise issue will not go away. The questions are these: what is the shared identity between the different groups which is required for a functioning society? What are the values (e.g. Englishness) which bind people of different communities and groups together? Or to put it differently: can Tower Hamlets be described as being in any meaningful sense in England? Are they real English »hamlets « but just rather different from those prettier versions in rural Bedfordshire? Gordon Brown has sensed something of the need for shared values in many of his speeches both before and after his appointment as Prime Minister, but there is a vagueness and somewhat nostalgic nationalism in many of his utterances. Nevertheless it is crucial that the limits of pluralism have to be defined to ensure that freedoms are protected. As Modood writes:

the plural state, unlike the liberal state, is able to offer an emotional identity with the whole to counterbalance the emotional loyalties to ethnic and religious communities, which should prevent the fragmentation of society into narrow, selfish communal-

50 See Blair's Britain: A Christian Critique, London 2005, esp. ch. 6. 
isms, while the presence of these strong community identities will be an effective check against monocultural statism ${ }^{51}$.

There are many ways in which this balance between pluralist and unified systems might be attempted. The French and Dutch versions seem to me to lack either plurality or commonality. At the same time the solutions which rest on a return to the values of the chocolate box village community, or the solidarity of heavy industry both seem at best impractical hankerings after a long dead past, and at worst ciphers for rampant xenophobic nationalism. Instead, a cohesive pluralist community might be something based on perpetual dialogue rather than premature foreclosure. It is the talking itself that becomes central. This is simply because, except in a very vague and probably ultimately pointless way, it is probably impossible to find many mutually shared universal values in a country as complex as modern Britain. While many communities claim universality and a vision of truth which would dismiss all others, the very fact of plurality forces a degree of coexistence. All those who wish to share the same space are required to think seriously about the nature of truth and how it can co-exist with other interpretations and visions.

This modest option resembles what Rowan Williams calls »interactive pluralism $\aleph^{52}$, and is not far from Anthony Giddens's idea of »sophisticated « as opposed to »naïve« multiculturalism. It resists simple categorization of ethnic and religious identity, but allows for a plurality of identities to coexist on the basis of government-promoted mutual respect. The minimum rules are laid down for negotiations to happen, but there is little sense in which the state itself provides the core of cultural identity. Many will no doubt choose to regard themselves simply as British or English or Welsh or Scottish, and identify with the dominant historical myths and traditions. But many will choose not to do so, and will hold more complex identities which depend on a whole range of ethnic and religious factors. What is key is that the state provides structures whereby these different identities can be held together ${ }^{53}$, Indeed, working out the necessary pragmatic principles for such a society to function seems to me to be one of the key roles for government and it may be most important in those places where the minorities are very small (as in Aspley Guise or in the particular town in the post-industrial northwest represented by the MP who asked me the question of whether I thought Tower Hamlets was in England).

51 Multicultural Politics, p. 140.

52 See my essay, Rowan Williams's Political Theology: Multiculturalism and Interactive Pluralism, in: Journal of Anglican Studies (forthcoming, 2010).

53 Anthony Giddens, Over to You, Mr Brown, Cambridge 2007, chapter 7. See also, SEN, Identity and Violence, p. 158-65. 
This means that the principal issue in modern multicultural politics is less that of finding shared values than that of providing structures so that people can learn to live with others who are in some ways different but also in some ways the same. This is what might be referred to as a form of »patriotism « which amounts to little more than a commitment to respect one another and to negotiate with one another despite cultural and religious differences. ${ }^{54}$ This, I think, is the cash value of much of the talk about Britishness and citizenship. The minimum requirement is to let others co-exist, even when they might disagree profoundly, provided that there is a mutuality of respect (as with the Tower Hamlets Interfaith Forum). In order for such a policy to work, it might at times be necessary for government action to restrain those who clamour for singular identity at the expense of others (including fundamentalists). Going much further, however, and providing too many positive values (what we might call »Aspley Guise Englishness«) seems both pointless and unnecessarily conflictual, especially for those whose historical identity is based on not being "British « in that way. What Giddens imagines instead is what he calls »acceptance of a common overall identity as members of a national community, as a >community of fate <that is, being bound by laws and collective decisions that affect everyone $\Sigma^{55}$, That may well be what citizenship - another recent concept in British politics - is really about. Britain (and any other country for that matter) is where people happen to live and it is best for them if they learn to live together with one another in relative peace and tranquillity. Community cohesion will then be founded on the »weak social capital« of democratic governance based on coming together to make decisions at the local level - and faith, as in Tower Hamlets, will obviously be for many a key feature in such decision making ${ }^{56}$, The local is where people live and engage with others. It is also where religious people principally express their faith. And for most of the time it is probably where governments most need to devote their energies. If the local changes, even modestly, then so will the nature of what it means to be English - even in Aspley Guise.

In post-Christian England, religious practice is likely to remain a minority activity: but it would be wrong to assume either that it can be relegated to the private and ignored or contorted into a vague universal "golden rule« religion. For this significant minority, religious belonging is likely to be one of the most important aspects of human identity and far more important than alternative national myths summarised in concepts of citizenship of

54 On this, see Charles TAYLOR, Multiculturalism: Examining the Politics of Recognition, Princeton 1994.

55 GidDENS, Over to You, Mr Brown, p. 156.

56 Sue Goss, Re-imagining the public realm, in: Gerry HASSAN (Ed.), After Blair: Politics after the New Labour Decade, London 2007, pp. 107-19, esp. pp. 114-15. 
Englishness. Furthermore, it is highly likely that such forms of religion will be expressed publicly. That being the case there is a need to understand the complexity and contested nature of religious, ethnic, national and global identities in the plethora of local communities that make up modern Britain. Speaking Bengali may not help much in Aspley Guise, where most people may still understand themselves as vaguely Christian, but it will be crucial in Tower Hamlets, where most people do not. 


\section{Risto Saarinen \\ Die neuesten Soziallehren der Kirchen und ihr europäisches Umfeld}

Das Ende des Kalten Krieges vor zwanzig Jahren hat viele europäische Kirchen vor neue Herausforderungen gestellt. Einerseits hat das Ende des osteuropäischen Kommunismus neue Möglichkeiten für die Kirchen und für die freie Ausübung der Religion eröffnet. Andererseits ist die Säkularisation in vielen europäischen Ländern mit größerer Geschwindigkeit fortgeschritten und hat die Kirchen zunehmend zu Marginalien der Gesellschaften werden lassen.

Darüber hinaus hat sich die globale Entwicklung der 1990er Jahren für die ethische Meinungsbildung der Kirchen sowie für ihre traditionelle Soziallehre als problematisch erwiesen. Die neue Ära der Globalisierung hat die Sozialethik vieler Kirchen überholt. Die protestantischen Kirchen sind traditionell auf besondere Weise mit der Perspektive des Nationalstaats verbunden und konnten in vielen Fällen die neue multiethnische und multireligiöse Wirklichkeit nicht verstehen. Die orthodoxen Kirchen Osteuropas haben ebenfalls den neuen und teilweise auch alten Nationalismus ihrer Herkunftsländer an die internationale Entwicklung anknüpfen müssen.

Für die historische und kirchengeschichtliche Forschung hat das Ende des Kalten Krieges in Europa viele interessante Themen angeboten. Es ist bekanntlich schwierig, die allerjüngste Geschichte zu verstehen. Mehrere größere Forschungsprojekte haben trotzdem diesen Schritt schon gewagt. Die folgende Berichterstattung basiert auf dem Projekt »Churches and European Integration«, das zwischen 2001 und 2004 von dem Forschungsdirektorat der Europäischen Kommission finanziert wurde' ${ }^{1}$. Meines Wissens war dies das erste theologische Projekt, das mit Forschungsmitteln der Europäischen Union finanziert wurde, sowie eins der ersten geisteswissenschaftlichen Projekte überhaupt.

Das Projekt wurde gemeinsam von fünf europäischen Fakultäten durchgeführt. Neben der Theologischen Fakultät von Helsinki (Aila Lauha und Risto Saarinen) waren die Katholisch-Theologische Fakultät Münster (Thomas Bremer), die Theologischen Fakultäten von Lund (Anders Jarlert)

\footnotetext{
1 Für dieses Projekt im Detail siehe Hugh MCLEOD [u. a.], North European Churches from the Cold War to Globalisation, Tampere 2006. Die Vorträge der Schlusskonferenz des Projekts wurden in Kirchliche Zeitgeschichte 1/2006 veröffentlicht.
} 
und Tartu (Riho Altnurme) sowie das Historische Institut der Universität Glasgow (Nicholas Hope) daran beteiligt. Mit den Projektmitteln wurden vor allem kirchengeschichtliche Doktorarbeiten und Habilitationsschriften finanziert, die mit dem Ende des Kalten Krieges und mit der kirchlichen Dimension der europäischen Integration zu tun hatten ${ }^{2}$. Die von mir unterstützten finnischen Doktorandinnen, Pauliina Arola und Riikka Reina, untersuchten die neuesten Entwicklungen der kirchlichen Soziallehren; meine folgende Darstellung basiert weitgehend auf ihrer Forschungsarbeit ${ }^{3}$.

Für meine Darstellung habe ich drei neue kirchliche Stellungnahmen gewählt: eine evangelisch-lutherische, eine orthodoxe und eine katholische Soziallehre. Es ist einerseits wichtig, den zeitgeschichtlichen Hintergrund dieser Stellungnahmen zu berücksichtigen; andererseits kann ich den jeweiligen Kontext sowie die Rezeption der Dokumente nur kurz und generell beleuchten.

\section{Finnland: Das gemeinsame Gute}

Das erste Beispiel betrifft meinen eigenen Kontext, nämlich die evangelisch-lutherische Kirche Finnlands. Für die finnische Gesellschaft bedeutete das Ende des Kalten Krieges in vielen Hinsichten eine Befreiung und eine neue Westorientierung. Obwohl Finnland während des Kalten Krieges die Marktwirtschaft, die Reisefreiheit und die westliche Orientierung behalten konnte, mussten die Politiker die guten Beziehungen in Richtung Osten, das heißt: Sowjetunion, stets beachten. Ab Anfang der 1990er Jahren war diese politische Vorsicht nicht mehr notwendig und Finnland konnte sich an die westeuropäischen Strukturen anpassen. Finnland wurde im Jahre 1995 Mitglied der Europäischen Union und hat unter den ersten Ländern die neue europäische Währung, den Euro, angenommen.

Die Kehrseite der politischen Freiheit und der westlichen Orientierung war aber eine tiefe wirtschaftliche Depression. In den 1970er und 1980er Jahren haben die Finnen vor allem Konsumwaren in die Sowjetunion exportiert und sehr preiswerte Energie importiert. Dieser bilaterale Handel kam um das Jahr 1990 unerwartet zu seinem Ende, und Finnland musste danach für alle importierte Energie mit westlicher Währung bezahlen. Die

2 Siehe North European Churches, S. 109-135. Ein Beispiel ist die Diss. von Heiko Overmeyer, Frieden im Spannungsfeld zwischen Theologie und Politik. Die Friedensthematik in den bilateralen Gesprächen von Arnoldshain und Zagorsk, Frankfurt 2005.

3 Siehe Riikka ReInA, Piispat Lutherin sosiaalietiikan jäljillä, Magisterarbeit, Helsinki 2000, sowie Pauliina Arola, Towards the Common Good: Social Responsibility, Globalisation and the Evangelical Lutheran Church of Finland, in: Kirchliche Zeitgeschichte 1/2006, S. 199-218. 
Jahre von 1990 bis 1995 waren von einer tiefen Depression und Finanzkrise geprägt.

In der zweiten Hälfte der 90er Jahre kam Finnland langsam und schrittweise aus der Krise, vor allem mit Hilfe des Elektronikherstellers Nokia, der die entstehenden Mobiltelefonmärkte rasch eroberte und sich zur ersten wirklich globalen finnischen Firma entwickelte. Bis zur Jahrtausendwende war aber die Arbeitslosigkeit ein großes Problem geblieben und die Globalisierung und die neoliberale Marktwirtschaft wurden von vielen als sehr negative Entwicklungslinien kritisiert.

Im Jahr 1999 haben die lutherischen Bischöfe Finnlands eine grundlegende Soziallehre veröffentlicht, mit deren Hilfe die Erfahrungen der Rezession, Globalisierung und EU-Mitgliedschaft bewältigt und verarbeitet wurden. Diese Soziallehre hat eine sehr breite Öffentlichkeit gefunden; sie wurde monatelang in den größten Tageszeitungen lebhaft diskutiert. Die meisten Parteien und leitenden Politikern haben, bisweilen ganz leidenschaftlich, dazu Stellung genommen ${ }^{4}$. Um diese Debatte verstehen zu können, müssen die kirchengeschichtlichen Hintergründe Finnlands kurz beleuchtet werden.

Zur finnischen evangelisch-lutherischen Kirche gehörten damals und gehören immer noch über $80 \%$ aller Finnen. Mehr als $90 \%$ aller geborenen Kinder werden getauft und im Alter von 15 Jahren konfirmiert $^{5}$. Während des gesamten 20. Jahrhunderts war die Staatskirche gegen Kommunismus und Sozialismus eingestellt. Im Zweiten Weltkrieg hat die Kirche dem finnischen Staat eine eminent wichtige moralische Unterstützung im Krieg gegen die Sowjetunion gegeben. Die traditionelle Zwei-Reiche-Lehre des Luthertums hat nie eine innere Krise in Finnland erlebt, sondern die Politiker wie die Kirchenleiter haben diese Lehre als angemessene Arbeitsteilung zwischen Kirche und Staat aufgefasst. Die finnischen Kommunisten waren traditionell kirchenfeindlich, aber die Sozialdemokraten, die von den 1960er Jahren bis heute als größte Partei fast ununterbrochen in der Macht geblieben sind, sind relativ kirchenfreundlich oder wenigstens neutral gegenüber der Kirche. Das politische Profil der Kirche war allerdings bis in die 1990er Jahre antisozialistisch und konservativ. Die Sozialdemokratische Partei hatte bis zu den 1990er Jahren in Finnland kaum kirchlichen Einfluss

4 Kohti yhteistä hyvää, Helsinki 1999 (die Seitenzahlen in Klammern beziehen sich auf diese Ausgabe, deutsche Übersetzungen von mir). Auf Englisch zugänglich in www.evl.fi/english/ towardscg.htm . Über die Rezeption siehe REINA, PIISPAT und Seija PARVIAINEN, Piispojen luterilainen sosiaalietiikka globaalitalouden paineessa, in: Kansantaloudellinen aikakauskirja 95 (1999), S. 353-372.

5 Vgl. Risto SAARINEN, Die Evangelisch-Lutherische Kirche Finnlands, in: Michael PLATHOW (Hg.),Lutherische Kirchen, Göttingen 2007, S. 111-124. 
gehabt. Dagegen waren viele Pfarrer und kirchliche Aktivisten in der Konservativen Partei sowie in der Agrarpartei tätig.

In englischer Übersetzung heißt die Soziallehre von 1999 Towards the Common Good; vielleicht kann man den Titel auf Deutsch einfach als Das gemeinsame Gute wiedergeben. Das Dokument enthält einerseits eine Analyse der neuen globalen Situation und diskutiert die damit verbundenen ethischen Probleme. Andererseits gibt das Dokument theologische Richtlinien für eine bewusst lutherische Ethik, die anhand der kirchlichen Lehre und Tradition die konkreten Handlungsanweisungen begründet.

Die Situationsanalyse betrachtet die globale Wirtschaft als ein Spielfeld des Neoliberalismus. Wenn das Kapital sich frei bewegen kann, haben die Nationalstaaten keine demokratischen Mittel, womit sie die Finanzen und Märkte kontrollieren können. Die Nationalstaaten stehen im Wettbewerb miteinander, um das frei bewegende Kapital als Investitionen in das Land locken zu können. Die Bischöfe sind der Meinung, dass eine solche Freiheit des Kapitals ethisch nicht verantwortlich ist. Sie glauben, eine demokratische Kontrolle der Märkte sei notwendig. Eine gerechte Marktwirtschaft braucht Regelungen und Kontrolle. Die Bischöfe benennen den anglosächsischen Liberalismus als eine grundlegend problematische Bestimmung der menschlichen Freiheit. Eine echte Freiheit der Bürger kann nicht in der Freiheit der Märkte bestehen, sondern sie entsteht durch die demokratische Regelung der Märkte. Die Globalisierung wird im Dokument kritisiert, weil sie die soziale und gerechte Marktwirtschaft nicht respektiert (21-29).

Diese Analyse der Gesellschaft und der Globalisierung zeigt viele Ähnlichkeiten mit den deutschen evangelischen und katholischen sozialethischen Dokumenten aus denselben Jahren ${ }^{6}$. Sowohl die finnischen als auch die deutschen kirchlichen Mahnschreiben befürworten die soziale Marktwirtschaft und verhalten sich kritisch zur Globalisierung. Die theologische Begründung der finnischen Soziallehre benutzt aber andere Prämissen als die deutschen Schriften.

Den ethischen Ausgangspunkt des finnischen Dokuments bildet eine Auslegung der Goldenen Regel der Reziprozität: »Alles nun, was ihr wollt, dass euch die Menschen tun sollen, das tut ihnen auch!« Diese Goldene Regel ist »die gemeinsame ethische Grundlage der gesamten Menschheit«. Diese Regel ist nicht kulturell bedingt, sondern überschreitet die kulturellen Kontexte. Die Regel der Reziprozität eignet sich sowohl für die altäglichen Probleme als auch für die komplexen ethischen Fragen der Gegenwart.

6 Z. B. mit dem Text: Für eine Zukunft in Solidarität und Gerechtigkeit. Wort des Rates der Evangelischen Kirche in Deutschland und der Deutschen Bischofskonferenz zur wirtschaftlichen und sozialen Lage in Deutschland, 1997. (Dieser Text ist als Broschüre und im Internet erhältlich). 
Obwohl sie biblisch begründet ist, ist ihre Gültigkeit mit der natürlichen Vernunft für alle Menschen offenbar (15-16).

Die Bischöfe lehren aber, dass die Goldene Regel häufig falsch verstanden worden ist:

Die Goldene Regel sagt nicht, dass wir einander das tun sollen, was uns selber am besten gefällt. Sie lehrt, dass wir uns an die Stelle des Anderen stellen sollen. Die Regel lehrt uns zu fragen, was wir für uns selber wünschen, wenn wir in der tatsächlichen Situation des Anderen wären. Das moralisch rechte Handeln setzt also voraus, dass wir uns an die Stelle des Anderen einfühlen und seine/ihre Situation als unsere Situation verstehen. Die lutherische Deutung dieser Regel betont, dass insbesondere die Situation der Schwächeren und Bedürftigen so verstanden wird (15-16).

Diese Auslegung der Goldenen Regel leitet die Bischöfe zur Hervorhebung einer Gemeinschaft, in der das gemeinsame Gute eine Priorität gegenüber dem individuellen Guten hat:

Die ökonomischen Ziele eines Individuum haben eine Grenze in der Gemeinschaft. Die Ziele eines Menschen müssen im Rahmen der Ziele aller anderen Menschen beurteilt werden. Ebenfalls sollen die Vorteile und Ziele einer Gesellschaft im Rahmen der Vorteile und Ziele anderer Gesellschaften überlegt werden, und ebenso die Vorteile eines Kontinents im Rahmen des globalen Wohlstandes(16).

Die finnischen Bischöfe verbinden diese Auffassung mit zwei Prinzipien der lutherischen Reformation. Das sogenannte Kommunions- oder Gemeinschaftsprinzip sagt, dass eine Stadt oder eine Gesellschaft das gemeinsame Gute fördern soll. Durch die Anwendung der Goldenen Regel soll eine solche Gemeinschaft das individuelle Gute im Rahmen des gemeinsamen Gutes auffassen. Insbesondere soll das Gute der Schwächeren und Hilfsbedürftigen sorgfältig überlegt werden. Das sogenannte Obrigkeitsprinzip betrachtet die Mehrheit der Menschen als grundlegend egoistische Akteure. Die Obrigkeit soll durch Gesetze und Machtausübung diesen Egoismus begrenzen, indem sie die Distribution der Güter durch Gesetze und ihre exekutive Macht regeln. In diesem Sinn fördert die Obrigkeit das gemeinsame Gute und benutzt die Richtlinien der Goldenen Regel. Die christliche Nächstenliebe motiviert zu diesem Verhalten (39-41). Aber es ist eindeutig, dass die Bischöfe vor allem anhand der natürlichen Vernunft und der gesunden Urteilskraft ihre Argumente präsentieren wollen. Die Argumente, die mit Hilfe der Goldenen Regel formuliert worden sind, sollen auch für die Nicht-Christen gute Argumente sein.

Diese globalisierungskritische Soziallehre widerspiegelt die neue gesellschaftliche Situation Finnlands nach vier Jahren Mitgliedschaft in der Europäischen Union. Zugleich setzt sie die lange nordeuropäische Linie einer solchen Sozialethik fort, in der die natürliche Vernunft und das sogenannte weltliche Regiment sehr stark präsent sind. Wenn die Bischöfe die 
gesellschaftliche Diskussion mitgestalten wollen, sollen sie nach diesem Ansatz nicht anhand des Evangeliums oder des Glaubensgehorsams argumentieren, sondern mit Hilfe des gesellschaftlichen Gebrauchs des Gesetzes, das durch die natürliche Vernunft allen zugänglich ist. Die Kraft solcher Argumente sollte auch den Nicht-Christen einleuchten. Der argumentative Gebrauch der Goldenen Regel bietet eine Brücke von der Verkündigung Jesu in die Sphäre der gemeinsamen ethischen Überlegung.

Die bischöfliche Argumentation zeigt im Weiteren Ähnlichkeiten mit der Gerechtigkeitstheorie von John Rawls, die in den 1990er Jahren in Nordeuropa eine politische Modeerscheinung war. Nach dieser Theorie sollten die gerechten Lösungen der gesellschaftlichen Probleme durch ein Spiel simuliert werden, in dem die Teilnehmer nicht wissen, welche partikuläre Rolle ihnen selber zukommt in der simulierten Gesellschaft. Nach Rawls werden in solcher Simulation die Grundrechte der Schwächeren ernst genommen, weil alle Menschen die Rolle der Schwächsten vermeiden wollen. So werden in einer idealen demokratischen Gesellschaft nach Rawls Schutzmechanismen aufgebaut, die die Unterdrückung von schwächsten Mitgliedern verhindern. Lutherische Sozialethiker haben die Theorie von Rawls mit der lutherischen Soziallehre verglichen?.

Für die kirchengeschichtliche Betrachtung ist aber die Rezeption des finnischen Dokuments von größtem Interesse ${ }^{8}$. Die politische Rezeption des Dokuments wurde für die öffentliche Diskussion ausschlaggebend. Die Politiker der Rechtsparteien - konservative und Agrarpartei - fühlten sich von der Kirche kritisiert. Traditionell hatte die finnische Volkskirche die Politik dieser Parteien unterstützt und gegen den Sozialismus und Kommunismus argumentiert. Jetzt aber hatte die Globalisierungskritik der Bischöfe viele Ähnlichkeiten mit der Rhetorik der Sozialdemokraten und anderen linksorientierten Politikern. Eine offenbare Parallele für die finnischen Rechtspolitiker war die Gesellschaftskritik der anglikanischen Bischöfe, wie sie gegen die konservative Regierung von Margaret Thatcher in den 1980er Jahren formuliert wurde. Die finnischen Konservativen wollten sich aber gar nicht mit dem anglosächsischen Neoliberalismus identifizieren, sondern sie fühlten sich auch als Befürworter der Grundrechte und der sozialen Sicherheit. Deswegen waren sie mit der Situationsbeschreibung der finnischen Bischöfe nicht zufrieden und argumentierten, dass die wirtschaftliche Krise Finnlands nach dem Kollaps der Sowjetunion überhaupt nichts mit der Globalisierung zu tun hatte und erst recht nicht mit dem

7 John Rawls, A Theory of Justice, Cambridge 1971. Für den theologischen Gebrauch von Rawls siehe Svend ANDERSEN, Power from Love: Reconstructing a Lutheran Political Ethics, Berlin / New York 2010.

8 Für das Folgende siehe ParviaInEn, Piispojen. 
altmodischen Sozialismus geheilt werden konnte. Viele Kritiker haben auch unterstrichen, dass die Bischöfe die Dynamik der Marktwirtschaft überhaupt nicht verstünden und nur den Sozialstaat der Vergangenheit nostalgisch restaurieren wollten.

Die Sozialdemokraten und sogar einige ehemalige Kommunisten haben aber das Dokument sehr positiv rezipiert. In dem sozialdemokratischen Lob für die finnischen Bischöfe erreichte eine neue geschichtliche Entwicklung ihren Kulminationspunkt. Paradoxerweise waren die Jahre der Rezession für die finnische Kirche eine sehr erfolgreiche Zeit. Die diakonische Arbeit der Kirche hatte kräftig zugenommen und viel weniger Menschen sind aus der Kirche ausgetreten als in den 1980er Jahren. Der lutherische Bischof von Helsinki, Eero Huovinen, leitete die sogenannte nationale Hungergruppe, die mit den Sozialdemokraten die Richtlinien der Sozialpolitik während der Rezession gestaltete. Der neue sozialdemokratische Staatspräsident, Martti Ahtisaari, war ein kirchlich engagierter Mensch, der seine internationale Karriere im Lutherischen Weltbund begonnen hatte. Der sozialdemokratische Premierminister Paavo Lipponen wurde während seiner Amtszeit demonstrativ wieder Mitglied der lutherischen Kirche.

Wegen diesen Entwicklungen war es politisch verständlich, dass die konservativen Parteien fühlten, dass jetzt auch die Kirche sich an die Seite der Sozialdemokratie gestellt hatte. Allerdings war das Dokument der Bischöfe wahrscheinlich weniger politisch motiviert und versuchte, vor allem eine bewusst lutherische Stellungnahme zu brennenden sozialethischen Fragen zu sein. Pauliina Arola betont die Zusammenhänge zwischen der Goldenen-Regel-Ethik einerseits und der finnischen Lutherinterpretation andererseits, für die die natürliche Vernunft, ziviler Gebrauch des Gesetzes und die Betonung von Billigkeit (aequitas) wichtige Richtlinien sind. Nach Arola folge die Globalisierungskritik der Bischöfe nicht in erster Linie dem Programm der Sozialdemokratie, sondern sie benutzt die traditionellen Argumente der Billigkeit, mit deren Hilfe der menschliche Egoismus in Grenzen gehalten wird?.

Obwohl das finnische Dokument vielleicht eher theologisch als politisch interpretiert werden soll, ist es auch wahr und kirchengeschichtlich äußerst bedeutsam, dass das Dokument in einer Zeit erschien, als die Volkskirche und die Sozialdemokratische Partei einander auf neue Weise gefunden haben. Das gemeinsame Gute ist das wichtigste kirchengeschichtliche Dokument, das die neue Nähe dieser zwei finnischen Machtzentren sichtbar macht. Die finnische Kirche hat die theologische Begründung ihrer Soziallehre aus ihrer eigenen Tradition des Luthertums geschöpft, aber es ist trotzdem kein Zufall, dass das Dokument ein sozialdemokratisches Profil

9 AROLA, Towards. 
hat. Das europäische Umfeld Finnlands in den 1990er Jahren war einerseits stark durch die neue europäische Westorientierung geprägt. Aber zugleich hat die wirtschaftliche Depression zur Folge gehabt, dass die Menschen eine neue Sicherheit in der Kirche und in der sozial betonten Marktwirtschaft suchten. Deswegen ist das finnische Dokument von 1999 auch ein Zeichen des Zeitgeistes, der sich gegen die Globalisierung und die neoliberale Wirtschaft stellte.

Dieser Trend hat sich in Finnland bis heute in vielen Hinsichten fortgesetzt. Der heutige Vize-Vorsitzende der Sozialdemokratischen Partei Finnlands, Dr. Ilkka Kantola, ist ein ehemaliger lutherischer Bischof und einer der Verfasser des Dokuments Das gemeinsame Gute. Der damalige sozialdemokratische Präsident Ahtisaari hat nach seiner Amtszeit ein FriedensVerhandlungsbüro gegründet und wurde im Jahr 2008 mit dem FriedensNobelpreis ausgezeichnet.

\section{Russland: Orthodoxe Soziallehre}

Das zweite Beispiel bewegt sich in geographischer Nähe von, aber trotzdem in großer gesellschaftlicher Distanz zu Finnland. Es handelt sich um die umfassende Soziallehre der Russischen Orthodoxen Kirche, die im Bischöflichen Jubiläumssynod des Moskauer Patriarchats im August 2000 verabschiedet wurde. Diese Soziallehre ist in der Forschung schon ausführlich behandelt worden; eine deutsche Übersetzung erschien $2001^{10}$.

Die orthodoxen Kirchen hatten früher nie eine offizielle Soziallehre veröffentlicht; schon deswegen ist das russische Dokument äußerst interessant. Das Dokument ist auch sehr ausführlich - es umfasst über 100 Seiten im Druck und nimmt Stellung zu den meisten modernen ethischen Probleme, vom Klonen bis zum Alkoholismus, von der Kriegsethik bis zur Schweigepflicht der Priester in den Fällen von Terrorismus. Als Quelle der normativen Ethik der Orthodoxen Kirche ist das Dokument einzigartig. Darüber hinaus ist es zeitgeschichtlich ergiebig als Zeugnis des großen Umbruchs, den die russische Kirche nach dem Ende des Kommunismus durchschritten hat.

10 Die Grundlagen der Sozialdoktrin der Russisch-Orthodoxen Kirche, Sankt Augustin 2001. Erhältlich in www.kas.de. Die Seitenzahlen in Klammern beziehen sich auf diese deutsche Ausgabe. Siehe auch Pauliina Arola / Risto SAARINEN, In Search of Sobornost and New Symphony: The Social Doctrine of the Russian Orthodox Church, in: The Ecumenical Review 54 (2002), S. 130-141, sowie Jennifer WASMUTH, Sozialethik in der russisch-orthodoxen Kirche der Gegenwart. Die >Grundlagen der Sozialkonzeption` in kritischer Betrachtung, in: Evangelische Theologie 64 (2004), S. 37-51. 
Auf den ersten Blick macht das Dokument einen kasuistischen Eindruck, weil es viele hunderte normative Stellungnahmen zu den verschiedensten konkreten ethischen Fragen bietet. Offenbar haben neben Bischöfen auch viele Juristen, Philosophen und Mediziner an der Arbeit teilgenommen. Trotz der Fülle von Details sind die normativen Schlussfolgerungen nicht immer ganz eindeutig. Zum Beispiel verbietet das Dokument zuerst das Klonen von Menschen kategorisch. Sofort danach wird aber festgestellt:

Nichtsdestoweniger stellt das Klonen isolierter Zellen und organischer Gewebe keinen Angriff auf die Würde der Persönlichkeit dar und erweist sich in der biologischen und medizinischen Praxis in zahlreichen Fällen als geeignet (78).

Der Eindruck entsteht, dass das Dokument nur das Klonen eines gesamten Menschen verbietet, nicht aber das Klonen einzelner Teile und Organe.

Hinter der Kasuistik sind zwei theologische Prinzipien am Werk. Als erstes Prinzip erscheint der sogenannte Sobornost, die pneumatische Wirklichkeit der christlichen Gemeinschaft, die die säkulare Welt so transformiert, dass sie eine neue Schöpfung wird. Im Anschluss an den russischen Religionsphilosophen Khomjakov argumentiert die Soziallehre, die Kirche sei »die Vollkommenheit der Göttlichen Gnade, die in der Vielzahl der vernünftigen, der Gnade untergebenen Geschöpfe lebt«. Als solche gottmenschliche Wirklichkeit ermöglicht die Kirche »die gnadenreiche Umwandlung und Reinigung der Welt, die sich in der Geschichte in schöpferischem Zusammenwirken von Gliedern und Haupt des Leibes der Kirche vollziehen«. Das Dokument sagt im Weiteren, dass die Christen aktiv an der weltlichen Arbeit der Gesellschaft teilnehmen sollen. Diese Teilnahme soll aber

vom Verständnis getragen sein, dass die Welt, die Gesellschaft und der Staat Gegenstände der Göttlichen Liebe sind, da sie für die Umwandlung und Reinigung nach den Grundsätzen der gottgebotenen Liebe bestimmt sind (2).

Der Gedanke von Sobornost geht also nicht von einer Autonomie der weltlichen oder gesellschaftlichen Organe aus, sondern ihm zufolge sind die weltlichen Strukturen auch Gegenstände der pneumatischen Umwandlung. Folglich versucht das Dokument nicht, anders als die finnische Soziallehre, vernünftige Argumente für die Nicht-Christen bieten, sondern es erläutert die theologische Dimension der Gesellschaft im Lichte des Glaubens. Wichtig in dieser Auffassung ist, dass die Transformation einerseits von der Kirche pneumatisch ausstrahlt, dass aber andererseits das gesamte Leben des Christen in allen Sphären theologisch bedeutsam ist. Die weltlichen Strukturen sind nicht säkular, autonom und erst recht nicht teuflisch, sondern bilden im Gegenteil einen Teil der Einwohnung des göttlichen Geistes in der Welt. So liefert der Gedanke von Sobornost ein holistisches Bild von der Welt. Die Christen sollen nicht von der Welt isoliert leben, sondern 
sie sollen das Werk des Geistes in allen Bereichen der Gesellschaft wahrnehmen.

Weil die transformative Kraft von der Kirche ausstrahlt, hat die Kirche für die Christen eine Hegemonie und Priorität gegenüber den Institutionen der Welt. Die starke Betonung dieser Hegemonie verwirrt leicht einen westeuropäischen Protestanten, der solche Rhetorik als arrogant und selbstzufrieden interpretiert. Für die Russische Kirche bedeutet diese Rhetorik aber eher eine Bejahung und Konsolidierung der alten Rolle der Kirche in der Gesellschaft.

Das zweite theologische Grundprinzip ist die sogenannte Symphonie, das harmonische Zusammenspiel von Kirche und Staat in einer orthodoxen Gesellschaft. Kirche und Staat sollen zusammenarbeiten und einander respektieren. Letzten Endes hat die Kirche dem Staat gegenüber Priorität, da die Kirche die Quelle des Geistes und das Licht der Welt ist, aber in der konkreten Wirklichkeit unterstützt die Kirche die Machthaber des Staates und betrachtet deren Machtausübung als Teil des transformativen Prozesses. Nach dem Leiden der Kirche unter dem Joch des Kommunismus mag eine solche Staatstreue merkwürdig erscheinen, aber das Prinzip der Symphonie ist uralte orthodoxe Lehre, die aus Byzanz stammt ${ }^{11}$. Im Vergleich mit dieser langen Tradition waren die Jahrzehnte des Kommunismus nur eine relativ kurze Störung des symphonischen Verhältnisses zwischen Kirche und Staat.

Die Macht und der Einflussbereich des Staates werden im Dokument ausführlich erläutert. Es wird öfters gesagt, dass der Staat nicht absolutisiert werden soll und dass die Kirche eine gewisse Autonomie gegenüber dem Staat braucht. Zugleich wird aber das byzantinische Modell der Symphonie betont. Das Wesen der Symphonie besteht

in gegenseitiger Zusammenarbeit, Unterstützung sowie Verantwortung unter Nichteinmischung in die jeweiligen, ausdrücklich vorbehaltenen Kompetenzbereiche. ... In den symphonischen Beziehungen zur Kirche sucht der Staat ihre moralische Unterstützung, ihr Gebet für sich selbst und ihren Segen für die Tätigkeit zugunsten des Ziels der Wohlfahrt der Bürger, während die Kirche ihrerseits der Förderung des Staates erfreut (12).

Die Grundprinzipien von Sobornost und Symphonie bilden zusammen ein gesellschaftliches Programm, das im Dokument als »christlichen Patriotismus « dargestellt wird. Dieses Programm basiert auf dem territorialen Denken, dem gemäß eine Kirche und ein Staat auf demselben Territorium legitim tätig sein können. Dieser Einsicht zufolge ist der legitime weltliche Partner der Kirche weder irgendeine Gruppe von Menschen noch die glo-

11 Siehe z. B. Wolfhart Pannenberg, Systematische Theologie, Bd. 3, Göttingen 1993, S. 519521. 
bale Gemeinschaft, sondern vor allem der souveräne Nationalstaat. Das Dokument definiert den Inhalt des Patriotismus wie folgt:

Der Patriotismus des orthodoxen Christen soll tätig sein. Er äußert sich in der Verteidigung des Vaterlands gegen den Feind, in der Arbeit zum Wohle der Heimat, im Einsatz für das öffentliche Leben, einschließlich der Teilnahme an den Angelegenheiten der Staatsverwaltung. Der Christ ist dazu aufgefordert, die nationale Kultur und das nationale Selbstbewusstsein zu wahren und weiterzuentwickeln. Wenn die Nation - bürgerlich oder ethnisch - vollständig oder überwiegend eine monokonfessionelle orthodoxe Gemeinschaft ist, kann sie in gewissem Sinne als einheitliche Glaubensgemeinschaft betrachtet werden - als orthodoxes Volk (7).

Zugleich wird aber vor übertriebenem Nationalismus und Xenophobie gewarnt.

Es ist offenbar, dass das Hauptgewicht der russischen Soziallehre auf die Restauration der Kirche und des nationalen Gefühls zielt. Aus dieser Perspektive sollen auch die Richtlinien zur Internationalisierung und Globalisierung verstanden werden. Das Dokument übt starke Kritik an der Globalisierung; trotz verschiedener Ausgangspunkte ist diese Kritik nicht selten den Einsichten der finnischen Bischöfe ähnlich. Die Macht der transnationalen Korporationen wird im Dokument kritisiert; wie die Finnen, so wollen die Russen auch eine weltweite Kontrolle der Korporationen und des Finanzsektors verwirklichen (98-102). Wie diese Kontrolle konkret aussehen soll, wird allerdings weder von den finnischen noch den russischen Bischöfen ausgeführt.

Interessanterweise begründen auch die Russen ihre Globalisierungskritik mit der Goldenen Regel: »Das christliche Ideal des Verhaltens der Völker und Regierungen im Bereich der internationalen Beziehungen ist in der >Goldenen Regel enthalten « (96). Aus dieser Regel leitet das Dokument das Recht auf Selbstverteidigung und der gerechten Teilung von Gütern ab, aber auch das Streben nach Frieden, die gegenseitige Hilfe und die Zusammenarbeit zwischen den Staaten. Es ist offenbar, dass die Grundeinheit des Staates und des Volkes für die internationalen Beziehungen maßgebend bleiben soll. Die Souveränität des Staates und die Unversehrtheit seines Territoriums werden von der Kirche betrachtet als »grundlegend bei der Verteidigung der berechtigten Interessen des Volkes sowie als Eckstein zwischenstaatlicher Verträge« (97).

Auf diese Weise ist die Soziallehre der russischen Kirche im Grunde genommen nostalgisch und restaurativ. Das Dokument beabsichtigt, den alten Nationalstaat mit seinen relativ monokulturellen und monoreligiösen Bürgern wiederherzustellen. Die Globalisierungskritik soll vor diesem grundlegenden Horizont verstanden werden. Wenn wir den weiteren Verlauf der Geschichte bis heute in Russland betrachten, so ist die russische Kirche den 
Vorgaben dieser Soziallehre gefolgt. Die engen Beziehungen zum Staat und das Aufblühen des Patriotismus sind von der Kirche bis heute kräftig unterstützt worden. Neue theologische Entwicklungen sind aber auch sichtbar geworden, die gewissermaßen ihren Hintergrund in dieser Soziallehre haben. So haben russische Theologen zum Beispiel das westliche Verständnis der Menschenrechte kritisiert, da es angeblich sehr individualistisch konzipiert worden ist und die Rolle der Gemeinschaft und der pneumatischen Umwandlung nicht beachtet ${ }^{12}$. Die weitere Entwicklung der russischen Soziallehre ist allerdings noch nicht sichtbar, denn es ist andererseits auch offenbar, dass die Fragen der Modernität zunehmend rezipiert werden, auch wenn sie zugleich kritisch behandelt werden. Wegen des starken ökonomischen Aufschwungs in Russland hat auch das Moskauer Patriarchat erneut eine globale und leitende Rolle in der weltweiten Orthodoxie eingenommen, allerdings nicht ohne Konflikte mit dem Patriarchat von Konstantinopel. Die griechischen Theologen und mediterranen Patriarchate haben aber meines Wissens keine vergleichbare Soziallehre entwickelt.

\section{Europäischer Katholizismus: Globale Ordnung}

Mein drittes und letztes Beispiel bewegt sich im Rahmen des gesamteuropäischen Katholizismus. Die Kommission der Bischofskonferenzen in der Europäischen Gemeinschaft, die sogenannte COMECE, hat im Jahre 2001 ein ausführliches Experten-Dokument veröffentlicht mit dem deutschen Titel Global Governance - unsere Verantwortung, Globalisierung für alle eine Chance werden zu lassen ${ }^{13}$. Diese katholische Expertengruppe wurde vom ehemaligen Generaldirektor des Internationalen Währungsfonds, Michel Camdessus, geleitet. Die Gruppe bestand aus Ökonomen und EUBeamten sowie aus Theologen, die für die Bischofskonferenz arbeiteten.

Schon der Titel des Dokumentes macht deutlich, dass diese Gruppe ein positives Verhältnis zum Phänomen der Globalisierung hat. Zugleich will die Gruppe bewusst von den christlichen Werten ausgehend Richtlinien für die europäische Integration und zur Behandlung der globalen Probleme an die Hand geben. Die Menschenwürde ist das erste ethische Grundprinzip der Gruppe. Sie gibt die grundlegenden Rechte für das Individuum und verpflichtet zur Wahrhaftigkeit vor den ethischen Fragen. Als zweiten

12 Im April 2006 publizierte das Zehnte Weltkonzil des Russischen Volkes eine »Russische Deklaration der Menschenrechte«. Im Sommer 2008 veröffentlichte die Russische Orthodoxe Kirche einen Text zu den Menschenrechten: »Grundlagen der Lehre der ROK über Würde, Freiheit und Rechte des Menschen«. Beide Texte sind im Internet in vielen Sprachen erhältlich.

13 Brüssel 2001/2002. Erhältlich auch in www.comece.org. Im folgenden werden die Paragraphen des Textes in Klammern gegeben. 
Grundwert nennt die Gruppe die Solidarität, die anhand der päpstlichen Enzykliken als Partizipation ohne jede Marginalisierung der Menschen beschrieben wird. Auch der dritte Grundwert von Subsidiarität ist aus der katholischen Soziallehre entnommen. Weil das Dokument die weltweite Verwaltung und die Globalisierung behandelt, ist die Subsidiarität ein besonders komplex ethisches Prinzip. Einerseits bedeutet Subsidiarität für die Arbeitsgruppe, dass die Rolle der lokalen und nicht-öffentlichen Organisationen von besonderer Wichtigkeit ist ( $\$ 25-43$ ).

Andererseits stellt die Gruppe auch im Zusammenhang der Subsidiarität fest, dass die internationalen Organisationen ihre Legitimität von den nationalen Regierungen erhalten. Diese Tatsache sollen die nationalen Organe erkennen, damit die Rolle der internationalen Organisationen wahrheitsgemäß gesehen wird:

Allzu oft werden die internationalen Institutionen als nicht rechenschaftspflichtig und als technokratisch dargestellt. Tatsächlich sind sie faktisch den Regierungen ihrer Mitgliedsländer gegenüber verantwortlich und rechenschaftspflichtig. Das eigentliche Problem ist, dass dies nicht gesehen wird. Ein Grund für diese mangelnde Transparenz ist die Tatsache, dass die Regierungen nicht gerne preisgeben, welche Rolle sie bei internationalen Entscheidungsprozessen spielen. Zum einen berufen sie sich auf ihre Pflichten gegenüber der Völkergemeinschaft, um unpopuläre Maßnahmen in ihrem Land zu rechtfertigen. Zum anderen ernten sie gerne selbst die Lorbeeren für Erfolge. Dies trägt zu einem oft verzerrten Bild internationaler Organisationen in der Öffentlichkeit bei (§41).

Auf diese Weise verteidigt das Dokument die Arbeit der globalen Organisationen. Diese Arbeit erhält ihre Legitimität durch eine Art von Subsidiarität, nämlich durch die nationalen Regierungen. Diese Tatsache wird aber oft verdunkelt, weil die Regierungen ambivalent handeln: einerseits werden sie Mitglieder der globalen Organisationen, andererseits wird die globale Ebene oft zu einem Sündenbock der bestehenden Probleme gemacht. Auf diese Weise verhält sich das Dokument zur Globalisierung grundlegend anders als unsere zwei anderen Texte. Während die Finnen und die Russen die transnationalen, globalen Organisationen als problematisch einstufen, sehen die katholischen Experten das grundlegende Problem eher in den nationalen Interessen der Regierungen. Es ist merkwürdig, dass eine solche Feststellung gerade im Kontext der Subsidiarität gemacht wird. Normalerweise wird das Prinzip der Subsidiarität eingeführt, um die Verdienste - und nicht den Missbrauch - der lokalen Ebene hervorzuheben. Im Dokument wird die Legitimität der weltweiten Ordnung durch subsidiäre staatliche Akteure hergestellt, aber zugleich sind diese Akteure für die globalen Fehler eigentlich verantwortlich. 
Trotz dieses Unterschieds bietet die ausführliche Analyse der katholischen Spezialisten auch viele Punkte, in denen eine Einigkeit mit unseren anderen Dokumenten festgestellt werden kann. Ein wichtiger gemeinsamer Nenner besteht in dem Bedarf nach einer globalen politischen Kontrolle der Märkte. Die katholische Gruppe konstatiert einerseits, dass die neue Freiheit der Märkte und die globale Distribution der Güter nicht rückgängig gemacht werden kann. Aber sie betont auch andererseits, dass eine demokratische Ordnung diese Entwicklungen weltweit steuern sollte. Das Dokument gibt im Weiteren Empfehlungen darüber, wie eine solche Ordnung konkret aussehen sollte. In vier verschiedenen administrativen Stufen kann eine globale Ordnung sichtbar werden. Erstens werden die sogenannten NGOs, die Nichtregierungsorganisationen, zu solcher Arbeit herausgefordert. Die Kirchen und religiösen Gemeinschaften gehören zu dieser Gruppe. Von den Kirchen konstatiert das Dokument:

Die Kirchen und anderen Religionsgemeinschaften können sich selbst und ihre Mitglieder über die globalen Herausforderungen informieren und zur Übernahme von Verantwortung aufrufen. Das Thema globale Ordnungspolitik muss in Bildungs- und katechetischen Programmen behandelt werden. Die Kirchen könnten die Frage der globalen Ordnung zum Thema des ökumenischen und interreligiösen Dialogs machen (§ 45).

Wie schon dieses Zitat zeigt, bleiben die Hinweise auf die NGOs relativ allgemein und zeigen eine gewisse Entfremdung von der konkreten Wirklichkeit der betreffenden Organisationen. Zweitens soll die Arbeit der Vereinten Nationen unterstützt und erweitert werden. Auch die Arbeit anderer internationalen Organisationen soll gestärkt werden. Drittens werden die Nationalstaaten als die allerwichtigsten Akteure angesprochen. Die Nationalstaaten tragen letzten Endes die Hauptverantwortung der politischen Kontrolle der globalen Entwicklungen (§ 47-49).

Viertens schlägt das Dokument vor, dass die Nationalstaaten neue weltweite Organisationen zur Bildung der globalen Ordnung gründen sollen. Eine entscheidende Rolle in dieser Ordnung sollte der sogenannten Global Governance Group obliegen:

Die Verfasser des vorliegenden Berichts empfehlen daher als Ergänzung der derzeitigen G7/G8-Struktur die Schaffung einer Global Governance Group (3G), die sich beispielsweise aus denjenigen 24 Regierungschefs der Staaten zusammensetzen könnte, die satzungsgemäß mit Direktoren in den Leitungsgremien des Internationalen Währungsfonds (IWF) und der Weltbank vertreten sind. [...] Die Global Governance Group würde jährlich einen Gipfel zu wirtschaftlichen, sozialen und umweltpolitischen Fragen abhalten und ihre Entscheidungen auf der Basis des Konsenses treffen. Sie würde als Aufsichtsinstanz fungieren und ein Mindestmaß an Kohärenz, Koordination und Konsens unter den internationalen Institutionen sicherstellen (§ 66). 
Diese kühne Skizze der weltweiten Ordnung stammt wahrscheinlich nicht in erster Linie aus der Kommission der Katholischen Bischofskonferenzen, sondern sie widerspiegelt die politischen Pläne, die besonders nach den Terroristenakten von 11. September 2001 in den sogenannten G8-Ländern entworfen wurden. Es ist aber interessant und merkwürdig, dass die Europäische Katholische Bischofskonferenz in ihrer Dokumentation diese Art von Weltpolitik sich zu Eigen macht. Die herkömmlichen Prinzipien der katholischen Soziallehre - Menschenwürde, Solidarität und Subsidiarität steuern also nicht in erster Linie lokale und regionale Ordnungen, sondern aus diesen Prinzipien wird eine neue globale Ordnung abgeleitet.

Die katholischen Bischöfe rezipierten das Dokument im Jahr 2001, aber die Arbeit der Gruppe hat sich in den letzten Jahren fortgesetzt. Die Gruppe hat den Bischöfen jährliche Berichte über das Wachsen der globalen Organisationen gegeben. Die Erwartungen der Arbeitsgruppe sind besonders stark mit der Zusammenarbeit von G8-Ländern verbunden; die katholischen Experten erwarten sogar, dass die G8-Gipfeltreffen sich wirklich zu Organen der neuen Weltordnung entwickeln. Zum Beispiel konstatiert der Bericht dieser Gruppe aus dem Jahre 2006, dass globale Erwartungen an den G8-Ländern gestellt werden und dass katholische Kirche deswegen mit dieser Gruppe zusammenarbeiten soll ${ }^{14}$. Die Berichte der katholischen Spezialisten sind einerseits bürokratisch und in ihrem Verlangen nach einer neuen globalen Ordnung sogar weltfremd, aber zugleich sind sie über die verschiedenen Entwicklungsprozesse in der EU und in der Welt ausgezeichnet informiert. Die fachliche Kompetenz dieser katholischen Gruppe und die Konkretheit ihrer Vorschläge sind viel höher als in den meisten protestantischen und orthodoxen Dokumenten.

\section{Fazit: Europäische Hoffnung}

Oben sind drei Dokumente zur christlichen Sozialehre aus der Zeit um die Jahrtausendwende kurz beschrieben worden. In allen Dokumenten spielt das europäische Umfeld eine erhebliche Rolle. Im finnischen Dokument hat die EU-Mitgliedschaft und die neue Westorientierung des Staates die Kirche fast paradoxerweise zu einer neuen Nähe zur Sozialdemokratie ge-

14 Global Governance Assessment 2006 (www.comece.org ): »[...] expectations will again turn to the G8 process which over time may take a more structured approach to its work, as well as acquiring a more legitimate composition. Still far from being the Global Governance Group that the initial COMECE report proposed, it should nevertheless have the potential to develop in that direction. For this reason the Catholic Church might be well advised to follow the G8's work more closely and in a more coordinated way«. - Eine ausführliche Sammlung von jährlichen Dokumenten findet sich in www.comece.org. 
bracht. Im russischen Dokument geht es um die Restauration einer Großmacht und ihrer Nationalkirche, die eine Gegenbewegung zur Globalisierung repräsentieren möchte. Im katholischen Experten-Dokument wird die europäische Integration auf eine solche Weise fortgesetzt, die eine neue globale Politik-Ordnung sichtbar zu machen versucht.

Obwohl die drei behandelten Dokumente kulturell, konfessionell und auch politisch voneinander verschieden sind, haben wir auch einige Gemeinsamkeiten festgestellt. In allen Dokumenten kommt die Nähe der Kirche zur Staatsmacht überraschend stark zum Vorschein. In anderen Kontexten haben die heutigen Kirchen oft gegen die Staatsmacht Stellung genommen und ein Gegengewicht zur säkularen Politik zu bilden versucht. Zum Beispiel hat sich die Ökumenische Bewegung oft gegen die politische Macht ausgesprochen, ebenfalls die amerikanischen Kirchen gegen die Politik der Bush-Regierung und der Vatikan gegen die säkularistische Politik vieler Staatsregierungen. In ihrer heutigen Soziallehre werden die einzelnen Kirchen vor ein schwieriges Dilemma gestellt: wenn sie als Protestbewegungen oder als alternative Gemeinschaften auftreten, werden die Kirchen leicht marginalisiert und von den Politikern nicht ernst genommen. Wenn die Kirchen überhaupt politischen Einfluss haben wollen, sollen sie in der Nähe der Staatsmacht ihre Position präsentieren.

In Finnland fühlten sich die konservativen Parteien von den Bischöfen verlassen, aber die Soziallehre der finnischen Bischöfe war in vielen Hinsichten mit der Politik der größten Regierungspartei, den Sozialdemokraten, einig. Nicht nur deswegen, aber auch deswegen konnte sie eine große Resonanz in der finnischen Öffentlichkeit finden. Die Nähe des Moskauer Patriarchats zur russischen Regierung ist im neuen Russland heute beinahe selbstverständlich. Mit dieser Strategie kann die orthodoxe Kirche ihre Stellung in der Gesellschaft konsolidieren und zugleich für die konservativen christlichen Werte plädieren. Die Mehrheit der Russen teilt solche Werte nicht ${ }^{15}$, aber sie wollen sich trotzdem mit der Kirche als Kulturträger identifizieren. Die katholischen Bischöfe, die in Moralfragen oft gegen ihre Gesellschaft predigen müssen, finden andererseits in der Europäischen Union eine Organisation, die die Prinzipien der katholischen Soziallehre einigermaßen rezipiert. Auf diese Art treten die Kirchen in allen drei Dokumenten als staatstreue Organisationen auf.

Es bleibt natürlich zu fragen, ob diese Art von Staatsnähe und sogar Staatstreue für die Kirchen letzten Endes nützlich ist. Wenn zum Beispiel

15 Dieses Urteil ist basiert auf neuen religionssoziologischen Studien, z. B. Maija TuRUNEN, Faith in the Heart of Russia: the Religiosity of Post-Soviet University Students, Helsinki 2005. An der Universität Helsinki werden diese Entwicklungen von dem sogenannten Aleksanteri Institute untersucht, siehe www.helsinki.fi/aleksanteri/english/index.html. 
die katholische Soziallehre zum Instrument einer neuen Weltordnung wird, die in den Gipfeltreffen der G8 oder G20-Ländern strukturiert und konsolidiert wird, verliert sie leicht ihren christlichen Inhalt und wird zum säkularen Machtinstrument. Zugleich ist es aber wenigstens kirchengeschichtlich bedeutsam, dass die Kirchen in der heutigen Gesellschaft keineswegs nur als marginalisierte Gegenstimmen auftreten. Meine drei Beispiele zeigen deutlich, dass die Kirchen auch heute in einem lebendigen Dialog mit der Staatsmacht bleiben. In diesem Sinn hat die christliche Soziallehre auch im Europa des 21. Jahrhunderts eine hohe Relevanz.

Eine zweite Gemeinsamkeit zwischen den drei Dokumenten besteht darin, dass die Existenz der Nationalstaate immer noch die allerwichtigste sozialethische Tatsache für die Kirchen bleibt. Für Finnland und Russland ist dies ganz deutlich, aber auch die katholischen Experten denken, dass die Nationalstaaten letzten Endes die größte politische Verantwortung über die globalen Entwicklungen tragen sollen. Alle drei Dokumente plädieren dafür, dass die Globalisierung anhand der Politik der Nationalstaaten gesteuert werden soll.

Die dritte Gemeinsamkeit zwischen den drei Dokumenten hängt mit der zweiten zusammen. Obwohl das finnische und russische Dokument eher globalisierungskritisch, das katholische Dokument aber globalisierungsfreundlich ist, sind alle drei Soziallehren hinsichtlich der politischen Steuerungsmechanismen eigentlich überraschend einig. Keiner empfiehlt Neoliberalismus und alle drei wollen globale Kontrollorgane einrichten. Die Einigkeit in diesem Punkt ist signifikant, denn es wäre durchaus denkbar, dass eine Kritik an transnationalen Korporationen auch eine Kritik an globalen Kontrollorganen einschließen könnte. Die europäischen Kirchenleiter denken aber offenbar, dass eine globale Kontrolle möglich und sogar empfehlenswert ist. Im Gegensatz dazu glauben zum Beispiel die amerikanischen Kommunitaristen, dass globale Systeme immer einen totalitären Anspruch haben und dass eine echte Demokratie nur regional und in relativ kleinen Gemeinschaften genuin bestehen kann ${ }^{16}$. Die Probleme der Globalisierung können dem kommunitären Ansatz zufolge nicht mit einer neuen globalen Ordnung gelöst werden, denn eine solche Ordnung wäre eine noch schlimmere Form von Globalisierung.

Indem alle drei Soziallehren an eine globale Kontrolle optimistisch glauben, die mit Hilfe von Nationalstaaten erreicht werden kann, sind sie profiliert europäische Soziallehren. Die amerikanischen und Dritte-Welt-An-

16 Siehe zum Beispiel Kurt SeElmann (Hg.), Kommunitarismus versus Liberalismus?, Stuttgart 2000. Unter den heutigen christlichen Kommunitaristen sind vor allem Alasdair MacIntyre und Stanley Hauerwas zu nennen. Für eine kritische Beurteilung solcher Positionen siehe Jeffrey Stout, Democracy and Tradition, Princeton 2004. 
sätze sind eher pessimistisch veranlagt hinsichtlich dieser Möglichkeit und plädieren für regionale Lösungen. Im Unterschied zu solchem Pessimismus glauben europäische Denker und Kirchenführer an die demokratische Staatsmacht und entwerfen ihre Gesellschaftstheorie als globale Ordnung. Die Hoffnung nach einer weltweiten, gerechten und demokratischen Ordnung ist somit eine typisch europäische Denkweise, eine europäische Hoffnung. 


\title{
Kirchliche Arbeit auf europäischer Ebene: Strukturen und Erfahrungen
}

\begin{abstract}
Einleitung
Bevor auf das eigentliche Thema, die COMECE, eingegangen wird, soll ein sehr kurzer Überblick gegeben werden über Strukturen der katholischen Kirche auf der Ebene der EU, um gleichsam den Rahmen anzudeuten und abzustecken, in dem die COMECE handelt. Dieser Überblick folgt der zeitlichen Entstehung dieser Einrichtungen.

Die ersten Jahre des europäischen Einigungsprozesses standen im Zeichen der Errichtung eines gemeinsamen Marktes, obschon die Gründungsväter - Robert Schuman, Alcide de Gasperi und Konrad Adenauer - den politischen Integrationsprozess, das geeinte Europa, als Reaktion auf die Zerstörung Europas durch zwei mörderische Kriege »visionär und beharrlich « als das große Ziel betrachteten. Im Vorfeld der Unterzeichnung der Römischen Verträge 1957 wurde der inhaltliche Diskurs über das künftige »Europa« intensiver.

Ein Jahr vorher, 1956, eröffneten die Jesuiten auf katholischer Seite die kirchliche Präsenz am Sitz der Europäischen Gemeinschaft, und zwar mit der Gründung eines »Katholischen Sekretariats für europäische Fragen« (CIDSE). 1970 nahm der Apostolische Stuhl diplomatische Beziehungen auf zu den »Europäischen Gemeinschaften «. 1971 errichteten die Bischofskonferenzen in Europa - im Gefolge des II. Vatikanischen Konzils (1965) den »Rat der Europäischen Bischofskonferenzen« (CCEE, Consilium Conferentiarum Episcoporum Europae). Knapp zehn Jahre später (1980) errichteten die Bischofskonferenzen in den Ländern der Europäischen Gemeinschaften die »Kommission der Bischofskonferenzen der Europäischen Gemeinschaft« (COMECE, Commissio Episcopatuum Communitatis Europensis).

1972 hatten die evangelischen, anglikanischen und orthodoxen Kirchen in Europa die »Europäische Ökumenische Kommission für Kirche und Gesellschaft « (EECCS) errichtet, die 1999 in »Kommission für Kirche und Gesellschaft« der Konferenz Europäischer Kirchen (KEK) umbenannt wurde.

Zurück zu den katholischen Initiativen: Bis zur Gründung der COMECE hatten neben den Jesuiten auch die Dominikaner, die Salesianer, die Franziskaner und andere Ordensgemeinschaften je ein Büro in Brüssel errichtet.
\end{abstract}


Aber auch verschiedene kirchliche Organisationen sahen immer deutlicher die Begleitung der europäischen Einigung aus der Perspektive ihres Tätigkeitsfeldes als wichtige Aufgabe an. Aus der großen Zahl der kirchlichen Organisationen in Brüssel seien die folgenden exemplarisch erwähnt: Caritasverband und Caritas Europa wie auch das Diakonische Werk und EuroDiakonia errichteten jeweils eigene Büros in Brüssel. Die zusammengeschlossenen Entwicklungshilfeorganisationen des Weltrates der Kirchen (APRODEV) und die katholische »Internationale Arbeitsgemeinschaft für Entwicklung und Solidarität« errichteten ebenfalls jeweils ein Sekretariat in Brüssel. Ebenso sind die großen Verbände wie etwa das Kolpingwerk oder die Frauenverbände in Brüssel präsent.

Last not least ist die Europäische Bischofssynode zu nennen, eine vom Papst einberufene Synode mit jeweils mehreren Vertretern der einzelnen Bischofskonferenzen in Europa. Die erste »Europa-Synode« hat 1991 stattgefunden, die zweite vom 1. - 23. Oktober 1999. Diese Europa-Synode ist für die innerkirchliche Meinungsbildung bezüglich Europas von großer Bedeutung, aber wegen ihrer langen Dauer (drei bis vier Wochen) auch ein wichtiger Ort der Begegnung und der Auseinandersetzung mit grundsätzlichen Fragen auch des europäischen Einigungsprozesses und insbesondere des Zusammenwachsens von Ost und West.

Die ein wenig bunte Präsenz der katholischen Kirche auf europäischer Ebene ist also nicht das Ergebnis eines zentral gesteuerten Master-Plans. Bestehende Einrichtungen - der Apostolische Stuhl, die Bischofskonferenzen und freie katholische Einrichtungen und Verbände - haben jeweils ihre Verantwortung für Europa entdeckt und wahrzunehmen versucht. Und sie nehmen ihre Verantwortung jeweils wahr im Sinn ihres genuinen Auftrags. Die umfassendste Verantwortung liegt nach dem Papst bei den Bischofskonferenzen bzw. ihrer Einrichtung auf europäischer Ebene. Somit obliegt faktisch der COMECE eine Art »Leit- oder Leitungsfunktion«, die sich aus der kirchlichen Struktur mit der umfassenden Verantwortung der Bischöfe ergibt. In der Praxis gibt es eine rege Kommunikation, gelegentlich gemeinsame Konferenzen und in besonders wichtigen Fragen gemeinsames, zumindest abgestimmtes Handeln. Die COMECE ist ihrerseits auf die Kompetenz der anderen kirchlichen Akteure angewiesen und beteiligt bei anstehenden Fragen die jeweils betroffenen Einrichtungen bzw. delegiert auch häufig Fragen und Aufgaben an die jeweiligen Einrichtungen. Dieses wesentlich auf Vertrauen basierende Zusammenspiel gelingt im allgemeinen durchaus, gelegentlich unausweichliche Zwischenfälle eingeschlossen.

Die Beziehung und Zusammenarbeit der COMECE mit Rom ist problemlos, zumal der Apostolische Nuntius an den Sitzungen von COMECE teilnimmt und mitarbeitet. 
COMECE: Aufgaben, Struktur und Arbeitsweise

\section{a. Aufgaben}

Warum gibt es zwei Einrichtungen der Bischofskonferenzen auf europäischer Ebene? Dies erklärt sich vor allem aus der Entstehung: Der CCEE ist der Zusammenschluss aller Bischofskonferenzen in Europa. So war es bereits bei der Entstehung 1971, also in der Zeit des »Kalten Krieges«, als eine Vereinigung Europas für lange Zeit unerreichbar erschien. Erstes Ziel der Gründung von CCEE war es, im Sinn des II. Vatikanischen Konzils die Begegnung, den Zusammenhalt und die Zusammenarbeit, also die Kollegialität der Bischöfe zu fördern. Zugleich war es erklärtes Ziel der CCEE, pastorale Fragen von grundsätzlicher und allgemeiner Bedeutung zu bearbeiten.

Sehr bald erkannten die Bischöfe die Notwendigkeit, dass das zunehmende Gewicht der Europäischen Gemeinschaften und die daraus sich ergebenden Veränderungen in Politik, Wirtschaft und Gesellschaft in den einzelnen Ländern auch eine Herausforderung für die Kirchen bedeuteten und eine intensivere Befassung mit dieser Entwicklung unausweichlich sei. Dies aber brachte die Vertreter der Bischofskonferenzen aus den Ländern aus dem Bereich des Kommunismus in erhebliche Schwierigkeiten gegenüber ihren Regierungen, die nun damit begannen, die Ausreise der Bischöfe zur Teilnahme an den Vollversammlungen der CCEE zu behindern oder gar zu untersagen.

Das Ergebnis war die Gründung einer eigenen Institution der Bischofskonferenzen der EG-Länder, eben der COMECE (1980).

Mit dem Fall der Mauer entfiel der Grund, zwei Einrichtungen der Bischofskonferenzen auf europäischer Ebene zu unterhalten, zumal sich abzeichnete, dass immer mehr Länder des östlichen Europa die Mitgliedschaft der EU energisch anstrebten und somit auch die Bischofskonferenzen dieser Länder sich vor die Aufgabe gestellt sahen, sich jetzt nachdrücklich auf den europäischen Integrationsprozess einzulassen. Da sich aber inzwischen die unterschiedliche Aufgabenstellung von CCEE und COMECE als durchaus sinnvoll erwiesen hatte und die Zusammenführung beider Aufgabenbereiche in eine Einrichtung zur Überforderung führen könnte, kam man überein, zwar eine institutionelle Verbindung beider Institutionen zu schaffen, aber grundsätzlich beide Institutionen beizubehalten. Dies hat sich inzwischen als durchaus praktikabel erwiesen, wenn auch weiter über eine $\mathrm{Zu}$ sammenführung beider Einrichtungen nachgedacht und diskutiert wird.

Die COMECE stellt ein Relais dar zwischen den Bischofskonferenzen der EU-Mitgliedsländer und den Institutionen der Europäischen Union. In diesem Sinn verfolgt die COMECE folgende vier Aufgaben: 
- Die Politik der EU, vor allem unter dem Aspekt ihrer Relevanz für das Selbstverständnis der Kirche und die daraus sich für die Kirche ergebenden Aufgaben, zu beobachten, analysieren und ggf. in geeigneter Weise sich dazu zu äußern, etwa in Gesprächen, Veranstaltungen oder Stellungnahmen.

- Die Bischofskonferenzen über aktuelle Entwicklungen der Politik und Rechtsetzung der EU, aber auch über grundlegende Tendenzen zu informieren und ggf. Maßnahmen zu empfehlen.

- Innerhalb der Kirche für »Europa« zu sensibilisieren: Personengruppen (z.B. Generalvikare, Schulleiter, Einrichtungen, Theologische Fakultäten, Akademien, Katholische Büros) anzusprechen und die europäische Dimension ihrer jeweiligen Arbeit zu erschließen helfen (etwa durch Seminare, Tagungen, Konferenzen).

- Schließlich versteht sich die COMECE als eine Art think tank: Die Mega-Tendenzen auszumachen, also das, was sich in allen Einzelereignissen und -problemen durchhält; die Tiefenströmungen im europäischen Integrationsprozess zu erspüren, aber auch das, was sich als tektonische Veränderung, als mainstream abzeichnet und die Welt gewissermaßen $\mathrm{zu}$ verändern scheint; in theologischer Sprache: die »Zeichen der Zeit« wahrzunehmen, zu verstehen und zu deuten versuchen und sich darauf einzustellen.

\section{b. Struktur}

Die Vollversammlung besteht aus je einem für vier Jahre delegierten Bischof der Bischofskonferenzen der EU-Länder. Der delegierte Bischof kann sich nicht vertreten lassen. Die Vollversammlung tagt zwei Mal jährlich (drei bis vier Tage).

Die Vollversammlung wählt aus ihrer Mitte den Präsidenten und drei Vizepräsidenten, die das Präsidium der COMECE bilden, das normalerweise zwischen den Vollversammlungen drei bis viermal zusammentritt. Das Präsidium ist das entscheidende Leitungsgremium der COMECE zwischen den Vollversammlungen; es ist befugt, kurzfristig notwendige Entscheidungen zu treffen. Dem Präsidium gehören der Generalsekretär und dessen Stellvertreter mit beratender Stimme an.

Die COMECE hat wenige ständige Kommissionen: Juristenkommission, Ethikkommission, Sozial- und Wirtschaftskommission, Islam-Kommission und Haushaltskommission. Nach Bedarf werden ad-hoc-Kommissionen eingerichtet, z.B. zur Begleitung des Europäischen Konvents, vor allem bei aktuellen Themen, die eine umfassende Bearbeitung erfordern. Die Mitglieder der Kommissionen werden von der Vollversammlung berufen, unter 
Berücksichtigung der Sprachfelder und nach Rückfragen in den Bischofskonferenzen.

Das Generalsekretariat besteht aus zwölf Mitarbeitern bzw. Mitarbeiterinnen aus sieben Mitgliedsstaaten: Theologen, Politologen, Ökonomen und Juristen. Arbeitssprachen des Sekretariates sind englisch, deutsch, französisch und italienisch. Das Generalsekretariat, der Dreh- und Angelpunkt in der operativen Arbeit der COMECE, kann seiner Aufgabe nur gerecht werden durch Hinzuziehung von Experten, vor allem aus den und seitens der Bischofskonferenzen, aber auch aus den einschlägigen Instituten und Fakultäten und nicht zuletzt aus den Einrichtungen der EU.

\section{c. Arbeitsweise}

Bisher waren alle Kontakte zwischen den Kirchen und der EU gleichsam inoffizieller Natur. Dies dürfte sich ändern, wenn jetzt der »Vertrag über die Europäische Union« in Kraft treten wird. Dort heißt es im »Vertrag über die Arbeitsweise der Europäischen Union« unter Titel II: »Allgemein geltende Bestimmungen«:

\section{Artikel 17}

1. Die Union achtet den Status, den Kirchen und religiöse Vereinigungen oder Gemeinschaften in den Mitgliedsstaaten nach deren Rechtsvorschriften genießen, und beeinträchtigt ihn nicht.

2. Die Union achtet in gleicher Weise den Status, den weltanschauliche Gemeinschaften nach den einzelstaatlichen Rechtsvorschriften genießen.

3. Die Union pflegt mit diesen Kirchen und Gemeinschaften in Anerkennung ihrer Identität und ihres besonderen Beitrags einen offenen, transparenten und regelmäßigen Dialog.

Diesen »offenen, transparenten und regelmäßigen Dialog « hat es »inoffiziell« seit Jahren gegeben. Wie sich diese neuerliche Bestimmung auswirken wird, wird gegenwärtig diskutiert. Gewiss wird man auf der bisherigen inoffiziellen Praxis aufbauen.

Zunächst soll die Arbeitsweise der einzelnen Organe der COMECE skizziert werden, um dann eine Art Zusammenfassung unter dem Aspekt »sehen-urteilen-handeln« zu versuchen. 


\section{Vollversammlung}

Um ihre Aufgabe des Informationsaustauschs, der Meinungsbildung und der grundlegenden Richtungsgebung gerecht werden zu können, hat sich ein bestimmtes Schema als Tagesordnung ergeben:

- »Lagebericht« des Präsidenten unter Hinweis auf die vorher zugesandten Tätigkeitsberichte, vor allem des Generalsekretärs und der Kommissionen und Arbeitsgruppen.

- Kurzberichte der Bischofskonferenzen aus den verschiedenen (und wechselnden) Sprachgebieten.

- Schwerpunktthema, zu dem jeweils wichtige Mitarbeiter aus dem entsprechenden Arbeitsbereich der EU-Kommission eingeladen werden.

- Anstehende wichtige Richtungsentscheidungen aus den einzelnen Arbeitsgebieten.

- Eine öffentliche Abendveranstaltung aus dem Bereich des Schwerpunktthemas, zu der Vertreter der jeweils einschlägigen anderen kirchlichen Institutionen, Vertreter anderer Kirchen, Vertreter der jeweils einschlägigen operativen Ebene der EU-Kommission eingeladen werden.

\section{Präsidium}

Ihm obliegt die Vorbereitung der Vollversammlungen (in Zusammenarbeit mit dem Generalsekretariat), ebenso die Nacharbeit der Vollversammlungen, notwendige Entscheidungen zwischen den Vollversammlungen, Erörterung der Arbeit des Sekretariats und der Kommissionen, Kontakte sowohl mit den Bischofskonferenzen als auch mit den Verantwortlichen der EUKommission. Entscheidend ist das enge Zusammenspiel zwischen Präsidium und Generalsekretariat.

\section{Kommissionen}

Beobachtung langfristiger Tendenzen im Sachbereich, ggf. Vorbereitung von Erklärungen, regelmäßiger Lagebericht an die Vollversammlung.

\section{Generalsekretariat}

Bearbeitung der alltäglichen Fragen (Anfragen, Aufträge), Vor- und Nachbereitung der Sitzungen des Präsidiums und der Vollversammlung. 
Wahrnehmung der Kontakte

- zum jeweiligen Ansprechpartner (der einzelnen Referenten) in den Bischofskonferenzen,

- zur operativen Ebene in der EU-Kommission und im EU-Parlament (Gesetzesvorhaben, Gesetzesentwürfe),

- zu Experten und wichtigen Einrichtungen, z.B. wichtigen europabezogenen think tanks.

Für Präsidium und Generalsekretariat, die auf eine enge Zusammenarbeit angewiesen sind, gilt gleichermaßen der Grundsatz: steuern, nicht rudern!

$»$ Sehen-urteilen-handeln «

Sehen

- Beobachtung und Einschätzung von Gesetzesvorhaben und langfristigen Trends aus katholischer Sicht.

- Pflege eines differenzierten Kommunikationsnetzes mit Generalisten und Spezialisten in den Bischofskonferenzen, in den anderen Kirchen, in den Universitäten und Instituten wie auch in den Institutionen der EUKommission und des EU-Parlaments.

- Beobachtung der Literatur und der einschlägigen Zeitschriften.

- Lagebesprechungen in den Vollversammlungen, im Präsidium und im Generalsekretariat.

\section{Urteilen (Meinungsbildung)}

- Intern in der Vollversammlung, im Präsidium und im Generalsekretariat,

- Gespräche mit Entscheidungsträgern in der EU (Kommission, Parlament),

- ggf. Klausurtagungen und Hinzuziehung von Experten.

\section{Handeln}

- Gespräche mit den zuständigen Referenten auf der Arbeitsebene und ggf. mit den Entscheidungsträgern (in Kommission oder Parlament der EU),

- Veranstaltungen: Foren, Symposien, Akademien,

- öffentliche Erklärungen,

- Pressekonferenzen, monatliches Informationsblatt »Europe Infos« (erscheint in deutsch, englisch, französisch und italienisch, Auflage 1.500). 
- Anregung von Initiativen, z.B. besteht seit 2006 eine »Sommeruniversität«, getragen von COMECE, Karl-Franzens-Universität Graz und Diözese Graz-Seckau (in vier Jahren insgesamt 310 Teilnehmer aus 35 Ländern, insbesondere Mittel-, Ost- und Südosteuropa).

- Vermittlung von Kontakten zwischen einzelnen Bischofskonferenzen und der EU-Kommission angesichts besonderer Probleme (z.B. Landwirtschaft, Polen, Bosnien-Herzegowina, Dayton-Abkommen), Besuche einzelner Bischofskonferenzen in Brüssel.

- Kontakte und periodische Symposien mit den Zusammenschlüssen der Bischofskonferenzen in den anderen Kontinenten (USA, Lateinamerika, Afrika, Asien).

\section{Erfahrungen mit der Arbeit der COMECE}

In den ersten Jahren beschränkte sich der Kontakt mit den Verantwortlichen der europäischen Institutionen mehr oder weniger auf gelegentliche freundliche Begegnungen. Deutlich intensiver wurde der Kontakt nach dem Fall der Berliner Mauer. Auch für die führenden Politiker gewann die Frage nach der Wertegrundlage der EU an Brisanz. Die Kirchen wurden aufmerksamer wahrgenommen. Es war Kommissionspräsident Jacques Delors, der in seiner Rede vom 14. April 1992 vor Kirchenvertretern erklärte:

Wenn es uns in den kommenden zehn Jahren nicht gelingt, Europa eine Seele, eine Spiritualität, einen Sinn zu geben, haben wir das Spiel verloren. Glauben Sie mir: Nur mit seinen juristischen Fähigkeiten und seinem wirtschaftlichen know how wird Europa keinen Erfolg haben.

In der Folge beauftragte Delors einen Berater seiner »Gruppe für Zukunftsanalysen « mit der Aufgabe, den Dialog mit den Kirchen und Religionsgemeinschaften zu fördern. Auf der Grundlage dieser Entscheidung entwickelte sich in den letzten Jahren ein ständiger, aber eben informeller Dialog, der sich insbesondere durch regelmäßige Informationsveranstaltungen im Anschluss an die Sitzungen des Europäischen Rates sowie in der gemeinsamen Organisation von Dialog-Seminaren mit Themen von beiderseitigem Interesse auszeichnete.

Alle Amtsnachfolger von Delors - die Kommissionspräsidenten Santer, Prodi und Barroso - haben an dieser Praxis festgehalten. Darüber hinaus nehmen die Kirchen an den offenen Konsultationen der Europäischen Kommission zu Gesetzesvorhaben teil, insbesondere wenn Fragen von kirchlichem Interesse anstehen.

Neben den Kontakten zu der Europäischen Kommission ließen sich informelle, aber gute Beziehungen zu dem Europäischen Parlament und mit 
dem Ministerrat aufbauen: Wie die anderen Kirchen und die vielen kirchlichen Organisationen unterhält die COMECE gute Kontakte zu einzelnen Abgeordneten und deren Gruppen im Europäischen Parlament. Insgesamt hat sich ein freundliches, wohlwollendes, offenes Klima entwickelt.

\section{Probleme}

Die Arbeit der COMECE muss »geerdet« sein in einem europäischen Bewusstsein in den Bischofskonferenzen, den Diözesen und Gemeinden, in den kirchlichen Einrichtungen und Verbänden. Diesbezüglich geschieht in manchen Bischofskonferenzen und Diözesen viel, in anderen weniger. Dies kann keine Aufgabe der COMECE sein. Wohl ist es die Frage, ob in den Kirchen der potenziellen EU-Mitgliedsländer nicht eine erhebliche Hilfe erforderlich ist, um sich auf die völlig neuen Herausforderungen einstellen zu können.

In der Arbeit der COMECE und in der ständigen Reflexion darüber haben sich in den vergangenen Jahren einige "Großthemen " herausgeschält, deren Bearbeitung unausweichlich erscheint, aber sehr großer Anstrengungen bedarf. Um nur die wichtigsten Themen zu nennen:

(1) Europa ist sensibel geworden für seine Schuldgeschichte, nicht nur für die des 20. Jahrhunderts. Von der Reconquista in Spanien (bis ins 15. Jahrhundert) über die blutigen Konfessionskriege (16. Jahrhundert) und dem Kolonialismus bis zum Versagen im postjugoslawischen Krieg: eine traurige Geschichte, die Traumata bei Opfern und Tätern ausgelöst hat - bis heute - und das in den Völkern ganzer Regionen wie in Südosteuropa und dem Vorderen Orient und ganzer Kontinente wie Afrika und Lateinamerika. Europa trägt die Last einer leidvollen Schuldgeschichte, über die nicht einfach hinweggegangen werden kann, zumal die Erkenntnis gewachsen ist, dass es eine spezifische Wirkmächtigkeit von Gewalt und Gewalterfahrung gibt. Versöhnung tut not, aber sie setzt voraus, die konkreten Geschichten der Gewalt zur Sprache zu bringen. Es ist der Versuchung zu widerstehen, in ein allgemeines Schuldbekenntnis auszuweichen, was letztlich an der Oberfläche verbleibt, weil es sich eben nicht der konkreten Schuld stellt. Die Kirchen sind in diese Schuldgeschichte mehr oder weniger verwickelt. Wie können sie an der anstehenden Versöhnung mitwirken?

(2) Die Eingliederung osteuropäischer Länder in die EU ist inzwischen vollzogen bzw. ist in den nächsten Jahren zu erwarten. Das geistige $\mathrm{Zu}$ sammenwachsen von Ost und West steht jedoch erst am Anfang. Viele sprechen von Europa, meinen aber offensichtlich nur das westliche. Geschichtliche Belastungen werden in Ost und West sehr unterschiedlich 
erinnert. Die Geschichte, vor allem des 19. Jahrhunderts, muss offensichtlich neu geschrieben werden, gemeinsam von den Historikern in West und Ost. Genügt das?

(3) Das ökumenische Gespräch - der Westkirchen mit der Orthodoxie und das interreligiöse Gespräch - mit dem Islam - ist unausweichlich, nicht nur auf höchster Ebene.

\section{Der Europäische Konvent (2002-2003) und die COMECE}

Die Kirchen haben sich im Lauf der Beratungen des Europäischen Konvents $\mathrm{zu}$ verschiedenen ihnen wichtigen Themen (z.B. Grundrechtecharta, Subsidiarität) geäußert. Ihre die Rolle der Kirchen im »Vertrag« betreffenden Anliegen waren:

1. Festschreibung des national geregelten Staatskirchenrechts und dessen Respektierung durch die EU.

2. Festschreibung der Religionsfreiheit in ihren drei Dimensionen (individuelle, gemeinschaftlich, institutionell).

3. Festschreibung eines Dialogs zwischen den EU-Institutionen und den Kirchen.

4. Erwähnung des Christlichen und eines Gottesbezuges in der Präambel.

Während die drei erstgenannten Anliegen erreicht werden konnten, ist das im vierten Punkt nicht gelungen.

Die Kirchen waren nicht offiziell im Europäischen Konvent vertreten, wohl aber als Beobachter bei den Beratungen des Konvents anwesend. Sie hatten, wie andere gesellschaftliche Gruppen, die Möglichkeit, sich schriftlich und in vereinbarten Gesprächen jederzeit an das Präsidium, an alle oder einige Mitglieder oder an einzelne Gruppierungen im Konvent zu wenden und natürlich am Diskurs in der Öffentlichkeit teilzunehmen.

Sowohl im Vorfeld des Konvents wie auch während der Arbeit des Konvents haben die Kirchen ihre Erwartungen und Vorstellungen in der jeweils eigenen Kirche - COMECE mit den nationalen Bischofskonferenzen und mit Rom - und untereinander erörtert und eine Übereinstimmung hinsichtlich Zielsetzung und Vorgehen abgesprochen und erreicht. Sie haben jeweils ihre Erwartungen sowohl als Ganzes benannt als auch vor allem bei der Beratung der vom Präsidium vorgelegten Teilabschnitte eingebracht: Sie haben ihre Vorstellungen an das Präsidium und an die Konventsmitglieder herangetragen, Kontakte gepflegt und Gespräche geführt mit dem Präsidium, mit einzelnen Gruppen im Konvent und mit vielen Einzelmit- 
gliedern. In den Debatten des Konvents haben einzelne Mitglieder oder Gruppen sich die Stellungnahmen und Formulierungsvorschläge der Kirchen zu eigen gemacht - oder eben nicht.

Die COMECE und auch die übrigen Kirchen haben sich außerdem immer wieder öffentlich geäußert und auch die Bischofskonferenzen ermuntert und dabei unterstützt, ihrerseits in den einzelnen Ländern tätig zu werden, sei es durch Kontakte mit den Regierungen, mit den Konventsmitgliedern ihres Landes oder in öffentlichen Äußerungen, z. B. Interviews. Nicht zuletzt sind natürlich Experten in bestimmten Fragen konsultiert und ggf. gebeten worden, sich an dem öffentlichen Diskurs zu beteiligen.

Das Präsidium machte seinerseits einen Textvorschlag, der im Konvent diskutiert wurde; dabei hatten die Konventsmitglieder jeweils drei Minuten Redezeit. Nach der Diskussion stellte das Präsidium den Konsens fest, anstelle von Abstimmungen, sodass eine klare und exakte Abbildung des Meinungsbildes im europäischen Konvent (auch hinsichtlich der Präambel) nicht erfolgen konnte. Das Präsidium formulierte seinerseits den definitiven Text, der vom Konvent zur Kenntnis genommen wurde; aber auch über diesen definierten Text gab es im Konvent keine Abstimmung.

Die Arbeitsweise des Konvents (insbesondere bei der Präambel-Beratung das späte Einbringen des Präambel-Vorschlages seitens des Präsidiums) ließ sehr wenig Zeit für grundlegende inhaltliche Diskussionen. Entsprechend kam es nicht zu einer inhaltlich konstruktiven Auseinandersetzung, sondern eher nur zu einer Verfestigung bereits bestehender gegensätzlicher Positionen. Es ist mehr als bedauerlich, dass weder über die öffentliche Rolle von Religion in der europäischen Gesellschaft noch über ihre Bedeutung für die rechtlichen Grundlagen des europäischen Gemeinwesens diskutiert worden ist.

Einen Gottesbezug oder die Erwähnung des »Christlichen Erbes« in die Präambel einzufügen, begegnete auch verschiedenen praktischen Schwierigkeiten:

Von den Verfassungen der EU-Mitgliedsländer verfügen nur 13 über eine wie auch immer geartete Präambel in ihrer Verfassung. Lediglich fünf EU-Mitgliedstaaten, nämlich Deutschland, Griechenland, Irland, Polen und die Slowakei, enthalten in den Präambeln ihrer nationalen Verfassungen einen Bezug auf Gott oder Christentum. Angesichts dieser recht unterschiedlichen Lage gab es nur ein begrenztes Interesse, den Erwartungen der Kirchen in dieser Frage entgegenzukommen.

Das Präsidium hatte die Erörterung der Präambel erst in der drittletzten Sitzung des Konvents aufgerufen. Man geriet unter Zeitdruck. Erst recht angesichts der (skizzierten) Arbeitsweise des Konvents war eine erforderliche Grundsatzdiskussion nicht möglich. 
Insgesamt: Es gab bei der großen Mehrheit eine grundsätzliche Offenheit für Anliegen und Stellungnahmen der Kirchen, wenn solche als mit dem bonum commune kompatibel erkennbar waren. Allerdings dürfte es bedeutsam sein, dass es in den Entscheidungsgremien kompetente und überzeugende Menschen gibt, die fähig und bereit sind, christliche Überzeugungen argumentativ mehrheitsfähig zu machen.

\section{Probleme}

Die Glaubwürdigkeit des Westens, auch der EU

Die vier Eckpfeiler des ökonomischen Liberalismus - freie Zirkulation von Gütern, Dienstleistungen, Kapital und Arbeitskräften - werden durch Protektionismus, selektive Einfuhrzölle und Subventionen unterlaufen. Die dadurch verhinderten Einkünfte der Länder in der sog. Dritten Welt werden durch Entwicklungshilfe nur zu einem Teil aufgewogen. Die Verzögerungen der Freizügigkeit von Arbeitskräften für die neuen Mitgliedsländer bringen diese in erhebliche Schwierigkeiten und der EU mit Recht den Vorwurf des Zynismus und des doppelten Standards. Die hochgepriesenen »universalen Werte« werden den jeweiligen politischen und wirtschaftlichen Interessen untergeordnet; »lokale Besonderheiten «, »institutionelle und operative Kapazitäten « der Förderländer verbergen eigene Interessen.

Besonders belastend sind sog. realpolitische Entscheidungen westlicher Großmächte im Laufe der Geschichte des 19. und 20. Jahrhunderts zum Nachteil kleinerer Länder. Sie sind dort nicht vergessen und geben Anlass zu Misstrauen, z.B. der Genozid der Armenier in der Türkei 1913, der Genozid in der Ukraine durch Stalin 1933, die Besetzung georgischer Staatsgebiete 2008 .

\section{Notwendigkeit gemeinsamen ökumenischen und unterreligiösen Handelns}

Wenn es auch in den großen sog. Glaubensdingen vor allem um politische und wirtschaftliche Interessen geht, hat sich die Kirche zumindest instrumentalisieren lassen. Ihr Friedens- und Versöhnungspotential ist noch nicht zur möglichen und notwendigen Entfaltung gekommen ${ }^{1}$.

1 Bischof Homeyer hatte den Schluss seines Vortrags nicht ausformuliert, sondern aufgrund einiger Stichworte frei gesprochen. Diese Stichworte waren: Interreligiöse Räte, Interreligiöse Institute, Interreligiöse Soziale Seminare, Versöhnung. 
Anhang

PRÄAMBEL

SEINE MAJESTÄT DER KÖNIG DER BELGIER, IHRE MAJESTÄT DIE KÖNIGIN VON DÄNEMARK, DER PRÄSIDENT DER BUNDESREPUBLIK DEUTSCHLAND, DER PRÄSIDENT DER GRIECHISCHEN REPUBLIK, SEINE MAJESTÄT DER KÖNIG VON SPANIEN, DER PRÄSIDENT DER FRANZÖSISCHEN REPUBLIK, DER PRÄSIDENT IRLANDS, DER PRÄSIDENT DER ITALIENISCHEN REPUBLIK, SEINE KÖNIGLICHE HOHEIT DER GROSSHERZOG VON LUXEMBURG, IHRE MAJESTÄT DIE KÖNIGIN DER NIEDERLANDE, DER PRÄSIDENT DER PORTUGIESISCHEN REPUBLIK, IHRE MAJESTÄT DIE KÖNIGIN DES VEREINIGTEN KÖNIGREICHS GROSSBRITANNIEN UND NORDIRLAND ${ }^{2}$,

ENTSCHLOSSEN, den mit der Gründung der Europäischen Gemeinschaften eingeleiteten Prozess der europäischen Integration auf eine neue Stufe zu heben,

SCHÖPFEND aus dem kulturellen, religiösen und humanistischen Erbe Europas, aus dem sich die unverletzlichen und unveräußerlichen Rechte des Menschen sowie Freiheit, Demokratie, Gleichheit und Rechtsstaatlichkeit als universelle Werte entwickelt haben,

EINGEDENK der historischen Bedeutung der Überwindung der Teilung des europäischen Kontinents und der Notwendigkeit, feste Grundlagen für die Gestalt des zukünftigen Europas zu schaffen,

IN BESTÄTIGUNG ihres Bekenntnisses zu den Grundsätzen der Freiheit, der Demokratie und der Achtung der Menschenrechte und Grundfreiheiten und der Rechtsstaatlichkeit,

IN BESTÄTIGUNG der Bedeutung, die sie den sozialen Grundrechten beimessen, wie sie in der am 18. Oktober 1961 in Turin unterzeichneten Europäischen Sozialcharta und in der Unionscharta der sozialen Grundrechte der Arbeitnehmer von 1989 festgelegt sind,

2 Seit dem ursprünglichen Vertragsschluss sind Mitgliedstaaten der Europäischen Union geworden: die Republik Bulgarien, die Tschechische Republik, die Republik Estland, die Republik Zypern, die Republik Lettland, die Republik Litauen, die Republik Ungarn, die Republik Malta, die Republik Österreich, die Republik Polen, Rumänien, die Republik Slowenien, die Slowakische Republik, die Republik Finnland und das Königreich Schweden. 
IN DEM WUNSCH, die Solidarität zwischen ihren Völkern unter Achtung ihrer Geschichte, ihrer Kultur und ihrer Traditionen zu stärken,

IN DEM WUNSCH, Demokratie und Effizienz in der Arbeit der Organe weiter zu stärken, damit diese in die Lage versetzt werden, die ihnen übertragenen Aufgaben in einem einheitlichen institutionellen Rahmen besser wahrzunehmen,

ENTSCHLOSSEN, die Stärkung und die Konvergenz ihrer Volkswirtschaften herbeizuführen und eine Wirtschafts- und Währungsunion zu errichten, die im Einklang mit diesem Vertrag und dem Vertrag über die Arbeitsweise der Europäischen Union eine einheitliche, stabile Währung einschließt,

IN DEM FESTEN WILLEN, im Rahmen der Verwirklichung des Binnenmarkts sowie der Stärkung des Zusammenhalts und des Umweltschutzes den wirtschaftlichen und sozialen Fortschritt ihrer Völker unter Berücksichtigung des Grundsatzes der nachhaltigen Entwicklung zu fördern und Politiken zu verfolgen, die gewährleisten, dass Fortschritte bei der wirtschaftlichen Integration mit parallelen Fortschritten auf anderen Gebieten einhergehen,

ENTSCHLOSSEN, eine gemeinsame Unionsbürgerschaft für die Staatsangehörigen ihrer Länder einzuführen,

ENTSCHLOSSEN, eine Gemeinsame Außen- und Sicherheitspolitik zu verfolgen, wozu nach Maßgabe des Artikels 42 auch die schrittweise Festlegung einer gemeinsamen Verteidigungspolitik gehört, die zu einer gemeinsamen Verteidigung führen könnte, und so die Identität und Unabhängigkeit Europas zu stärken, um Frieden, Sicherheit und Fortschritt in Europa und in der Welt zu fördern,

ENTSCHLOSSEN, die Freizügigkeit unter gleichzeitiger Gewährleistung der Sicherheit ihrer Bürger durch den Aufbau eines Raums der Freiheit, der Sicherheit und des Rechts nach Maßgabe der Bestimmungen dieses Vertrags und des Vertrags über die Arbeitsweise der Europäischen Union zu fördern,

ENTSCHLOSSEN, den Prozess der Schaffung einer immer engeren Union der Völker Europas, in der die Entscheidungen entsprechend dem Subsidiaritätsprinzip möglichst bürgernah getroffen werden, weiterzuführen,

IM HINBLICK auf weitere Schritte, die getan werden müssen, um die europäische Integration voranzutreiben,

HABEN BESCHLOSSEN, eine Europäische Union zu gründen; sie haben zu diesem Zweck zu ihren Bevollmächtigten ernannt: 
(Aufzählung der Bevollmächtigten nicht wiedergegeben)

DIESE SIND nach Austausch ihrer als gut und gehörig befundenen Vollmachten wie folgt ÜBEREINGEKOMMEN: [...] 



\section{Personenregister}

Adenauer, Konrad 42, 107

Ahtisaari, Martti 95, 96

Alfrink, Bernard Jan, Erzbischof von Utrecht, Kardinal 70

Altmeier, Peter 68

Amery, Leo 14

Arola, Pauliina 90, 95, 96

Attlee, Clement Richard 5

Aylwen, George 12

Barroso, José Manuel Durão 114

Barth, Karl 17

Bell, George, Bischof von Chichester 9, 14, 19

Benedikt von Nursia 25

Benedikt XV., Papst 22

Berning, Wilhelm, Bischof von Osnabrück 57, 58

Beveridge, William Henry Lord 5, 59

Bidault, Georges 42, 59, 60

Billotte, Pierre Armand 54

Blair, Tony 76,87

Bornewasser, Franz Rudolf, Erzbischof von Trier 54, 57, 58

Brentano, Heinrich von 42

Brown, Gordon 82, 85

Bürckel, Josef 39

Busek, Erhard 44

Camdessus, Michel 100

Campbell, Alastair 76

Carr, Edward Hallett 5, 16

Carter, Henry 16

Casanova, José 83

Chirac, Jacques 47
Churchill, Winston 1, 10, 11, 13, $15,18,19,59$

Cicognani, Gaetano 39

Consalvi, Ercole 22

Coudenhove-Kalergi, Richard Nikolaus 14

Dawson, Christopher 10

Delors, Jacques 36, 114

Dewey, Thomas E. 16

Dodds, Harold W. 16

Dollfuß, Engelbert 37

Dorries, Nadine 78, 79

Dubourg, Maurice-Louis, Erzbischof von Besançon 64, 65

Dumas, Roland 45

Eckert, Franz 35, 36, 51, 52

Emanuel, Isidor Markus, Bischof von Speyer 57, 62, 68, 70, 71, 72

Feltin, Maurice, Erzbischof von Paris, Kardinal 65

Fisher, Geoffrey, Erzbischof von Canterbury 7-14, 16-20

François-Poncet, André 68

Frings, Joseph, Erzbischof von

Köln, Kardinal 53, 54, 67, 70

Funder, Friedrich 43

Galen, Clemens August Graf von, Bischof von Münster, Kardinal 57, 58

Gasperi, Alcide de 107

Georg VI., König von England 12 
Gföllner, Johannes Maria, Bischof von Linz 38

Giddens, Anthony 86, 87

Graham, Billy 17

Griffin, Bernard William, Erzbischof von Westminster, Kardinal 10,67

Gröber, Conrad, Erzbischof von Freiburg 57, 59

Groner, Josef Fulko 23

Guterres, António 47

Hauerwas, Stanley 105

Hitler, Adolf 38, 39

Hochhuth, Rolf 21

Huddleston, Trevor 14

Huntington, Samuel 76

Huovinen, Eero, Bischof von Helsinki 95

Hurdes, Felix 43

Innitzer, Theodor, Erzbischof von Wien, Kardinal 37-39, 41, 67

Jankowitsch, Peter 44

Janssen, Heinrich Maria, Bischof von Hildesheim 62

Jeanne d'Arc 65

Jenkins, Daniel 17

Johannes Paul II., Papst 46, 48, 49

Johnson, Hewlett 18

Jong, Jan de, Erzbischof von Utrecht, Kardinal 61, 67, 69, 71

Kantola, Ilkka 96

Kapellari, Egon, Bischof von Gurk bzw. Graz-Seckau 45, 52

Keller, Michael, Bischof von Münster 55, 57, 60, 62, 65, 67

Kerkhofs, Louis-Joseph, Bischof von Lüttich 66
Khomjakov, Alexei 97

König, Franz, Erzbischof von Wien, Kardinal 46

Koenig, Pierre Marie 53, 54

Krenn, Kurt, Bischof von St. Pölten 45

Kuntner, Florian 45

Laffon, Émile 53

Lang, Cosmo Gordon, Erzbischof von Canterbury 12

Lemmens, Guilelmus, Bischof von Roermond 60

Leo XIII., Papst 22, 23

Lipponen, Paavo 95

Lommel, Léon, Bischof von Luxemburg 57, 62, 66, 70, 71

Machens, Joseph Godehard, Bischof von Hildesheim 57, 58

MacIntyre, Alasdair 105

Mangers, Jacob, Bischof von Oslo 70

Maritain, Jacques 24, 25

Marshall, George C. 40

Matthews, Walter Robert 18

Miliband, David 76

Mock, Alois 44

Modood, Tariq 76, 85

Montini, Giovanni Battista 64

Napoleon I., Kaiser von Frankreich 22

Nazir-Ali, Michael 82

Paul VI., Papst Siehe Montini, Giovanni Battista

Paulus, Apostel 33

Pawlikowski, Ferdinand Stanislaus, Fürstbischof von Seckau 38 
Petit de Julleville, Pierre, Erzbischof von Rouen, Kardinal 58

Pflimlin, Pierre 42

Philippe, Joseph, Bischof von Luxemburg 57

Phillips, Trevor 82

Picard de la Vacquerie, Robert, Bischof von Orléans 63-65, 68, 69

Pitt, Valerie 81

Pius VII., Papst 22

Pius X., Papst 21

Pius XI., Papst 21, 39

Pius XII., Papst 1, 2, 21-33, 41, 54,64

Pohlschneider, Johannes, Bischof von Aachen 62, 65

Prodi, Romano 114

Rauch, Wendelin, Erzbischof von Freiburg 57, 62-65, 68, 69

Rawls, John 94

Richardson, J.M. 10

Riess-Passer, Susanne 47

Robbins, Lionel 5

Roeder, Felix, Bischof von Beauvais 70

Roey, Jozef-Ernest van, Erzbischof von Mecheln, Kardinal 67

Roncalli, Angelo Giuseppe 58

Santer, Jacques 114

Schneider, Heinrich 36

Schönborn, Christoph, Erzbischof von Wien, Kardinal 45

Schüssel, Wolfgang 46

Schuman, Robert 42, 43, 107

Seipel, Ignaz 37

Seiterich, Eugen, Erzbischof von Freiburg 57, 62, 68
Sentamu, John 82

Sinowatz, Fred 44

Skorpil, Robert 40, 41

Smith, John 82

Sproll, Joannes Baptista, Bischof von Rottenburg-Stuttgart 63

Steger, Norbert 44

Stohr, Albert, Bischof von Mainz 57, 59, 63, 65, 68

Stratmann, Franziskus Maria 55

Streng, Franziskus, Bischof von Basel 59

Suhard, Emmanuel Célestin, Erzbischof von Paris, Kardinal 58, 67

Suhr, Johannes Theodor, Bischof von Kopenhagen 70

Temple, William, Erzbischof von Canterbury 7-9, 12, 19, 82

Tenhumberg, Heinrich, Bischof von Münster 65

Thatcher, Margaret 94

Théas, Pierre-Marie, Bischof von Montauban 65, 67, 71

Utz, Arthur Fridolin 23

Vacquerie, Robert Picard de la, Bischof von Orléans 64

van Gogh, Theo 83

Velden, Johannes Joseph van der, Bischof von Aachen 57, 61, 62, 65-67, 69, 71

Vranitzky, Franz 44

Waldheim, Kurt 44

Wand, William. Bischof von London 13

Wehr, Matthias, Bischof von Trier 70

Weizsäcker, Ernst von 21 
Wendel, Joseph, Bischof von Wildhaber, Luzius 47

Speyer 57, 59, 63, 68, 72

Wendt, Hans Heinrich 9

Williams, Rowan Douglas, Erzbischof von Canterbury 80,86 


\section{Autorenverzeichnis}

Professor Dr. Mark D. Chapman, Oxford University, Ripon College Cuddesdon, Oxford OX44 9EX

Dr. Josef Homeyer, em. Bischof von Hildesheim ( $\dagger)$

Professor Dr. Heinz Hürten, Schwanenstr. 1 a, 85049 Ingolstadt

Professor Dr. Michael Kißener, Johannes Gutenberg-Universität, Historisches Seminar, Saarstr. 21, 55122 Mainz

Professor Dr. Anita Prettenthaler-Ziegerhofer, Universität Graz, Institut für Österreichische. Rechtsgeschichte, Universitätsstrasse 15/A3, 8010 Graz

Professor Dr. Keith Robbins, Rhydyfran, Cribyn, Lampeter, Ceredigion SA48,

Professor Dr. Risto Saarinen, University of Helsinki, Department of Systematic Theology, Aleksanterinkatu 7, 00014 Helsinki 



\section{Veröffentlichungen des Instituts für Europäische Geschichte Mainz, Beihefte}

Band 83: Heinz Duchhardt ( $\mathrm{Hg}$.

Der Pyrenäenfriede 1659

Vorgeschichte, Widerhall, Rezeptionsgeschichte

2010. VI, 103 Seiten, gebunden

ISBN 978-3-525-10098-1

Band 82: Irene Dingel /

Matthias Schnettger ( $\mathrm{Hg}$.)

\section{Auf dem Weg nach Europa}

Deutungen, Visionen, Wirklichkeiten

2010. VI, 274 Seiten mit 15 Abbildungen,

gebunden. ISBN 978-3-525-10095-0

Band 81: Henning P. Jürgens /

Thomas Weller (Hg.)

\section{Religion und Mobilität}

Zum Verhältnis von raumbezogener Mobilität und religiöser Identitätsbildung im frühneuzeitlichen Europa

2010. VI, 419 Seiten mit 16 Abb., gebunden

ISBN 978-3-525-10094-3

Band 80: Klaus-Jürgen Grün

\section{Russland, der Ferne Osten und die "Deutschen"}

2009. VI, 123 Seiten mit 5 Abb., gebunden ISBN 978-3-525-10092-9

Band 79: Kerstin Armborst-Weihs / Judith Becker ( $\mathrm{Hg}$.)

\section{Toleranz und Identität}

Geschichtsschreibung und Geschichtsbewusstsein zwischen religiösem Anspruch und historischer Erfahrung

2010. VIII, 301 Seiten mit 2 Abbildungen, gebunden. ISBN 978-3-525-10096-7
Band 78: Irene Dingel /

Christiane Tietz (Hg.)

Das Friedenspotenzial von Religion

2009. VIII, 124 Seiten mit 1 Abb., gebunden ISBN 978-3-525-10091-2

Band 77: Rolf Decot (Hg.)

Konfessionskonflikt, Kirchenstruktur, Kulturwandel Die Jesuiten im Reich nach 1556

2007. IX, 222 Seiten, gebunden ISBN 978-3-525-10088-2

Band 76: Christine Roll / Matthias Schnettger (Hg.)

\section{Epochenjahr 1806?}

Das Ende des Alten Reichs in zeitgenössischen Perspektiven und Deutungen

2008. V, 155 Seiten, gebunden ISBN 978-3-525-10087-5

Band 75: Johannes Arndt /

Esther-Beate Körber ( $\mathrm{Hg}$.)

Das Mediensystem im Alten Reich der Frühen Neuzeit 1600-1750

2010. VI, 248 Seiten, gebunden

ISBN 978-3-525-10093-6

Band 74: Wolf-Friedrich Schäufele / Irene Dingel ( $\mathrm{Hg}$.)

Kommunikation und Transfer im Christentum der Frühen Neuzeit 2008. IX, 325 Seiten, gebunden ISBN 978-3-525-10086-8

\section{Vandenhoeck \& Ruprecht}




\section{Veröffentlichungen des Instituts für Europäische Geschichte Mainz, Beihefte}

\section{Band 73: Horst Carl / \\ Martin Wrede (Hg.)}

Zwischen Schande und Ehre.

Erinnerungsbrüche und die Kontinuität des Hauses

Legitimationsmuster und Traditionsverständnis des frühneuzeitlichen Adels in Umbruch und Krise

2007. VIII, 480 Seiten, gebunden

ISBN 978-3-525-10085-1

\section{Band 72: Matthieu Arnold / \\ Rolf Decot (Hg.) \\ Christen und Juden im Reformationszeitalter \\ 2006. XVI, 315 Seiten, gebunden \\ ISBN 978-3-525-10084-4}

Band 71: Thomas Nicklas /

Matthias Schnettger (Hg.)

Politik und Sprache im

frühneuzeitlichen Europa

2007. VI, 184 Seiten, gebunden

ISBN 978-3-525-10083-7

Band 70: Irene Dingel /

Wolf-Friedrich Schäufele (Hg.)

\section{Zwischen Konflikt}

\section{und Kooperation}

Religiöse Gemeinschaften in Stadt und

Erzstift Mainz in Spätmittelalter und Neuzeit

2006. VIII, 260 Seiten, gebunden

ISBN 978-3-525-10082-0
Band 69: Ralph Melville /

Jiri Pesek / Claus Scharf (Hg.)

Zwangsmigrationen im mittleren und östlichen Europa

Völkerrecht - Konzeption - Praxis

(1938-1950)

2007. XV, 463 Seiten, gebunden

ISBN 978-3-525-10081-3

Band 68: Gerhard May

\section{Markion}

Gesammelte Aufsätze

2005. VIII, 131 Seiten, gebunden

ISBN 978-3-525-10080-6

Band 67: Fred van Lieburg (Hg.)

Confessionalism and Pietism

Religious Reform in Early Modern Europe

2006. VI, 324 Seiten p.w.figs., gebunden

ISBN 978-3-525-10079-0

Band 66: Heinz Duchhardt /

István Németh (Hg.)

Der Europa-Gedanke in Ungarn und Deutschland in der Zwischenkriegszeit

2005. X, 172 Seiten, gebunden ISBN 978-3-525-10078-3

Ältere Bände und mehr Informationen zur Reihe unter www.v-r.de

\section{Vandenhoeck \& Ruprecht}

